\title{
Smart Energy and Spectral Efficiency (SE) of Distribution Broadband over Power Lines (BPL) Networks - Part 1: The Impact of Measurement Differences on SE Metrics
}

\author{
Athanasios G. Lazaropoulos ${ }^{*}$ \\ School of Electrical and Computer Engineering / National Technical University of Athens / \\ 9 Iroon Polytechniou Street / Zografou, GR 15780
}

Received June 7, 2018; Accepted August 17, 2018; Published August 21, 2018

\begin{abstract}
This paper assesses the impact of measurement differences on the spectral efficiency (SE) of distribution broadband over power lines (BPL) networks when CS2 module is applied. The broadband performance of distribution BPL networks is investigated in the $3-88 \mathrm{MHz}$ frequency range when appropriate injected power spectral density limits (IPSD limits) and uniform additive white Gaussian noise (AWGN) PSD levels from the BPL literature are assumed. The impact of measurement differences on SE of the distribution BPL networks is here assessed through appropriate SE metrics. These SE metrics assessing this impact are detailed in order to act as the benchmark metrics of the countermeasures techniques against measurement differences of the companion paper.
\end{abstract}

Keywords: Smart Grid; Broadband over Power Lines (BPL); Power Line Communications (PLC); Distribution Power Grid; Spectral Efficiency.

\section{Introduction}

Smart grid allows the transformation of today's power grid to an advanced IP-based power network with a plethora of relevant broadband applications. Depending on the number and the requirements of the supported smart grid applications, high spectral efficiency (SE) potential of this power network should be assured [1]-[9].

Apart from the smart grid applications, which act as SE consumers, the various communications technologies, which interoperate in order to assure the fine operation of the smart grid, act as the SE producers. Among the available communications technologies that can interoperate under the aegis of the smart grid, a significant role can be played by the broadband over power lines (BPL) technology that exploits the already installed power grid infrastructure [10]-[12].

Since distribution BPL networks -i.e., overhead (OV) and underground (UN) medium-voltage (MV) and low-voltage (LV) BPL networks- are benchmarked in this paper, the spectral behavior of distribution BPL networks is described through the hybrid model [1]-[8], [13]-[22]. Hybrid model has extensively been employed to examine the behavior of various multiconductor transmission line (MTL) configurations in BPL 
networks and, of course, in distribution BPL networks such those that are examined in this paper. The hybrid model is modular and consists of: (i) a bottom-up approach that is based on an appropriate combination of MTL theory and similarity transformations; and (ii) a top-down approach that is based on the concatenation of multidimensional transmission matrices of the cascaded network BPL connections. Recently, a refinement of a top-down approach that is denoted as CS2 module, which affects the way that BPL signals are injected onto and extracted from the power lines of distribution BPL connections, has been proposed in [23]. CS2 module is the improved offspring of the initial CS1 module. On the basis of broadband performance metrics supported by the hybrid method such as coupling channel attenuation, capacity and SE, the impact of CS2 module on the performance of the distribution BPL networks has been assessed in $[24]$.

Nevertheless, as already been mentioned in [25]-[32], measurement differences between the experimental and theoretical results occur during the transfer function determination of distribution BPL networks that further affect the computation of all the derivative spectral efficiency metrics, such as capacity and SE. These measurement differences are due to a number of practical reasons and "real-life" conditions. In accordance with [25], [26], [28], [31], these measurement differences can comfortably be handled as error distributions such as continuous uniform distributions (CUDs). Since measurement differences affect the measurement process of coupling channel attenuation of CS2 module, further theoretical computations of capacity and, thus, SE are also influenced. In this paper, the correlation between measurement differences and SE performance of CS2 module is first presented when appropriate injected power spectral density limits (IPSD limits) and uniform additive white Gaussian noise (AWGN) PSD levels from the BPL literature are assumed. A set of statistical metrics is applied in order to assess the impact of measurement differences on the SE of distribution BPL networks. Among these, two sets of SE metrics are going to be used as the benchmark metrics either for assessing the impact of measurement differences on SE in this paper or for the assessment of the mitigation of measurement differences in the companion paper are reported while their behavior is investigated.

The rest of this paper is organized as follows: In Section 2, a brief synopsis of MTL configurations of distribution power grids, indicative distribution BPL topologies, signal transmission in distribution BPL networks and CS2 module is given. Section 3 deals with the measurement differences, applied IPSD limits, AWGN PSD levels and SE. In Section 4, numerical results and discussion are provided, aiming at numerically correlating the measurement differences and SE when CS2 module is applied. Two sets of statistical metrics are applied while those that are going to be used as the benchmark during the countermeasure techniques against the measurement differences of the companion paper are reported and highlighted. Section 5 concludes this paper.

\section{Distribution BPL Network Synopsis}

\subsection{Distribution Power Grid MTL Configuration}

A typical case of an OV MV and LV distribution line is depicted in Figs. 1(a) and 1(b), respectively. Overhead distribution lines hang above the ground and they consist of the three parallel non-insulated phase conductors and the neutral 
conductor. In this paper, the neutral conductor is considered only in the case of the

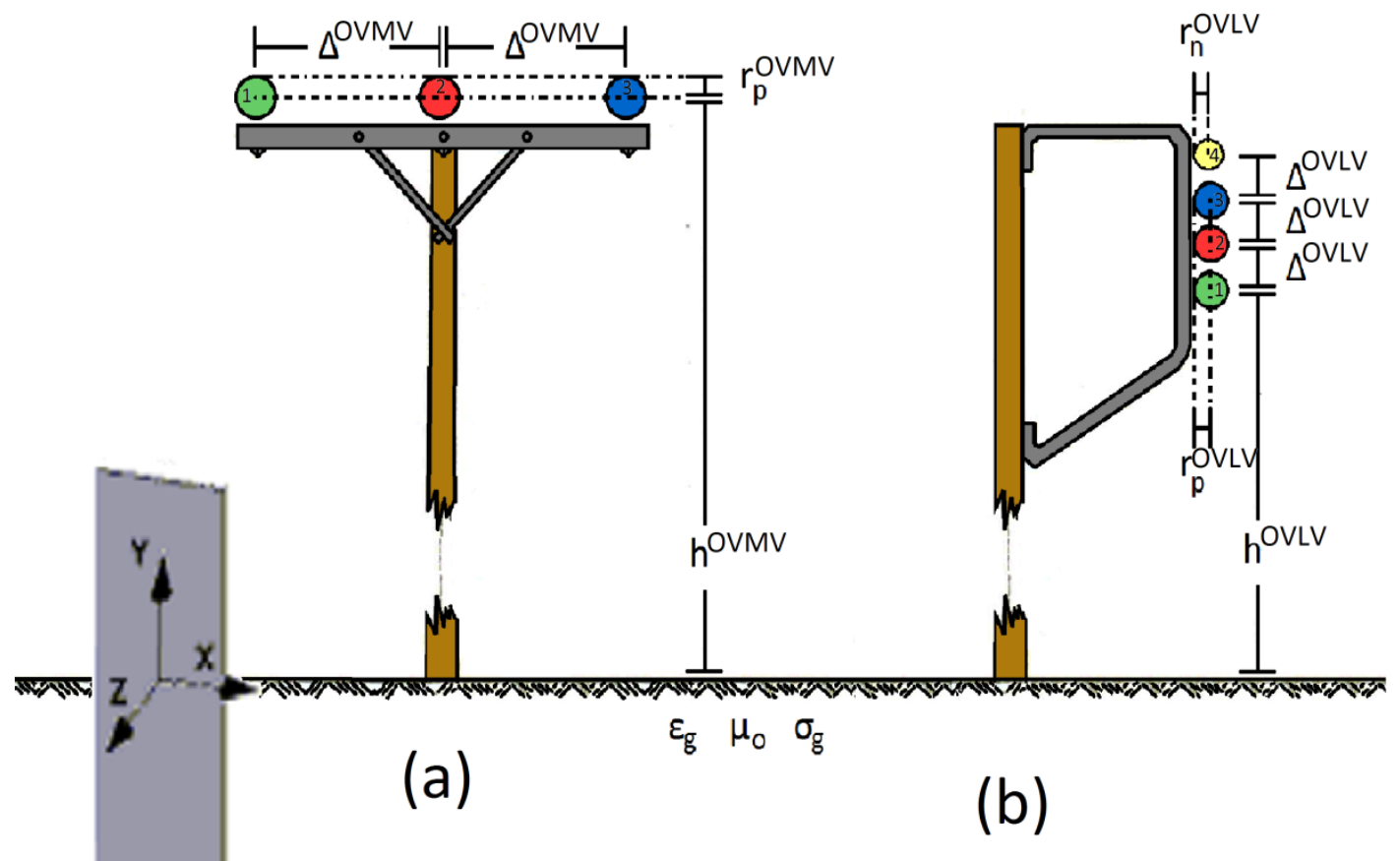

Armor Insulation

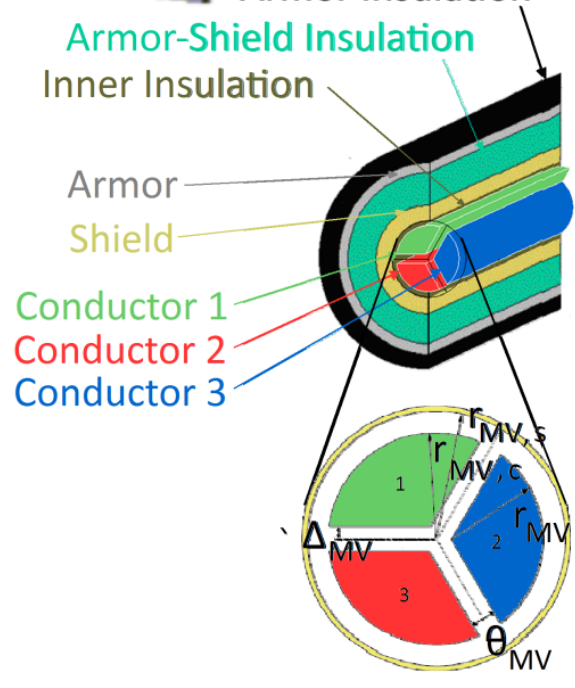

(c)

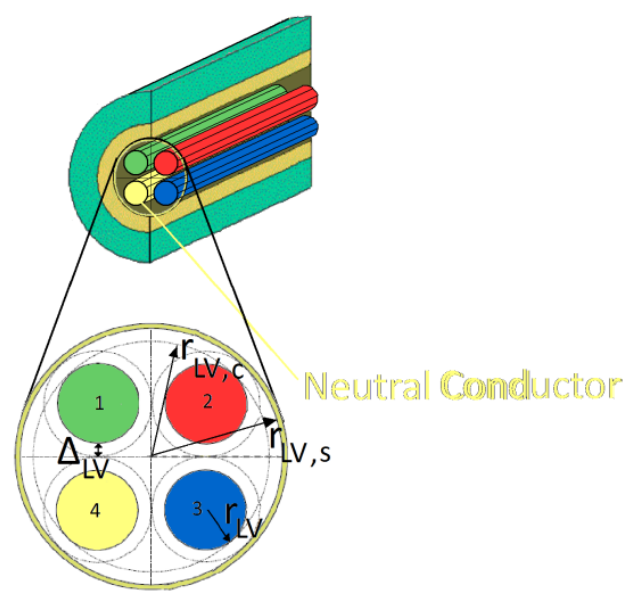

(d)

Fig. 1. Typical MTL configurations. (a) Overhead MV [1]. (b) Overhead LV [1]. (c) Underground MV [1]. (d) Underground LV [2].

OV LV distribution line while the conductors are assumed to be steel reinforced aluminum conductors (ACSR conductors). More details regarding the dimensions of the overhead distribution MTL configurations are given in [1], [3], [4], [15], [33], [34]. 
In Figs. 1(c) and 1(d), the UN MV and UN LV distribution lines are depicted, respectively. As the UN MV distribution line is concerned, the three-phase sector-type Paper Insulated Lead Covered (PILC) cable is assumed while in the case of the UN LV distribution line, three-phase four-conductor core-type Cross-linked polyethylene (XLPE) cable is assumed. Both cables of this paper are buried inside the ground and they consist of one shield conductor that is grounded at both ends. More details regarding the dimensions of the OV distribution MTL configurations are given in [1], [2], [5], [16], [17], [34]-[39].

In all the MTL configurations of the distribution power grid, which are examined in this paper, the conductivity of the ground is assumed $\sigma_{\mathrm{g}}=5 \mathrm{mS} / \mathrm{m}$ and its relative permittivity is equal to $\varepsilon_{\mathrm{rg}}=13$, which define a realistic scenario [1], [3], [4], [7], [13]-[15]. In OV distribution power grids, the ground is considered as the reference conductor whereas the grounded shield is considered as the reference conductor in the UN distribution power grids. The impact of imperfect ground on high frequency signal propagation via distribution power grids is detailed in [2]-[7], [13]-[15], [33], [38], [40]-[43].

\subsection{Indicative Distribution BPL Topologies}

In accordance with [23], BPL networks are divided into cascaded BPL connections, which can be treated separately. Each BPL connection is bounded by the transmitting end and receiving end repeaters that allow the amplification and regeneration of the attenuated BPL signals. Between the transmitting and receiving end of a BPL connection, the number of branches as well as the topological characteristics may vary depending on the type of the supported power grid. On the basis of its topological characteristics, each BPL connection can be treated as a different distribution BPL topology. This BPL connection consideration remains common either OV or UN distribution BPL networks are studied. In Fig. 2(a), a typical BPL connection with $N$ branches is shown.

With respect to Figs. 2(b) and 2(c), the hybrid model is interested in the topology of the BPL connections. Since the distribution BPL topology is known, the hybrid model separates the BPL topology into network modules. Through the two supported approaches of the hybrid model, each network module is treated separately and then their results are synthesized in order to produce the required metrics of the examined distribution BPL topology. In Table 1, the topological characteristics of indicative OV distribution BPL topologies are reported, which are common for both MV and LV power grids. Similarly to Table 1, indicative BPL topologies are presented in Table 2 but in the case of UN distribution BPL topologies. 
a)

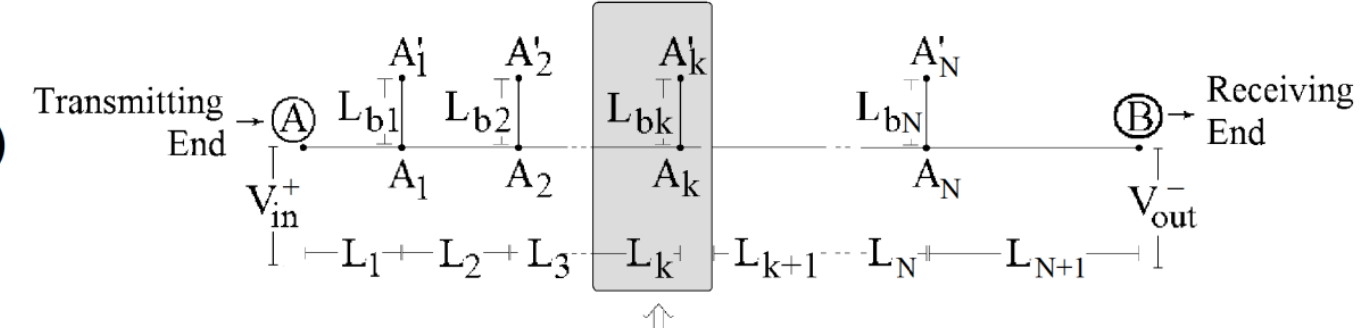

b)

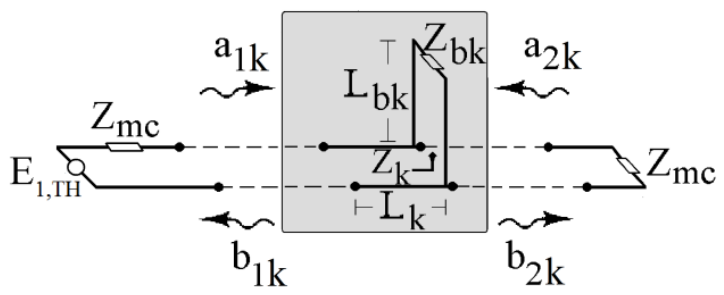

c)

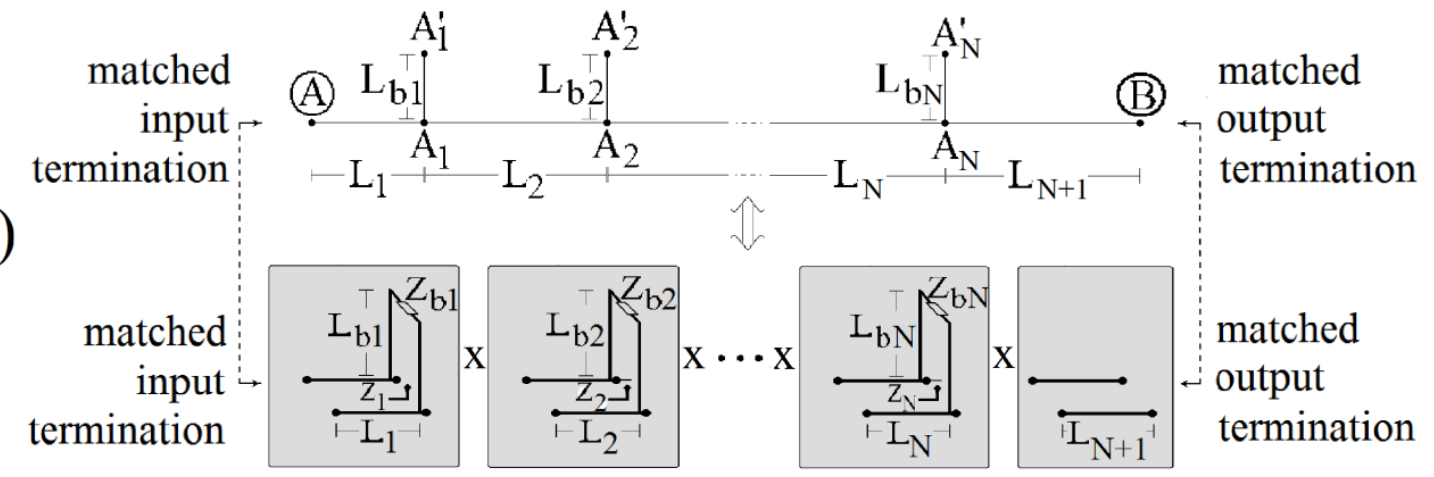

Fig. 2. (a) End-to-end BPL connection with $N$ branches. (b) Network module. (c) An indicative BPL topology considered as a cascade of $N+1$ modules corresponding to $N$ branches [1], [23].

Table 1. OV Distribution BPL Topologies

\begin{tabular}{|c|c|c|c|c|}
\hline $\begin{array}{c}\text { Topology } \\
\text { Name }\end{array}$ & Topology Description & $\begin{array}{c}\text { Number of } \\
\text { Branches }\end{array}$ & $\begin{array}{c}\text { Length of } \\
\text { Distribution Lines }\end{array}$ & $\begin{array}{c}\text { Length of } \\
\text { Branching Lines }\end{array}$ \\
\hline Urban case A & Typical OV urban topology & 3 & $\begin{array}{c}\mathrm{L}_{1}=500 \mathrm{~m}, \\
\mathrm{~L}_{2}=200 \mathrm{~m}, \\
\mathrm{~L}_{3}=100 \mathrm{~m}, \mathrm{~L}_{4}=200 \mathrm{~m}\end{array}$ & $\begin{array}{c}\mathrm{L}_{\mathrm{b} 1}=8 \mathrm{~m}, \mathrm{~L}_{\mathrm{b} 2}=13 \mathrm{~m}, \\
\mathrm{~L}_{\mathrm{b} 3}=10 \mathrm{~m}\end{array}$ \\
\hline Urban case B & $\begin{array}{c}\text { Aggravated OV urban } \\
\text { topology }\end{array}$ & 5 & $\begin{array}{c}\mathrm{L}_{1}=200 \mathrm{~m}, \mathrm{~L}_{2}=50 \mathrm{~m}, \\
\mathrm{~L}_{3}=100 \mathrm{~m}, \\
\mathrm{~L}_{4}=200 \mathrm{~m}, \\
\mathrm{~L}_{5}=300 \mathrm{~m}, \mathrm{~L}_{6}=150 \mathrm{~m}\end{array}$ & $\begin{array}{c}\mathrm{L}_{\mathrm{b} 1}=12 \mathrm{~m}, \mathrm{~L}_{\mathrm{b} 2}=5 \mathrm{~m}, \\
\mathrm{~L}_{\mathrm{b} 3}=28 \mathrm{~m}, \mathrm{~L}_{\mathrm{b}}=41 \mathrm{~m}, \\
\mathrm{~L}_{\mathrm{b} 5}=17 \mathrm{~m}\end{array}$ \\
\hline Suburban case & OV suburban topology & 2 & $\begin{array}{l}\mathrm{L}_{1}=500 \mathrm{~m}, \\
\mathrm{~L}_{2}=400 \mathrm{~m}, \mathrm{~L}_{3}=100 \mathrm{~m}\end{array}$ & $\mathrm{~L}_{\mathrm{b} 1}=50 \mathrm{~m}, \mathrm{~L}_{\mathrm{b} 2}=10 \mathrm{~m}$ \\
\hline Rural case & OV rural topology & 1 & $\mathrm{~L}_{1}=600 \mathrm{~m}, \mathrm{~L}_{2}=400 \mathrm{~m}$ & $\mathrm{~L}_{\mathrm{b} 1}=300 \mathrm{~m}$ \\
\hline "LOS" case & OV Line-of-Sight & 0 & $\mathrm{~L}_{1}=1000 \mathrm{~m}$ & - \\
& transmission & & & \\
\hline
\end{tabular}


Table 2. UN Distribution BPL Topologies

\begin{tabular}{|c|c|c|c|c|}
\hline $\begin{array}{c}\text { Topology } \\
\text { Name }\end{array}$ & Topology Description & $\begin{array}{c}\text { Number of } \\
\text { Branches }\end{array}$ & $\begin{array}{c}\text { Length of } \\
\text { Distribution Lines }\end{array}$ & $\begin{array}{c}\text { Length of } \\
\text { Branching Lines }\end{array}$ \\
\hline Urban case A & Typical UN urban topology & 3 & $\begin{array}{c}\mathrm{L}_{1}=70 \mathrm{~m}, \mathrm{~L}_{2}=55 \mathrm{~m}, \\
\mathrm{~L}_{3}=45 \mathrm{~m}, \mathrm{~L}_{4}=30 \mathrm{~m}\end{array}$ & $\begin{array}{c}\mathrm{L}_{\mathrm{b}}=12 \mathrm{~m}, \\
\mathrm{~L}_{\mathrm{b} 2}=7 \mathrm{~m}, \\
\mathrm{~L}_{\mathrm{b} 3}=21 \mathrm{~m}\end{array}$ \\
\hline Urban case B & $\begin{array}{c}\text { Aggravated UN urban } \\
\text { topology }\end{array}$ & 5 & $\begin{array}{c}\mathrm{L} 1=40 \mathrm{~m}, \mathrm{~L}_{2}=10 \mathrm{~m}, \\
\mathrm{~L}_{3}=20 \mathrm{~m}, \mathrm{~L}_{4}=40 \mathrm{~m}, \\
\mathrm{~L}_{5}=60 \mathrm{~m}, \mathrm{~L}_{6}=30 \mathrm{~m}\end{array}$ & $\begin{array}{c}\mathrm{L}_{\mathrm{b} 1}=22 \mathrm{~m}, \mathrm{~L}_{\mathrm{b} 2}=12 \mathrm{~m}, \\
\mathrm{~L}_{\mathrm{b} 3}=8 \mathrm{~m}, \mathrm{~L}_{\mathrm{b} 4}=2 \mathrm{~m}, \\
\mathrm{~L}_{\mathrm{b} 5}=17 \mathrm{~m}\end{array}$ \\
\hline Suburban case & UN suburban topology & 2 & $\begin{array}{c}\mathrm{L}_{1}=50 \mathrm{~m}, \mathrm{~L}_{2}=100 \mathrm{~m}, \\
\mathrm{~L}_{3}=50 \mathrm{~m}\end{array}$ & $\mathrm{~L}_{\mathrm{b} 1}=60 \mathrm{~m}, \mathrm{~L}_{\mathrm{b} 2}=30 \mathrm{~m}$ \\
\hline Rural case & UN rural topology & 1 & $\mathrm{~L}_{1}=50 \mathrm{~m}, \mathrm{~L}_{2}=150 \mathrm{~m}$ & $\mathrm{~L}_{\mathrm{b} 1}=100 \mathrm{~m}$ \\
\hline "LOS" case & $\begin{array}{c}\mathrm{L}_{1}=200 \mathrm{~m} \\
\text { transmission }\end{array}$ & 0 & & - \\
\hline
\end{tabular}

Apart from the topological characteristics of Tables 1 and 2, the hybrid model receives as input the circuital parameters of the distribution BPL topologies as well as several assumption affecting the transmission and propagation of the BPL signal across the distribution BPL topologies. As the circuital parameters are concerned, those are detailed in [1]-[8], [13], [15], [17], [34], [35], [44]-[46]. As the transmission and propagation assumptions are concerned, those can be synopsized as follows: (i) the cables of the branching lines are assumed identical to the distribution ones; (ii) the interconnections between the distribution and branch lines are assumed to be fully activated; (iii) the transmitting and the receiving ends are assumed matched to the characteristic impedance of the distribution lines; and (iv) the branch terminations are assumed open circuit.

\subsection{BPL Signal Transmission}

Hybrid model that deals with the BPL signal propagation and transmission across MTL configurations of distribution BPL networks is based on: (i) a matrix approach of the bottom-up approach that extends the standard transmission line (TL) analysis to the MTL one, which involves more than two conductors; and (ii) the concatenation of multidimensional transmission matrices of the cascaded network modules of the top-down approach. One of the main outputs of the hybrid model is the $n^{\mathrm{G}} \times n^{\mathrm{G}}$ channel transfer function matrix $\mathbf{H}\{\cdot\}$ that relates line voltages $\mathbf{V}(z)=\left[\begin{array}{llll}V_{1}(z) & \cdots & V_{n^{\mathrm{G}}}(z)\end{array}\right]^{\mathrm{T}}$ at the transmitting $(z=0)$ and the receiving $(z=L)$ ends where $n^{\mathrm{G}}$ is the number of the conductors of the examined MTL configuration and []$^{\mathrm{T}}$ denotes the transpose of a matrix. The channel transfer function matrix depends on the frequency, the power grid type, the physical properties of the cables and the geometry of the MTL configuration [1], [3], [44], [47].

\subsection{BPL Signal Coupling and CS2 Module}

According to how signals are injected onto and extracted from the lines of distribution BPL networks, different coupling schemes occur [1], [4], [7], [13]-[15]. With reference to Figs. 3(a) and 3(b), the components of a coupling scheme module at the transmitting and the receiving end are highlighted, respectively.

In [23], [24], CS2 module has been introduced and compared against its predecessor CS1 module. The performance differences among different coupling scheme 
modules come from the adjustment of the elements $C_{i}^{\mathrm{in}}, i=1, \cdots, n^{\mathrm{G}}$ at the transmitting end and of the elements $C_{i}^{\text {out }}, i=1, \cdots, n^{\mathrm{G}}$ at the receiving end. The elements $C_{i}^{\text {in }}, i=1, \cdots, n^{\mathrm{G}}$ of the input coupling vector $\mathbf{C}^{\text {in }}$ are the input coupling coefficients as well as the participation percentages of the conductors of the MTL configuration during the BPL signal injection while the elements $C_{i}^{\text {out }}, i=1, \cdots, n^{\mathrm{G}}$ of the output coupling vector $\mathbf{C}^{\text {out }}$ are the output coupling coefficients. On the basis of a number of restrictions detailed in [23], [24], the coupling scheme channel transfer function of a coupling scheme module that relates output BPL signal $V^{\text {out- }}$ and input BPL signal $V^{\text {int }}$ is given by

$$
H^{\mathrm{C}}\{\cdot\}=\frac{\left[V^{\text {out }}\right]^{\mathrm{c}}}{\left[V^{\text {int }}\right]^{\mathrm{C}}}=\left[\mathbf{C}^{\text {out }}\right]^{\mathrm{c}} \cdot \mathbf{H}\{\cdot\} \cdot\left[\mathbf{C}^{\text {in }}\right]^{\mathrm{c}}
$$

where $[\cdot]^{c}$ denotes the applied coupling scheme.

In accordance with [23], [24] and eq. (1), CS2 module can support three types of coupling schemes, namely:

- Coupling Scheme Type 1: Wire-to-Ground (WtG) or Shield-to-Phase (StP) coupling schemes. The signal is injected into only one conductor at the transmitting end and returns via the ground or the shield for overhead or underground BPL connections, respectively. The signal is extracted from the same conductor at the receiving end. Hereafter, WtG or StP coupling between conductor $s, s=1, \cdots, n^{\mathrm{G}}$ and ground or shield will be detoned as $\mathrm{WtG}^{\mathrm{s}}$ or $\mathrm{StP}^{\mathrm{s}}$, respectively.

- Coupling Scheme Type 2: Wire-to-Wire (WtW) or Phase-to-Phase (PtP) coupling schemes. The signal is injected in equal parts between two conductors. The signal is extracted from the same conductors. WtW or PtP coupling between conductors $p$ and $q, p, q=1, \cdots, n^{\mathrm{G}}$ will be detoned as $\mathrm{WtW}^{p \cdot q}$ or $\mathrm{PtP}^{p \cdot q}$, respectively.

- Coupling Scheme Type 3: MultiWire-to-MultiWire(MtM) or MultiPhase-to-MultiPhase (MtM) coupling schemes. The signal is injected among multiple conductors with different participation percentages for OV or UN BPL connections, respectively. Similarly to the previous coupling scheme types, the signal is extracted from the same conductor set at the receiving end. As it concerns MTM coupling scheme notation, for example, MtM coupling among the three conductors $p, q$ and $\mathrm{r}, p, q, r=1, \cdots, n^{\mathrm{G}}$ with participation percentages equal to $C_{p}^{\text {in }}, C_{q}^{\text {in }}$ and $C_{r}^{\text {in }}$, respectively, will be detoned as $\mathrm{MtM}_{C_{\mathrm{p}-C_{\mathrm{q}}-C_{\mathrm{r}}^{\text {in }}}^{p-q-r}}^{\text {in }}$.

\section{Factors Affecting SE Performance}

\subsection{Measurement Differences}

Although the theoretical computation of the coupling scheme channel transfer function, as described in eq. (1), is well-defined and verified, a set of practical reasons 


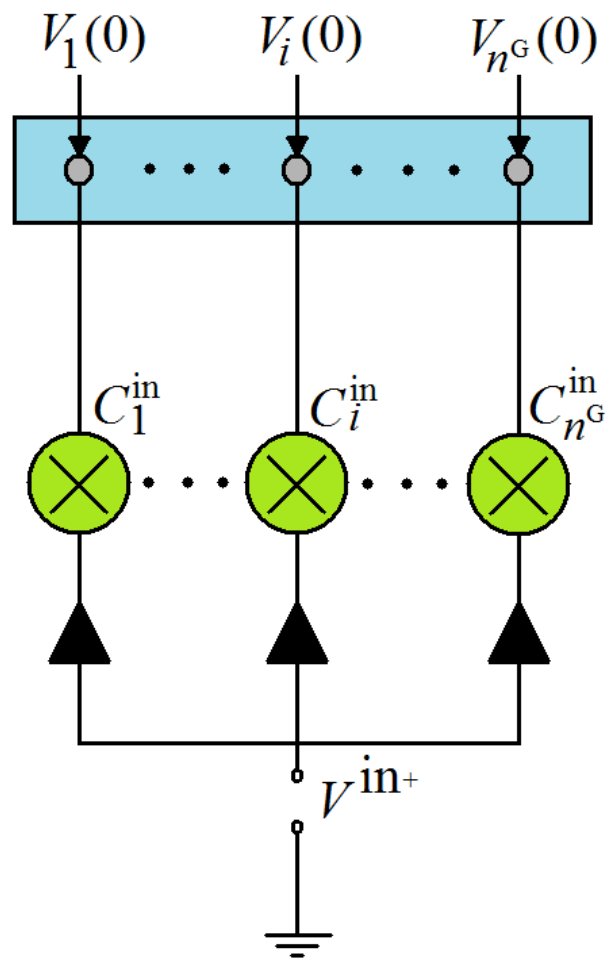

(a)

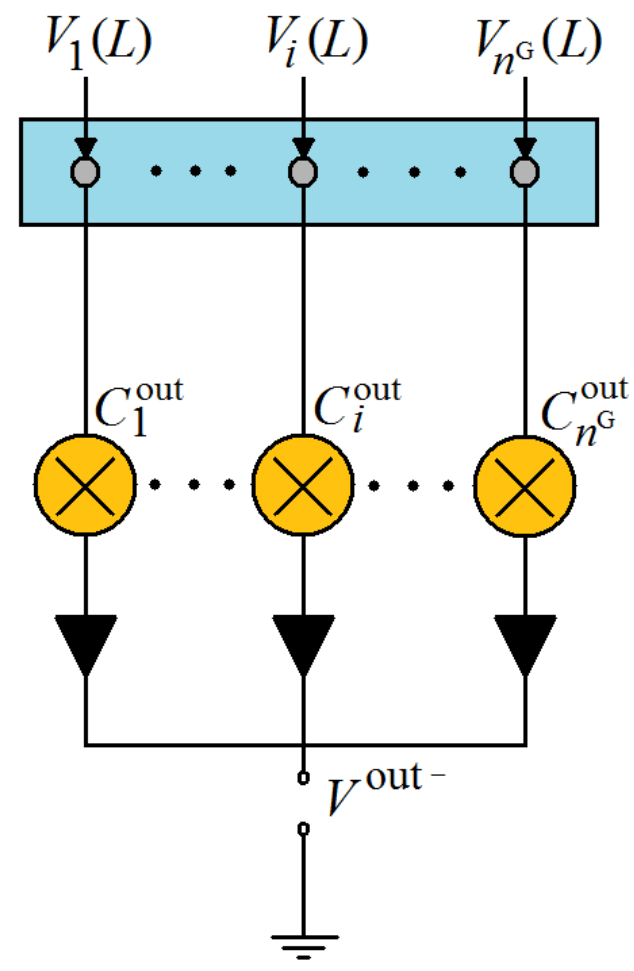

(b)

Fig. 3. Coupling scheme module [23], [24]. (a) BPL signal injection interface at the transmitting end. (b) BPL signal extraction interface at the receiving end.

and "real-life" conditions create significant differences between experimental measurements and theoretical results during the determination of the measured coupling scheme channel transfer function of distribution BPL topologies. In accordance with [25], [27], [30], the causes of these measurement differences can be grouped into six categories while the measured coupling scheme transfer function $\overline{H^{\mathrm{C}}}\{\cdot\}$ for given coupling scheme can be determined in mathematical terms by

$$
\overline{H^{\mathrm{C}}}\left(f_{i}\right)=H^{\mathrm{C}}\left(f_{i}\right)+e\left(f_{i}\right), i=1, \ldots, u
$$

where $f_{i}, i=1, \ldots, u$ denotes the measurement frequency, $e\left(f_{i}\right)$ synopsizes the total measurement difference in $\mathrm{dB}$ due to the six categories and $u$ is the number of subchannels in the examined frequency range. According to [27], [30]-[32], the total measurement difference can be assumed to follow either continuous uniform distribution (CUD) with minimum value $-a_{\text {CUD }}$ and maximum value $a_{\text {CUD }}$ or normal distribution (ND) with mean $\mu_{\mathrm{ND}}$ and standard deviation $\sigma_{\mathrm{ND}}$. In this pair of papers, only the CUD case is examined.

\subsection{EMI Policies and Power Constraints}

A variety of EMI policies that implies corresponding IPSD limits concerning the BPL operation occurs. The goal of these IPSD limits is to regulate the EMI emissions of the BPL technology in order not to interfere with other wireless and wireline services that operate at the same frequency band. The IPSD limits proposed by Ofcom are adopted in this paper [1]-[8], [13], [48]-[54]. Synoptically, in the 3-30 $\mathrm{MHz}$ frequency range, 
maximum levels of $-60 \mathrm{dBm} / \mathrm{Hz}$ and $-40 \mathrm{dBm} / \mathrm{Hz}$ constitute appropriate IPSD limits $p(f)$ for OV and UN distribution BPL networks, respectively, whereas in the $30-88 \mathrm{MHz}$ frequency range, maximum IPSD limits $p(f)$ equal to $-77 \mathrm{dBm} / \mathrm{Hz}$ and $-57 \mathrm{dBm} / \mathrm{Hz}$ for the respective OV and UN distribution BPL networks are assumed.

\subsection{Noise Characteristics}

As the noise properties of distribution BPL networks are concerned in the 3-88 $\mathrm{MHz}$ frequency range [1]-[8], a uniform AWGN PSD levels $N(f)$ will be assumed equal to $-105 \mathrm{dBm} / \mathrm{Hz}$ and $-135 \mathrm{dBm} / \mathrm{Hz}$ in the case of $\mathrm{OV}$ and $\mathrm{UN}$ distribution $\mathrm{BPL}$ networks, respectively.

\subsection{SE}

In accordance with [24], SE refers to the information in bps/Hz that can be reliably transmitted over the used BPL bandwidth for the examined distribution BPL topology. In general terms, SE describes the maximum achievable transmission rate per $\mathrm{Hz}$ that can be reliably transmitted over the examined BPL network. SE depends on the applied MTL configuration, the examined BPL topology, the coupling scheme applied, the EMI policies adopted and the noise environment [1]-[8]. SE for given coupling scheme channel is determined from

$$
S E\left(f_{i}\right)=\log _{2}\left\{1+\left[\frac{\left\langle p\left(f_{i}\right)\right\rangle_{L}}{\left\langle N\left(f_{i}\right)\right\rangle_{L}} \cdot\left|H^{C}\left(f_{i}\right)\right|^{2}\right]\right\}, i=1, \ldots, u
$$

where \langle\rangle$_{L}$ is an operator that converts $\mathrm{dBm} / \mathrm{Hz}$ into a linear power ratio $(\mathrm{W} / \mathrm{Hz})$. On the basis of eq. (3), the min, max and average SE are going to be examined in this paper in order to highlight the impact of the measurement differences and the different coupling schemes.

\section{Numerical Results and Discussion}

The numerical results of the supported coupling schemes by the CS2 module for various power grid types and distribution BPL topologies as well as the different intensity levels of measurement differences aim at assessing the impact of the measurement differences on the SE performance.

\subsection{SE without Measurement Differences}

The broadband performance, in terms of $\mathrm{SE}$ in the 3-88 $\mathrm{MHz}$ frequency band, is assessed by applying CS2 module when the indicative OV and UN distribution BPL topologies of Sec.2.2 are considered. The IPSD limits of Sec.3.2 and the AWGN levels of Sec.3.3 are applied. Also, three representative coupling schemes, each one representing a coupling scheme type, are considered in OV distribution BPL networks; say, $\mathrm{WtG}^{1}$, $\mathrm{WtW}^{1-2}$ and $\mathrm{MtM}_{0.8-0.1-0.1}^{1-2-3}$ coupling schemes for the coupling scheme type 1, 2 and 3, respectively. Similarly to OV distribution BPL networks, $\mathrm{StP}^{1}, \mathrm{PtP}^{1-2}$ and $\mathrm{MtM}_{0.8-0.1}^{1-2-3}$ coupling schemes for the coupling scheme type 1, 2 and 3, respectively, are considered for the UN distribution BPL networks.

In Figs. 4(a)-(c), SE of the indicative OV MV BPL topologies is plotted versus the frequency when $\mathrm{WtG}^{1}, \mathrm{WtW}^{1-2}$ and $\mathrm{MtM}_{0.8_{-}^{-0.1-0.1}}^{1-2-3}$ coupling scheme is applied, 


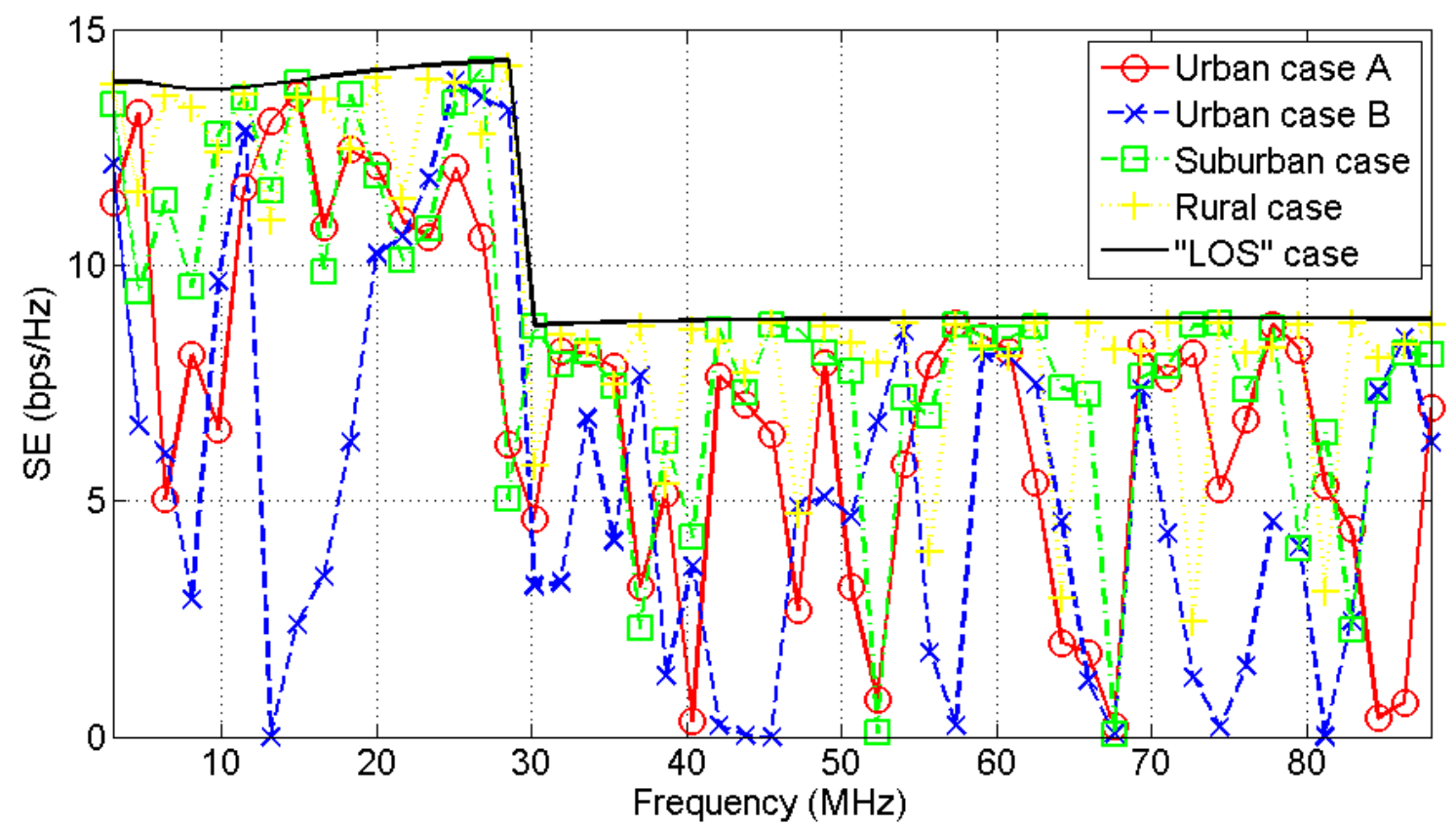

(a)

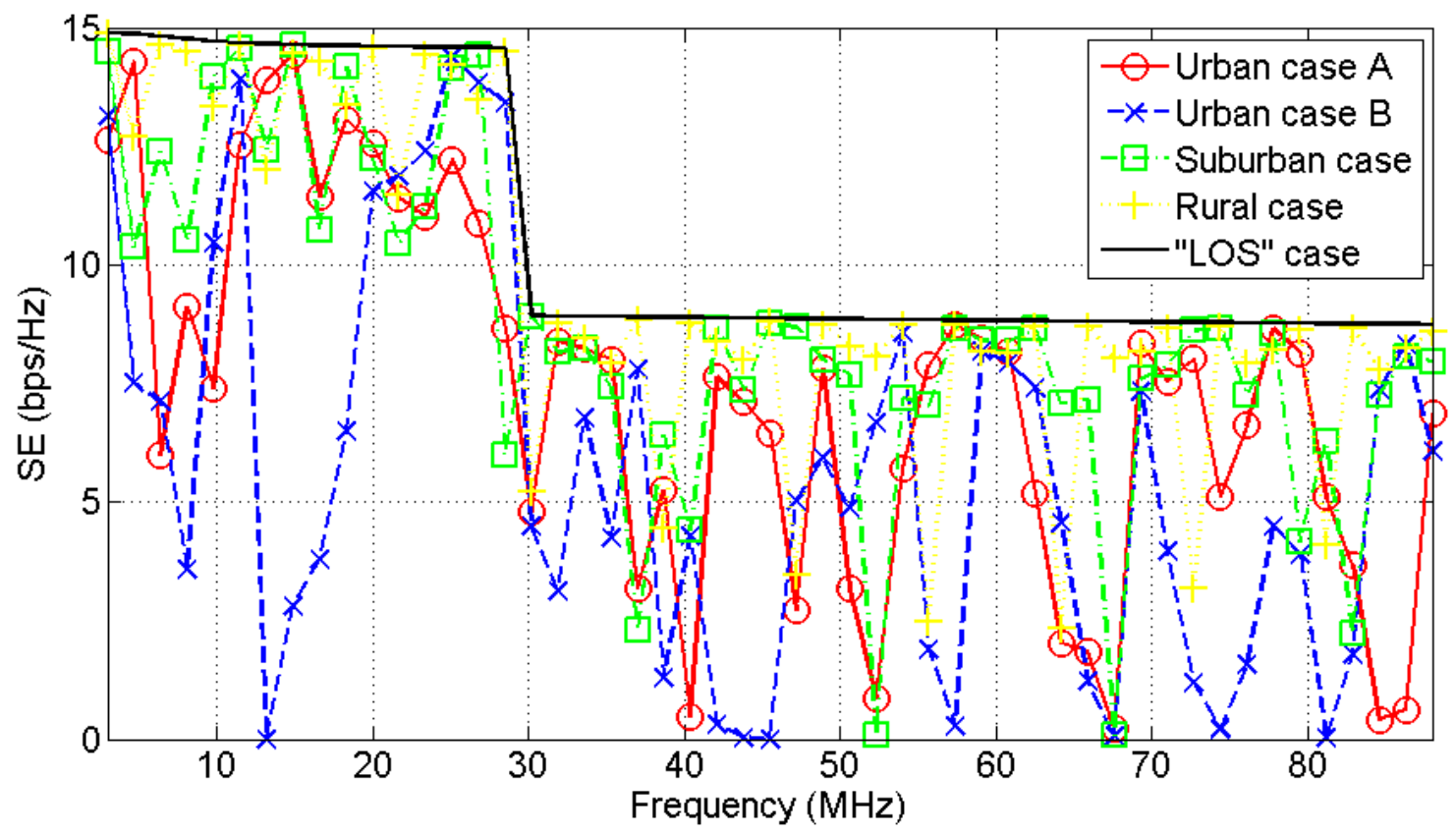

(b) 


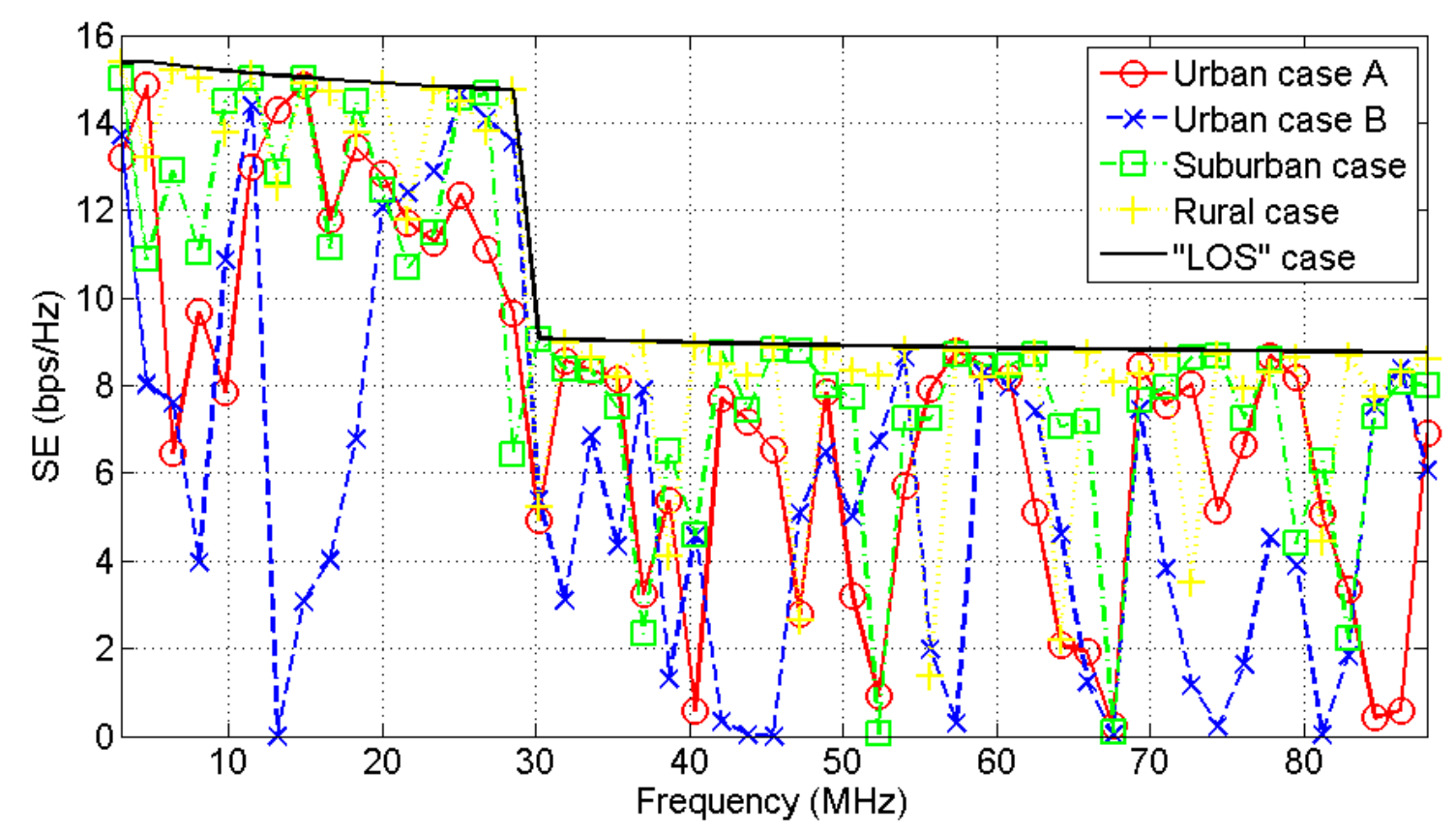

(c)

Fig. 4. SE of the indicative OV MV BPL topologies in the 3-88 MHz frequency band when different coupling schemes are applied. (a) $\mathrm{WtG}^{1}$ coupling scheme. (b) $\mathrm{WtW}^{1-2}$ coupling scheme. (c) $\mathrm{MtM}_{0.8}^{1-2-3}-0.11_{-}-0.1$ coupling scheme. 


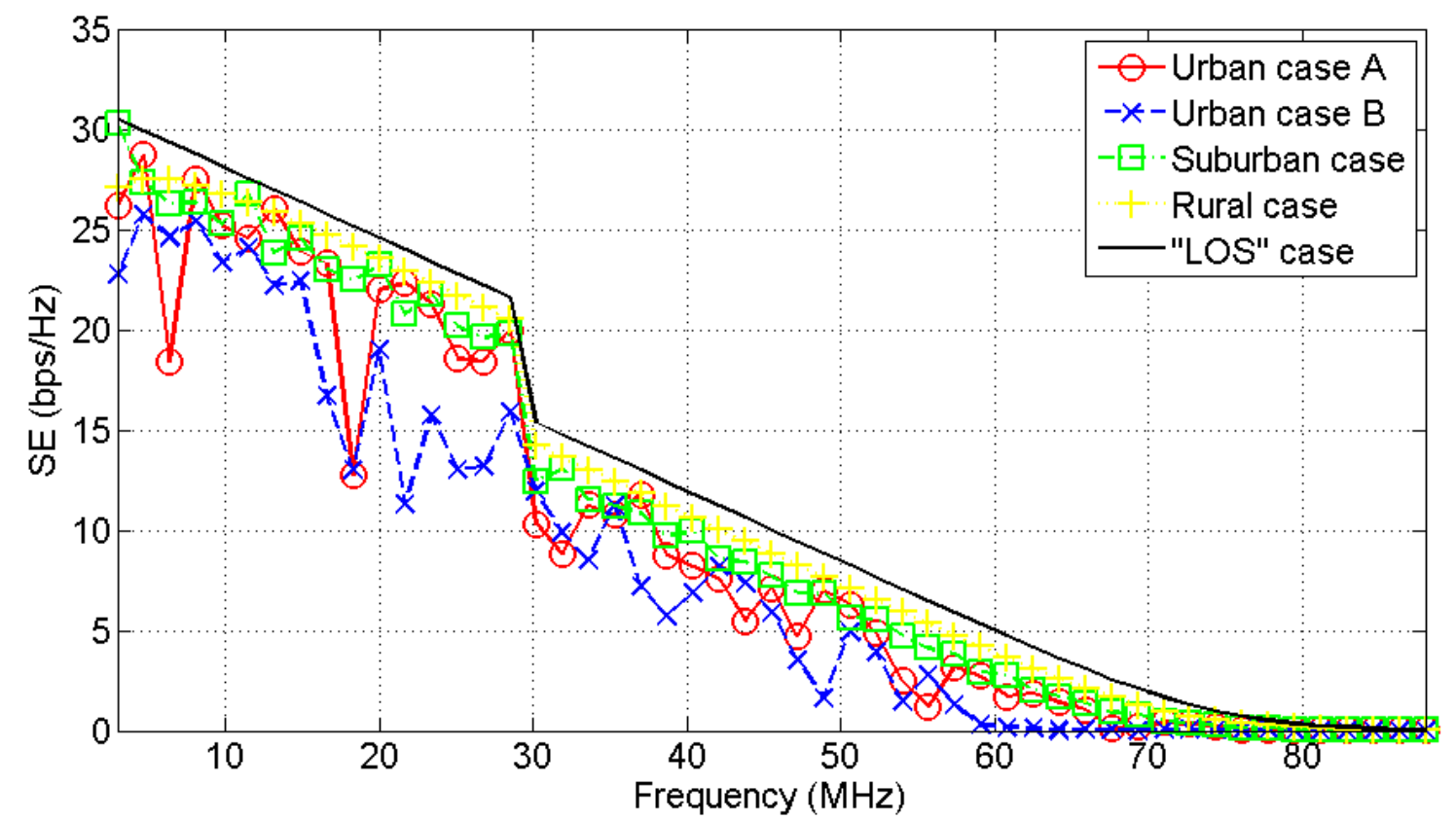

(a)

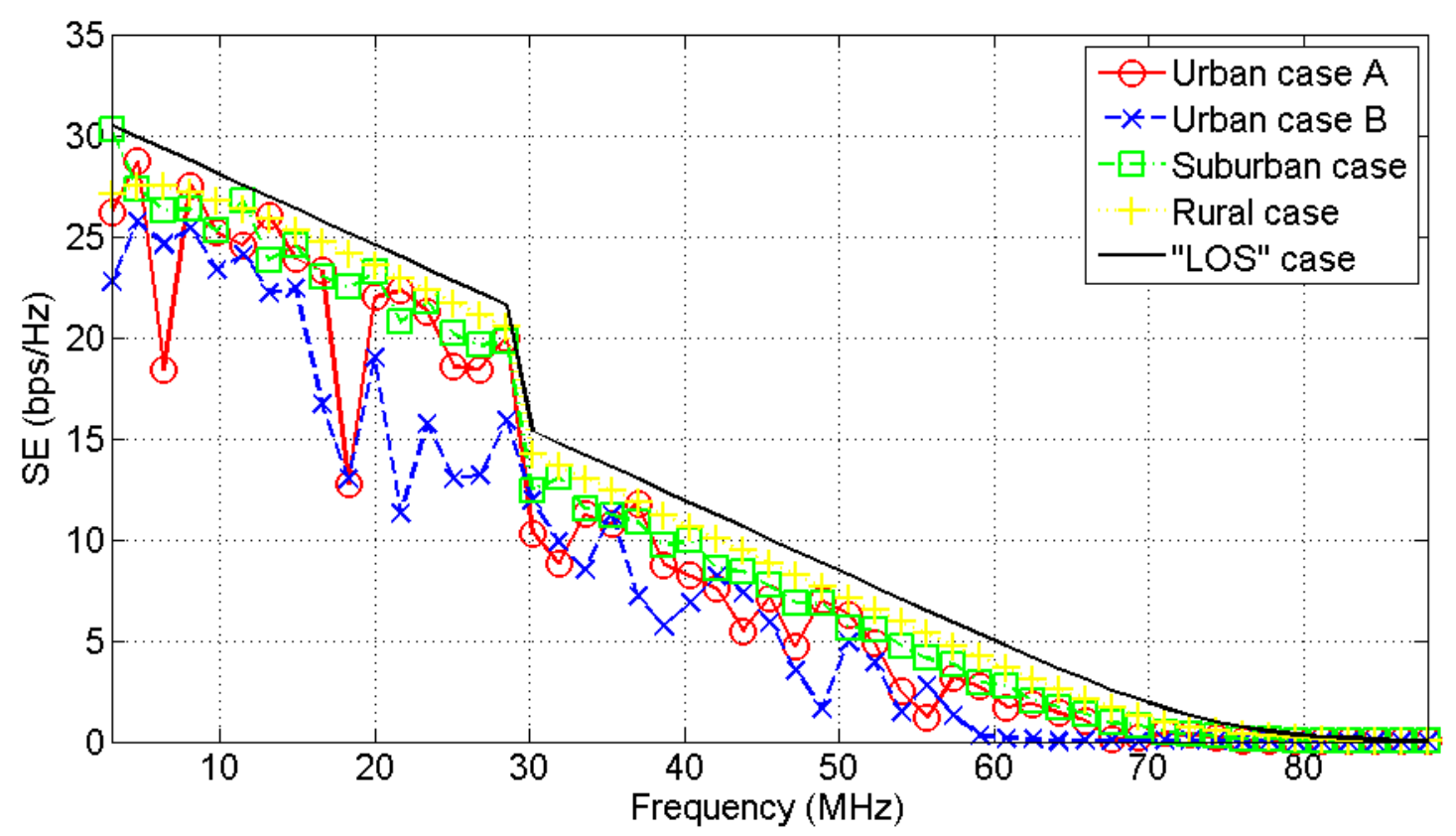

(b) 


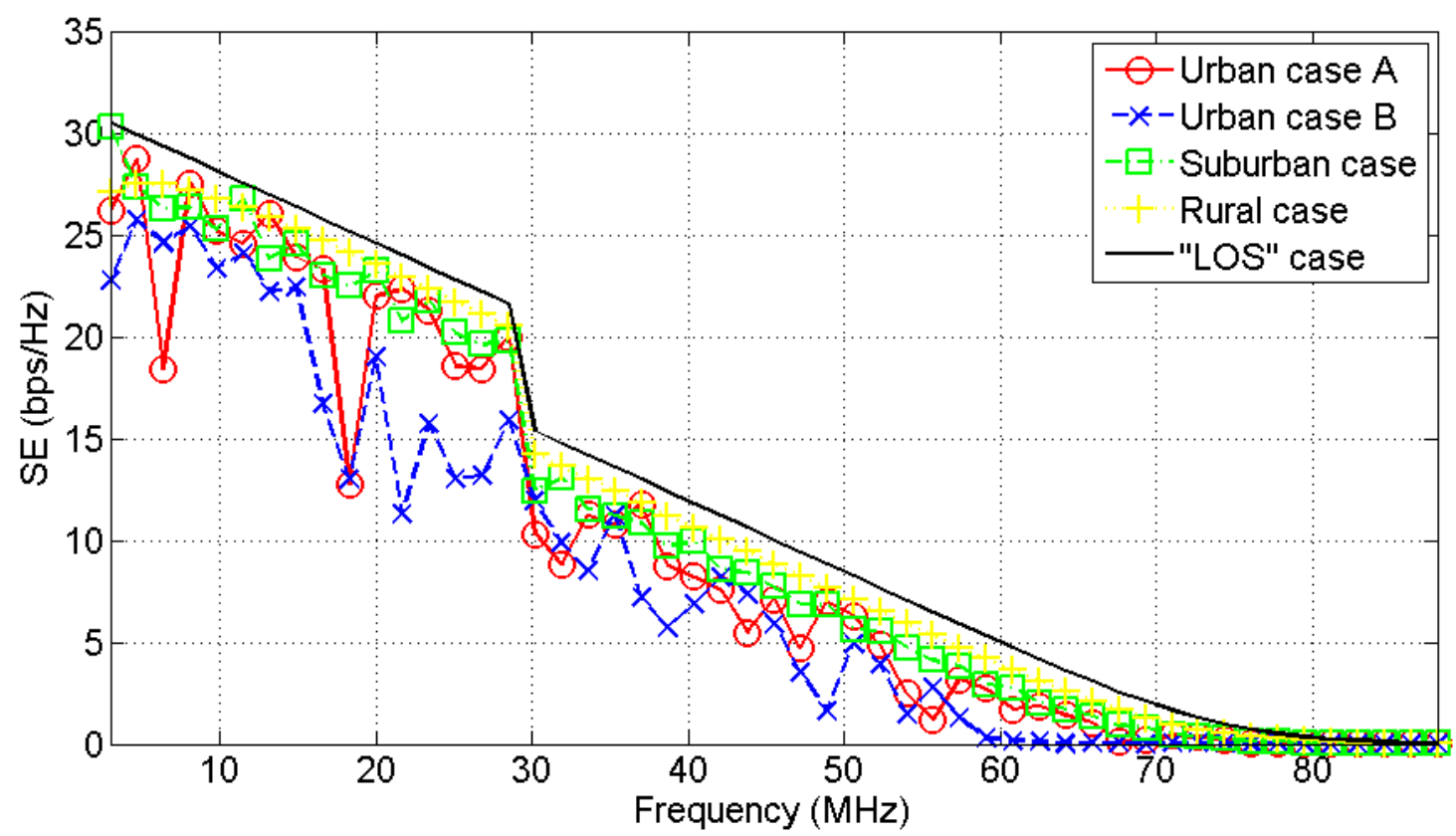

(c)

Fig. 5. SE of the indicative UN MV BPL topologies in the 3-88 MHz frequency band when different coupling schemes are applied. (a) $\mathrm{StP}^{1}$ coupling scheme. (b) $\mathrm{PtP}^{1-2}$ coupling scheme. (c) $\mathrm{MtM}_{0.8_{-}-0.1_{-}-0.1}^{1-2-1}$ coupling scheme. 


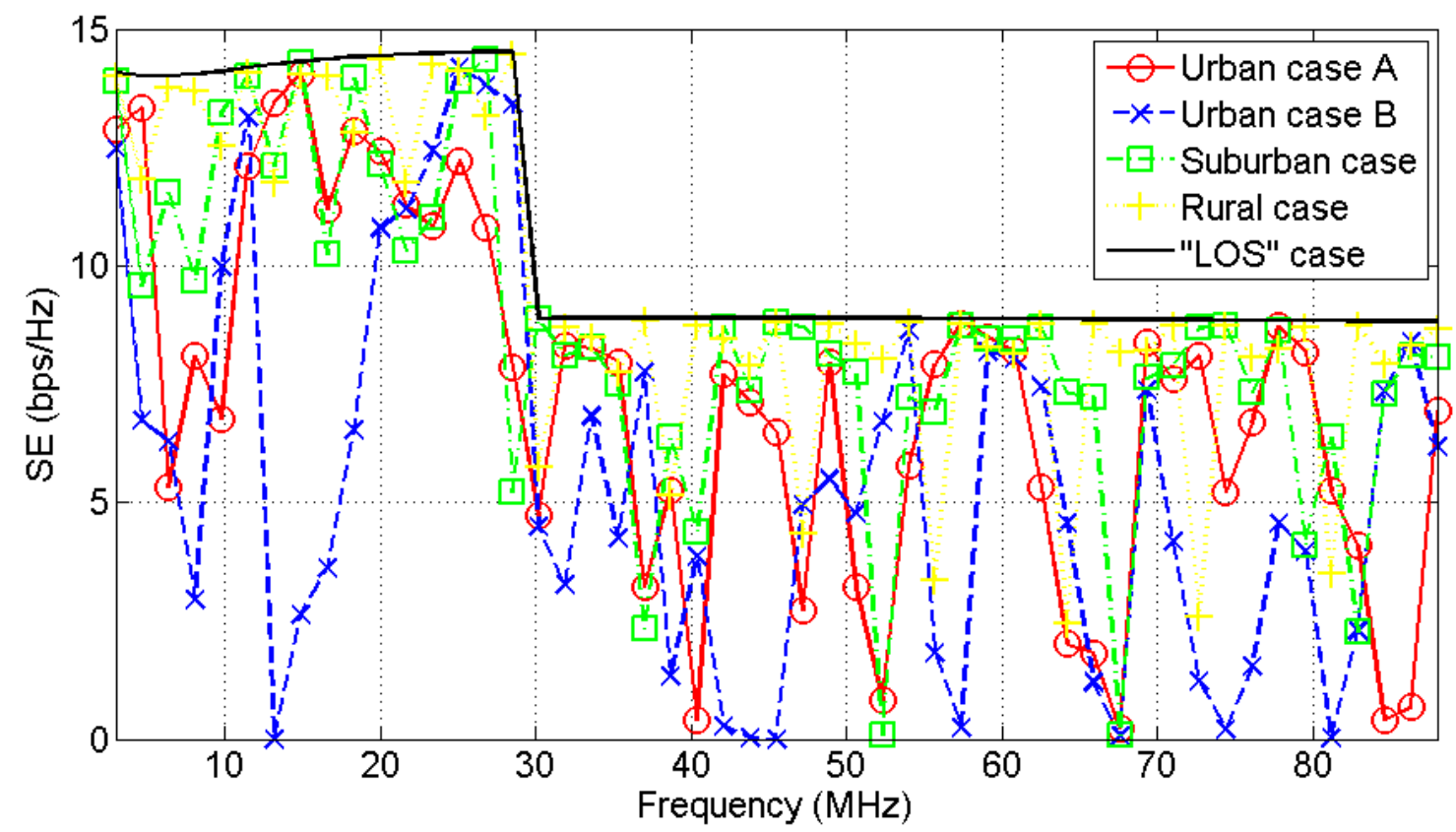

(a)

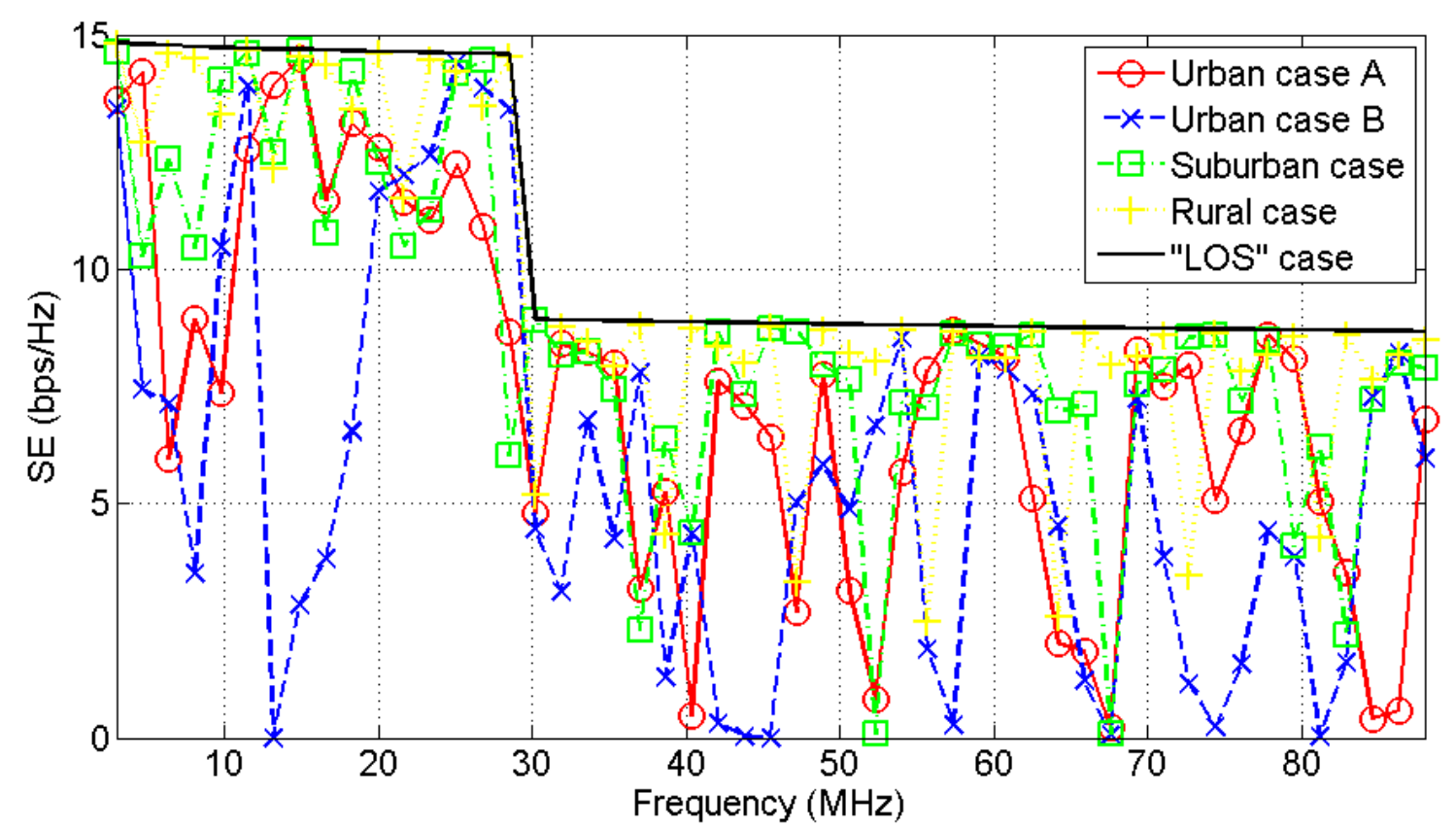

(b) 


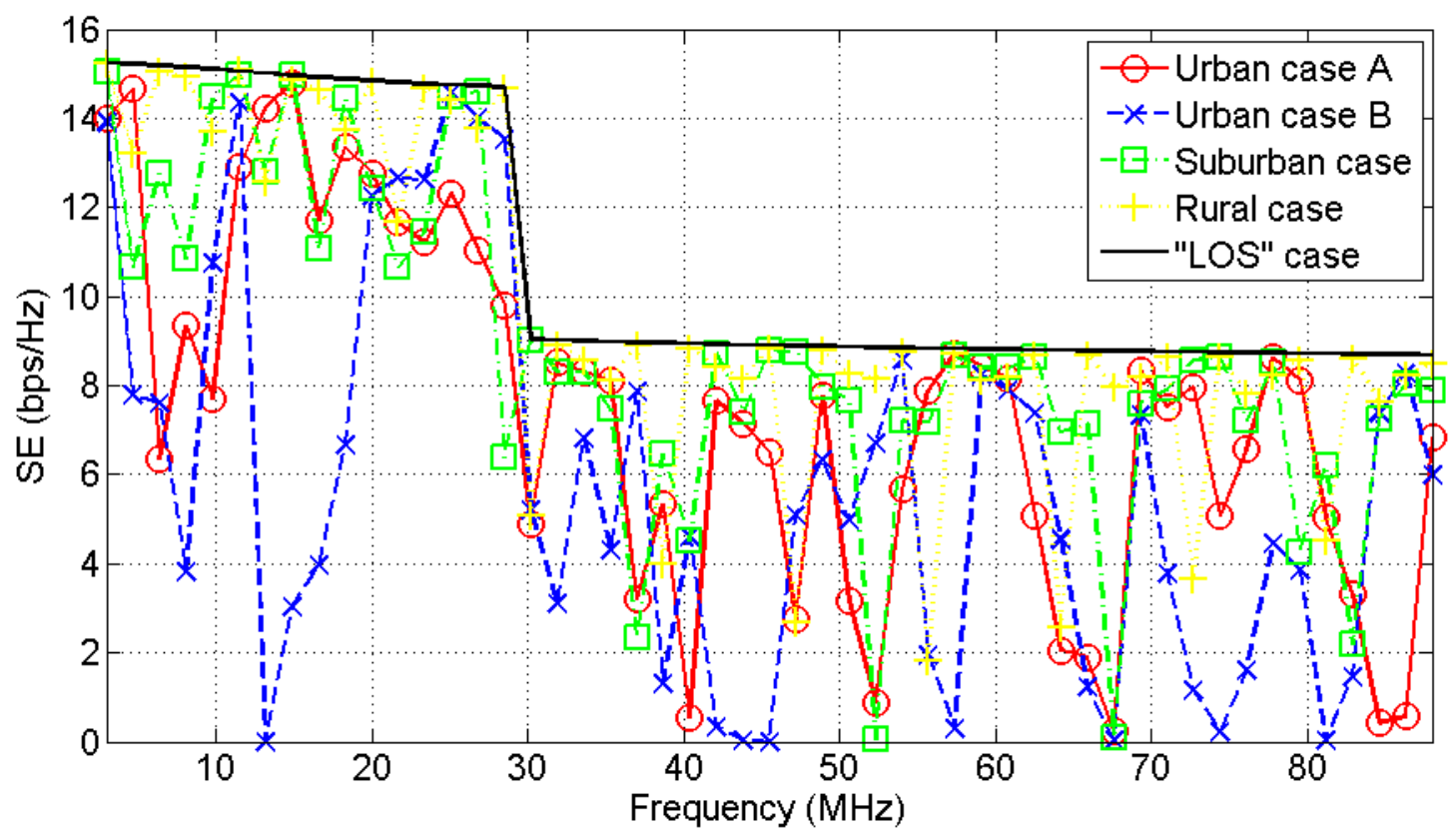

(c)

Fig. 6. Same with Fig. 4 but for the case of the indicative OV LV BPL topologies. 


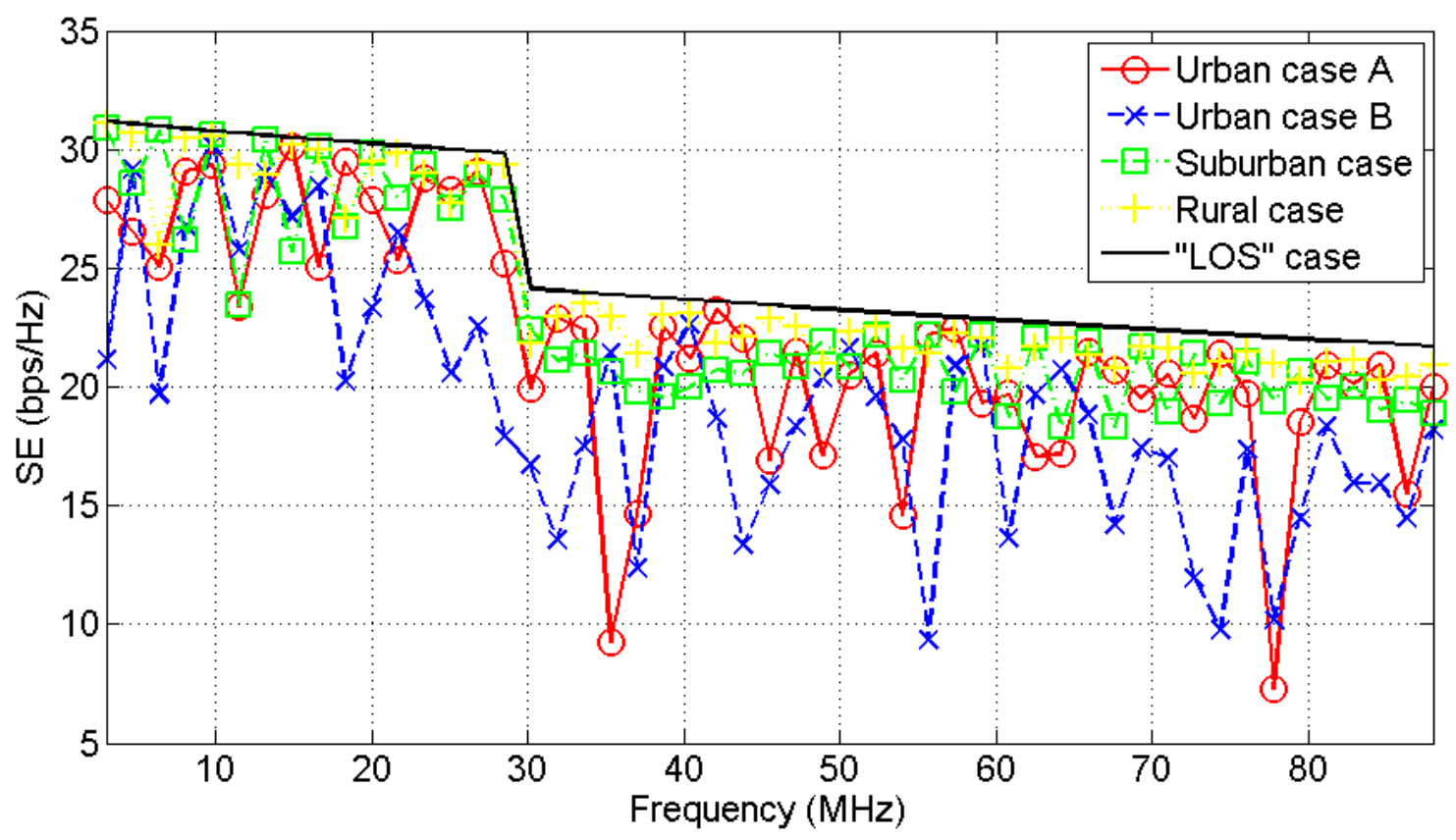

(a)

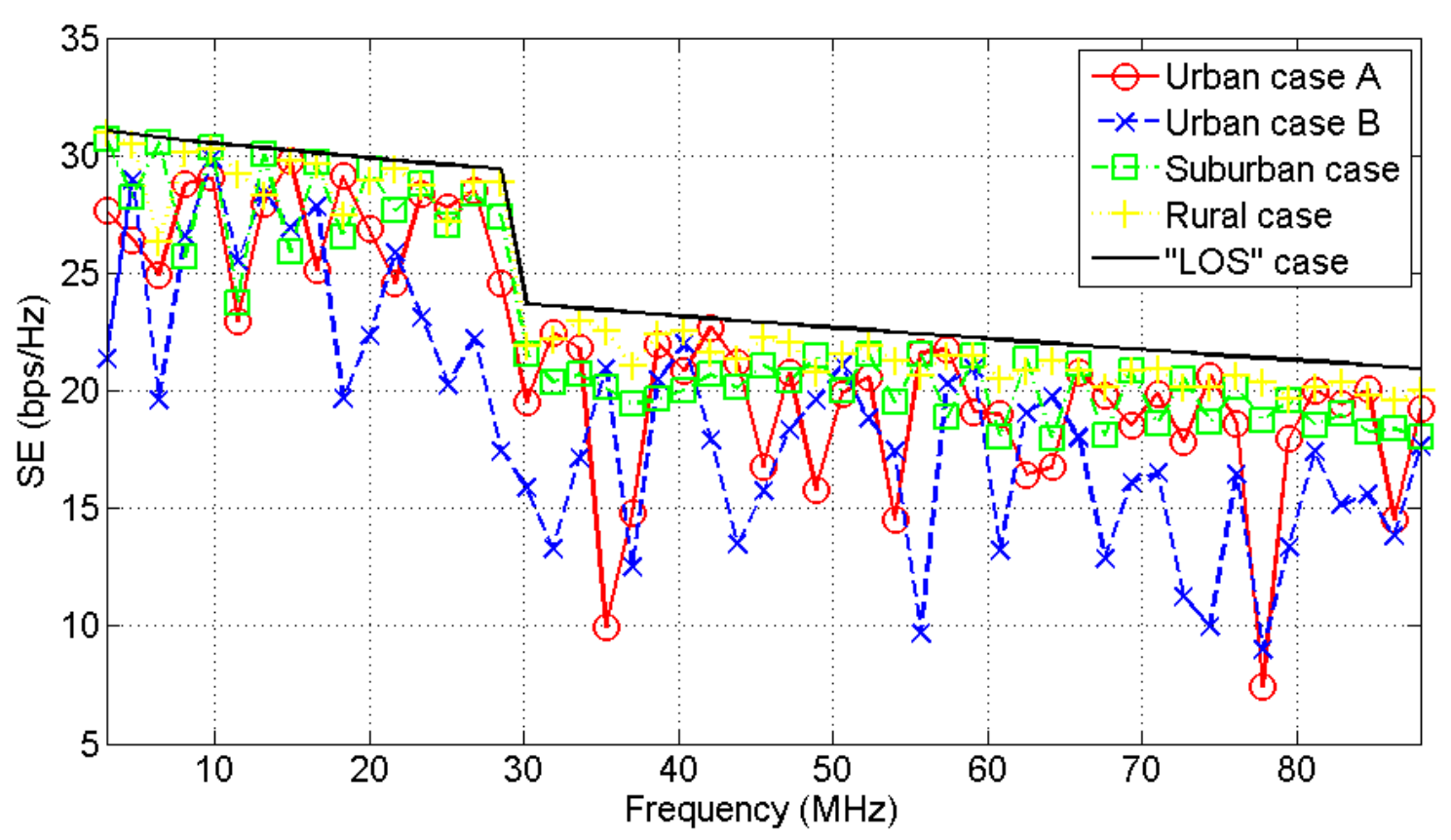

(b) 


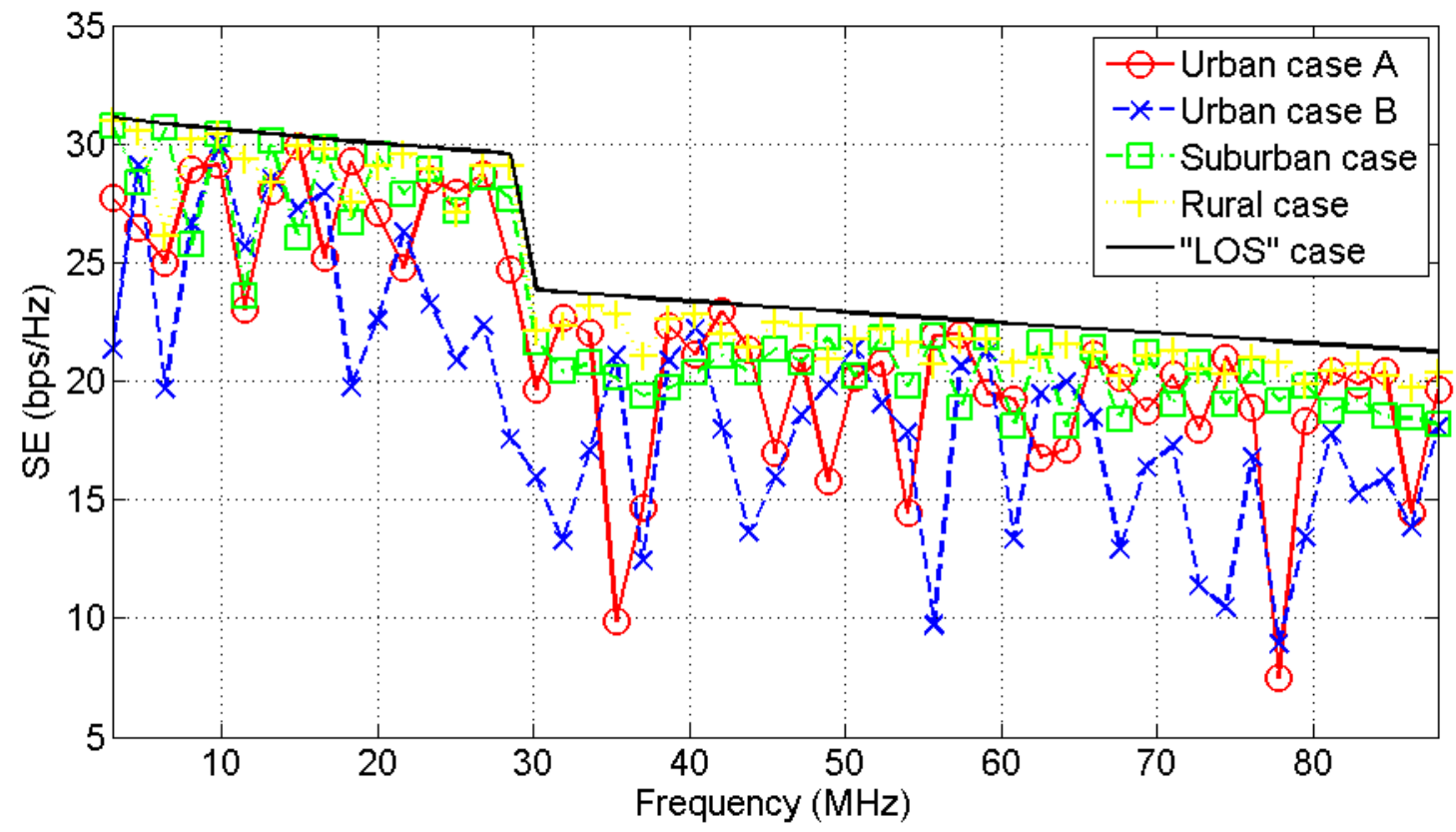

(c)

Fig. 7. Same with Fig. 5 but for the case of the indicative UN LV BPL topologies.

respectively. In Figs. 5(a)-(c), SE of the indicative UN MV BPL topologies is plotted versus the frequency when $\mathrm{StP}^{1}, \mathrm{PtP}^{1-2}$ and $\mathrm{MtM}_{0.8-0.1_{-}-0.1}^{1-2-3}$ coupling scheme is applied, respectively. In Figs. 6(a)-(c), same plots with Figs. 4(a)-(c) are given but for the case of the indicative OV LV BPL topologies while in Figs. 7(a)-(c), same curves with Figs. 5(a)-(c) are presented but for the case of the indicative UN LV BPL topologies.

Observing Figs. 4(a)-(c), 5(a)-(c), 6(a)-(c) and 7(a)-(c), it is evident that the SE of the "LOS" case acts as a SE mask for the other indicative distribution BPL topologies of the same distribution power grid type and coupling scheme. Since "LOS" topologies present the most favorable transmission behavior in comparison with the other branched BPL topologies, this profile of low channel attenuation of "LOS" topologies is also reflected on a favorable SE performance that is the best of the other respective ones of the other distribution BPL topologies.

Also, in all the indicative BPL topologies examined, there are two distinctive frequency bands of SE performance that are bounded by a SE step of the "LOS" case. This SE step is approximately equal to $5 \mathrm{bps} / \mathrm{Hz}$ and is located at $30 \mathrm{MHz}$ in all the indicative distribution BPL topologies regardless of their distribution power grid type and the coupling scheme. This SE step is explained by the fact that a significant change of the applied IPSD limits occurs at $30 \mathrm{MHz}$, while IPSD limits remain higher at the frequency band of 3-30 MHz in comparison with the ones at the frequency band of $30-88 \mathrm{MHz}$ despite the examined power grid type. In general, the higher IPSD limits of UN distribution BPL networks with the lower noise AWGN levels explain the higher SE values of distribution BPL topologies.

In addition, the recent research effort regarding the capacity enhancement of distribution BPL networks through the wise use of coupling scheme modules has significantly improved the SE of WtW/PtP coupling schemes while proposes new 
SE efficient with low electromagnetic interference (EMI) such as MtM coupling schemes [23], [24]. Indeed, for the same power grid type and coupling scheme, the SE differences among the different applied coupling schemes remain now relatively low. In contrast with CS1 module [1], [8], [47], CS2 module allows the WtW and PtP coupling schemes to present approximately the same SE results with the WtG and StP coupling schemes, respectively. Here it should be reminded the better EMC performance of WtW and PtP coupling schemes [15], [33]. Also, the careful selection of the used conductors of the examined MTL configurations as well as the respective participation percentages can offer higher SE results than the SE of the traditional WtG and WtW coupling schemes with even better electromagnetic compatibility (EMC) behavior through the use of MtM coupling schemes in OV and UN distribution BPL topologies.

In order to easily distinguish the SE performance differences among different power grid types, indicative BPL topologies and coupling schemes, a set of statistical metrics, which is denoted hereafter as set A and consists of the minimum, the maximum and the average value, of SE for each of the examined cases in Figs. 4(a)-(c), 5(a)-(c), 6(a)-(c) and 7(a)-(c), is reported in Table 3.

From Table 3, it is evident that MtM coupling schemes achieve the best SE performance statistical metrics in comparison with the coupling schemes of coupling scheme type 1 and 2. This favorable SE performance can be combined with appropriate adjustment of the participation percentages so that better EMC can be assured and IPSD limits can be further relaxed. However, the complexity of the BPL unit installation is a critical issue since more than two conductors of the MTL configurations are required. As the coupling schemes of the coupling scheme type 1 and 2 are examined, WtW and PtP coupling schemes are indeed almost SE equivalent to WtG and StP coupling schemes, respectively, when CS2 module is adopted. In addition, by observing SE minimum values of all the cases examined, it is evident that the rich multipath environment of the urban and suburban distribution BPL topologies creates spectral notches that further affect the SE performance regardless of the examined power grid type. This last observation explains the almost zero values of the SE minimum values of the Table 3. In contrast, in accordance with the Figs. 4(a)-(c), 5(a)-(c), 6(a)-(c) and 7(a)-(c), the SE maximum values of the examined distribution BPL topologies follow the "LOS" mask for given power grid type and coupling scheme type. In fact, the maximum value for the "LOS" cases is observed at $3 \mathrm{MHz}$ whereas in all the other cases their SE maximum value is observed in the $3-30 \mathrm{MHz}$ frequency band in relation with the "LOS" mask. Hence, the average SE for each examined distribution BPL topology offers a very descriptive statistical metric for the performance since describes the impact of the channel attenuation, IPSDM limits and AWGN levels across the entire 3-88 $\mathrm{MHz}$ frequency band. In order to examine the impact of the measurement differences on the SE performance, only the average SE performance for each distribution BPL topology is examined, hereafter. 
Table 3. SE Statistical Metrics of Set A for the Different Indicative Distribution BPL Topologies (the frequency spacing is equal to $0.1 \mathrm{MHz}$ )

\begin{tabular}{|c|c|c|c|c|c|c|c|c|c|c|}
\hline \multirow[b]{3}{*}{$\begin{array}{c}\text { Distribution } \\
\text { power grid } \\
\text { type }\end{array}$} & \multirow[b]{3}{*}{$\begin{array}{l}\text { Topology } \\
\text { Name }\end{array}$} & \multicolumn{9}{|c|}{$\begin{array}{c}\mathrm{SE} \\
(\mathrm{bps} / \mathrm{Hz})\end{array}$} \\
\hline & & \multicolumn{3}{|c|}{$\left(\mathrm{WtG}^{1} / \mathrm{StP}^{1}\right)$} & \multicolumn{3}{|c|}{$\left(\mathrm{WtW}^{1-2} / \mathrm{PtP}^{1-2}\right)$} & \multicolumn{3}{|c|}{$\mathrm{MtM}_{0.8_{-}-0.1-0.1}^{1-2-3}$} \\
\hline & & Min & Max & Average & Min & Max & Average & Min & Max & Average \\
\hline \multirow{5}{*}{ OVMV } & $\begin{array}{c}\text { Urban } \\
\text { case A }\end{array}$ & 0 & 13.96 & 7.00 & 0 & 14.57 & 7.19 & 0 & 15.00 & 7.35 \\
\hline & $\begin{array}{l}\text { Urban } \\
\text { case B }\end{array}$ & 0 & 14.19 & 5.39 & 0 & 14.51 & 5.59 & 0 & 14.77 & 5.74 \\
\hline & $\begin{array}{c}\text { Suburban } \\
\text { case }\end{array}$ & 0 & 14.35 & 8.29 & 0 & 14.63 & 8.49 & 0 & 15.05 & 8.64 \\
\hline & $\begin{array}{c}\text { Rural } \\
\text { case }\end{array}$ & 2.45 & 14.25 & 9.25 & 2.25 & 14.87 & 9.43 & 1.34 & 15.41 & 9.58 \\
\hline & $\begin{array}{l}\text { "LOS" } \\
\text { case }\end{array}$ & 8.73 & 14.37 & 10.48 & 8.75 & 14.89 & 10.68 & 8.76 & 15.41 & 10.83 \\
\hline \multirow{5}{*}{ OVLV } & $\begin{array}{l}\text { Urban } \\
\text { case A }\end{array}$ & 0 & 14.34 & 7.12 & 0 & 14.62 & 7.19 & 0 & 15.04 & 7.30 \\
\hline & $\begin{array}{c}\text { Urban } \\
\text { case B }\end{array}$ & 0 & 14.43 & 5.51 & 0 & 14.53 & 5.58 & 0 & 14.75 & 5.70 \\
\hline & $\begin{array}{c}\text { Suburban } \\
\text { case }\end{array}$ & 0 & 14.51 & 8.40 & 0 & 14.76 & 8.47 & 0 & 15.18 & 8.59 \\
\hline & $\begin{array}{c}\text { Rural } \\
\text { case }\end{array}$ & 2.33 & 14.45 & 9.37 & 2.38 & 14.81 & 9.43 & 1.83 & 15.24 & 9.55 \\
\hline & $\begin{array}{l}\text { "LOS" } \\
\text { case }\end{array}$ & 8.82 & 14.53 & 10.60 & 8.67 & 14.83 & 10.67 & 8.69 & 15.23 & 10.78 \\
\hline \multirow{5}{*}{ UNMV } & $\begin{array}{l}\text { Urban } \\
\text { case A }\end{array}$ & 0 & 28.69 & 9.57 & 0 & 28.69 & 9.57 & 0 & 28.69 & 9.57 \\
\hline & $\begin{array}{l}\text { Urban } \\
\text { case B }\end{array}$ & 0 & 28.52 & 8.05 & 0 & 28.52 & 8.05 & 0 & 28.52 & 8.05 \\
\hline & $\begin{array}{c}\text { Suburban } \\
\text { case }\end{array}$ & 0 & 30.26 & 10.46 & 0 & 30.26 & 10.46 & 0 & 30.26 & 10.46 \\
\hline & $\begin{array}{c}\text { Rural } \\
\text { case }\end{array}$ & 0.02 & 30.07 & 11.37 & 0.02 & 30.07 & 11.37 & 0.02 & 30.07 & 11.37 \\
\hline & $\begin{array}{l}\text { "LOS" } \\
\text { case }\end{array}$ & 0.05 & 30.51 & 12.33 & 0.05 & 30.51 & 12.33 & 0.05 & 30.51 & 12.33 \\
\hline \multirow{5}{*}{ UNLV } & $\begin{array}{l}\text { Urban } \\
\text { case A }\end{array}$ & 6.89 & 30.50 & 21.73 & 7.12 & 30.19 & 21.21 & 7.19 & 30.31 & 21.41 \\
\hline & $\begin{array}{l}\text { Urban } \\
\text { case B }\end{array}$ & 5.67 & 30.36 & 19.20 & 5.80 & 30.07 & 18.68 & 5.75 & 30.20 & 18.89 \\
\hline & $\begin{array}{c}\text { Suburban } \\
\text { case }\end{array}$ & 17.62 & 31.10 & 22.95 & 17.16 & 30.92 & 22.43 & 17.26 & 30.98 & 22.64 \\
\hline & $\begin{array}{c}\text { Rural } \\
\text { case }\end{array}$ & 20.00 & 31.10 & 24.12 & 19.38 & 30.93 & 23.60 & 19.59 & 30.99 & 23.81 \\
\hline & $\begin{array}{l}\text { "LOS" } \\
\text { case }\end{array}$ & 21.69 & 31.20 & 25.29 & 20.93 & 31.06 & 24.77 & 21.25 & 31.11 & 24.97 \\
\hline
\end{tabular}




\subsection{SE with Biased Measurement Differences}

With reference to eq. (2), the SE impact of measurement differences is examined in this subsection. As measurement differences can be expressed in $\mathrm{dB}$, the average $\mathrm{SE}$ and the range of the average SE for given positive value $a$ in $\mathrm{dB}$ is presented in the following figures when the indicative distribution BPL topologies are assumed. In detail, the lower and the upper limit of the average SE range are calculated for given $a$ value when the minimum value $-a$ and the maximum value $a$ are applied across the entire set of the measured coupling scheme transfer function, respectively. In this subsection, it should be noted that the assumed value of $a$ is added to the measured coupling scheme transfer function of each measurement frequency thus acting as a bias.

More specifically, in Figs. 8(a)-(c), the upper and the lower limits of the average SE range of the indicative OV MV BPL topologies are plotted versus the value $a$ when $\mathrm{WtG}^{1}, \mathrm{WtW}^{1-2}$ and $\mathrm{MtM}_{0.8_{-}-0.1_{-}-0.1}^{1-2-3}$ coupling scheme is applied, respectively. In Figs. 9(a)-(c), the upper and the lower limit of the average SE range of the indicative UN MV BPL topologies is plotted versus the value $a$ when $\mathrm{StP}^{1}, \mathrm{PtP}^{1-2}$ and

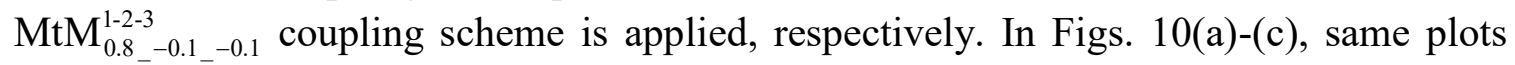
with Figs. 8(a)-(c) are given but for the case of the indicative OV LV BPL topologies while in Figs. 11(a)-(c), same curves with Figs. 9(a)-(c) are presented but for the case of the indicative UN LV BPL topologies. In Table 3, the results concerning the average SE range of Figs. 8-11 with respect to the different $a$ values of the measurement differences are reported. 


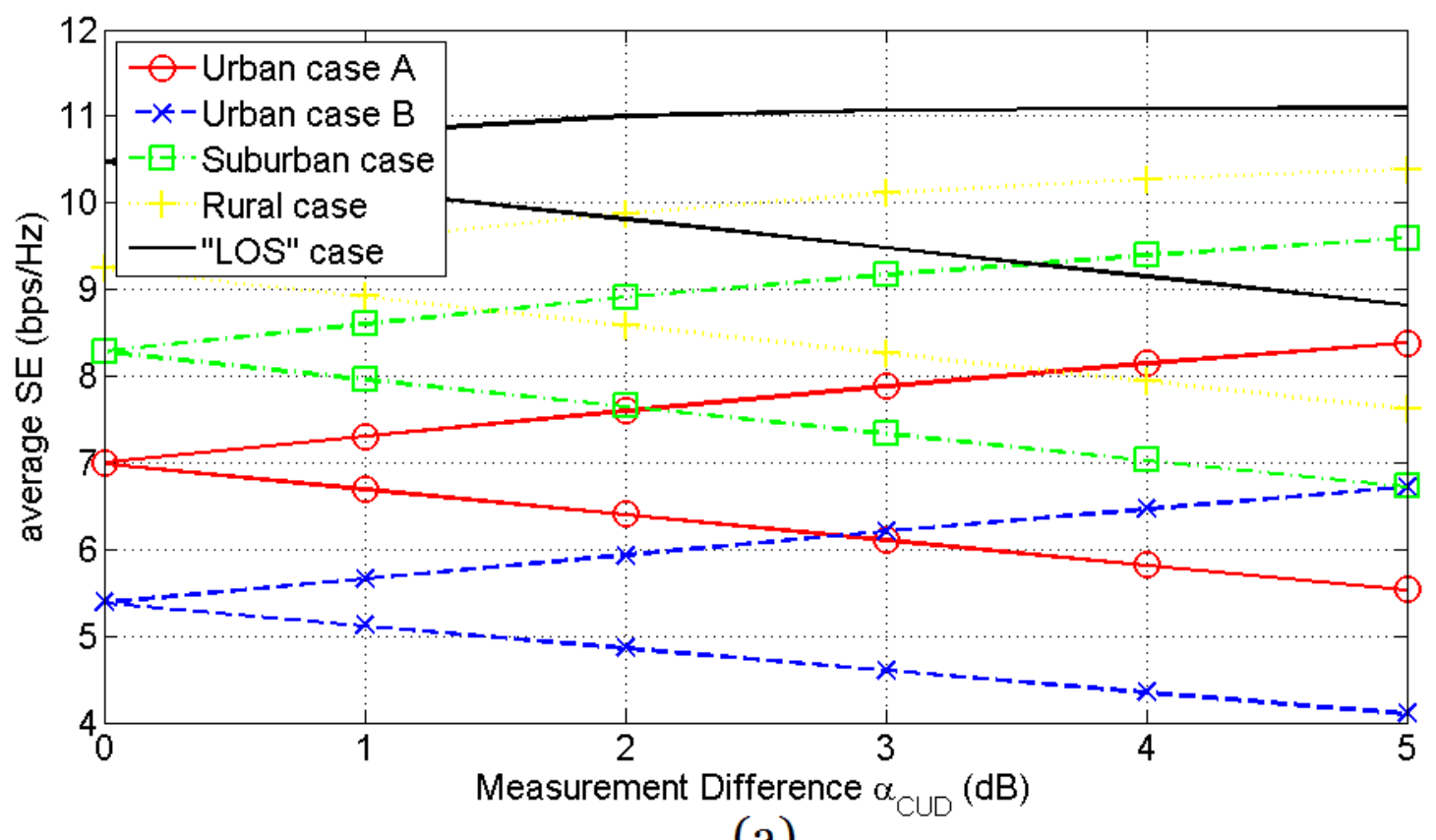

(a)

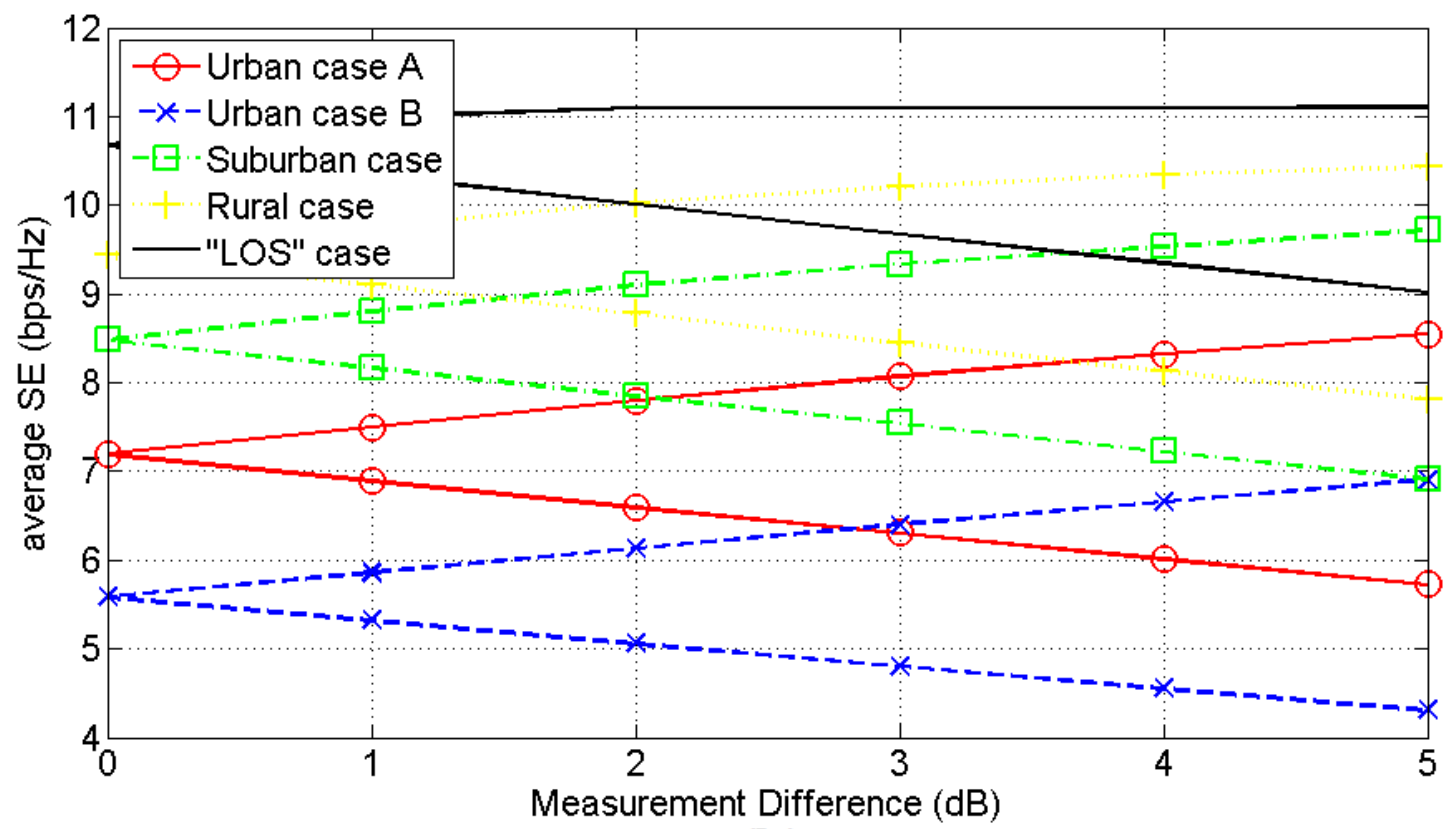

(b) 


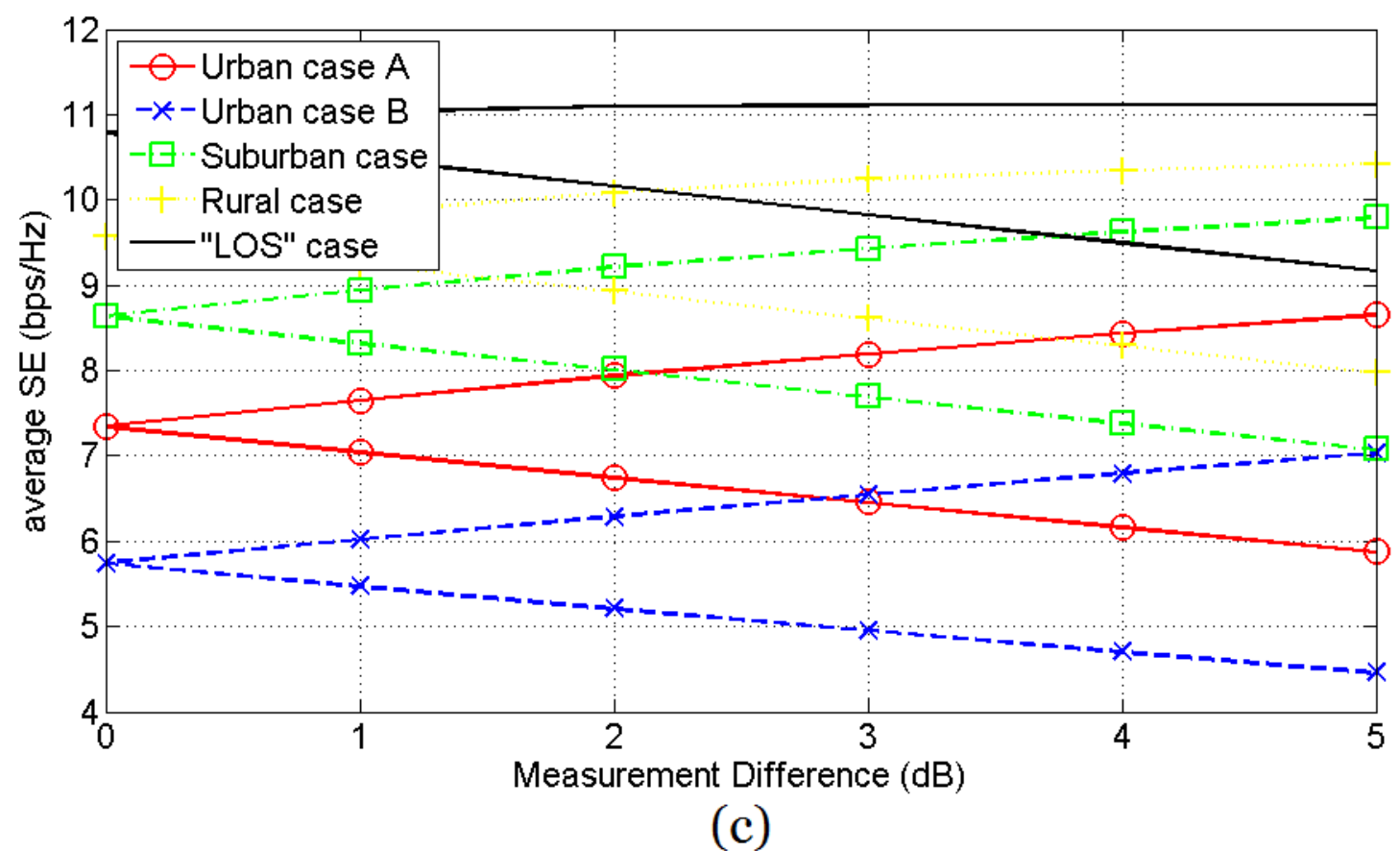

Fig. 8. Limits of the average SE range of the indicative OV MV BPL topologies in the 3-88 $\mathrm{MHz}$ frequency band when FCC limits are assumed and different coupling schemes are applied. (a) $\mathrm{WtG}^{1}$ coupling scheme. (b) $\mathrm{WtW}^{1-2}$ coupling scheme. (c) $\mathrm{MtM}_{0.8-0.1}^{1-2-3-0.1}$ coupling scheme. 


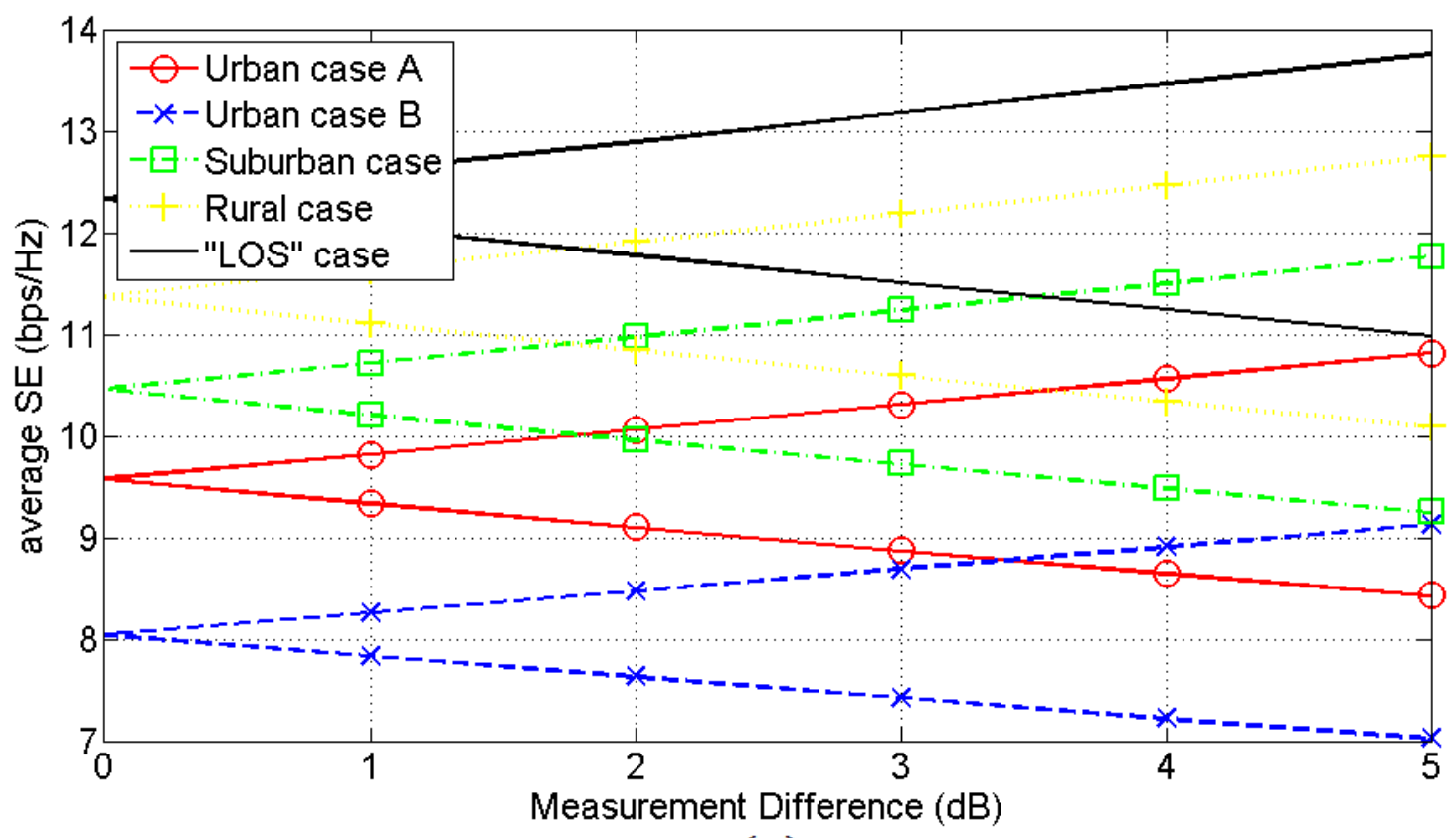

(a)

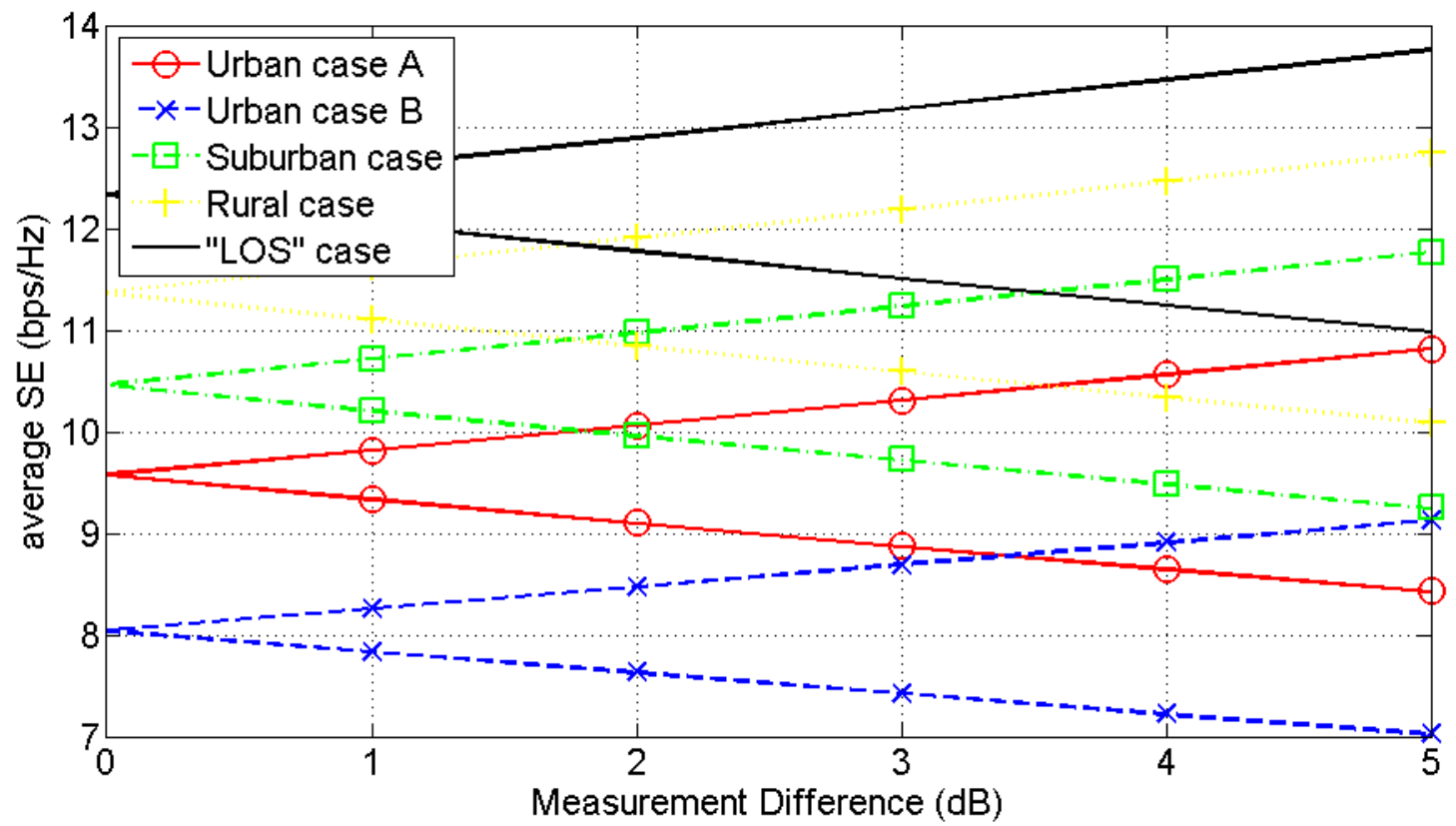

(b) 


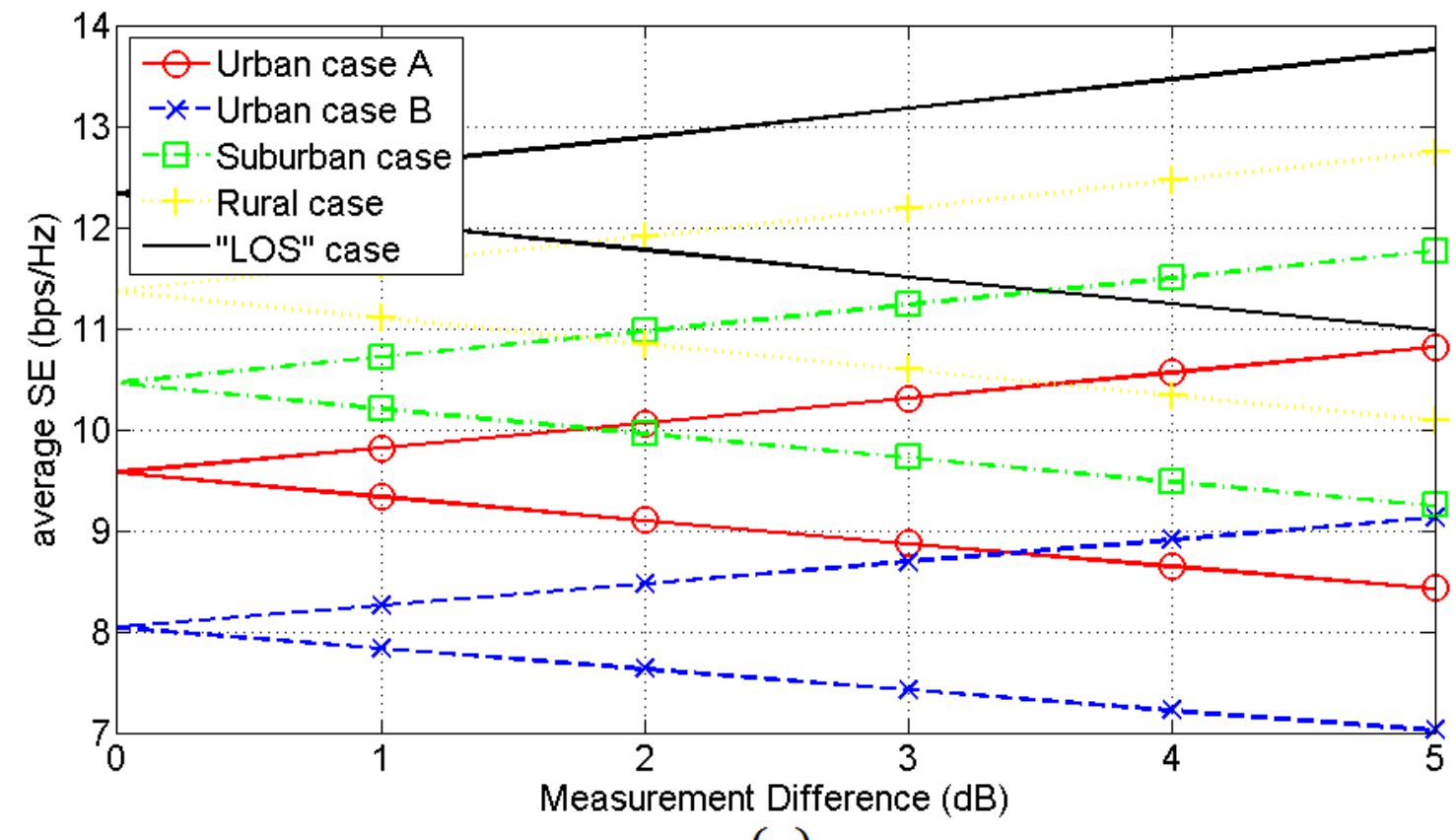

(c)

Fig. 9. Limits of the average SE range of the indicative UN MV BPL topologies in the 3-88 $\mathrm{MHz}$ frequency band when FCC limits are assumed and different coupling schemes are applied. (a) $\mathrm{StP}^{1}$ coupling scheme. (b) $\mathrm{PtP}^{1-2}$ coupling scheme. (c) $\mathrm{MtM}_{0.8-0.1-0.1}^{1-2-3}$ coupling scheme. 


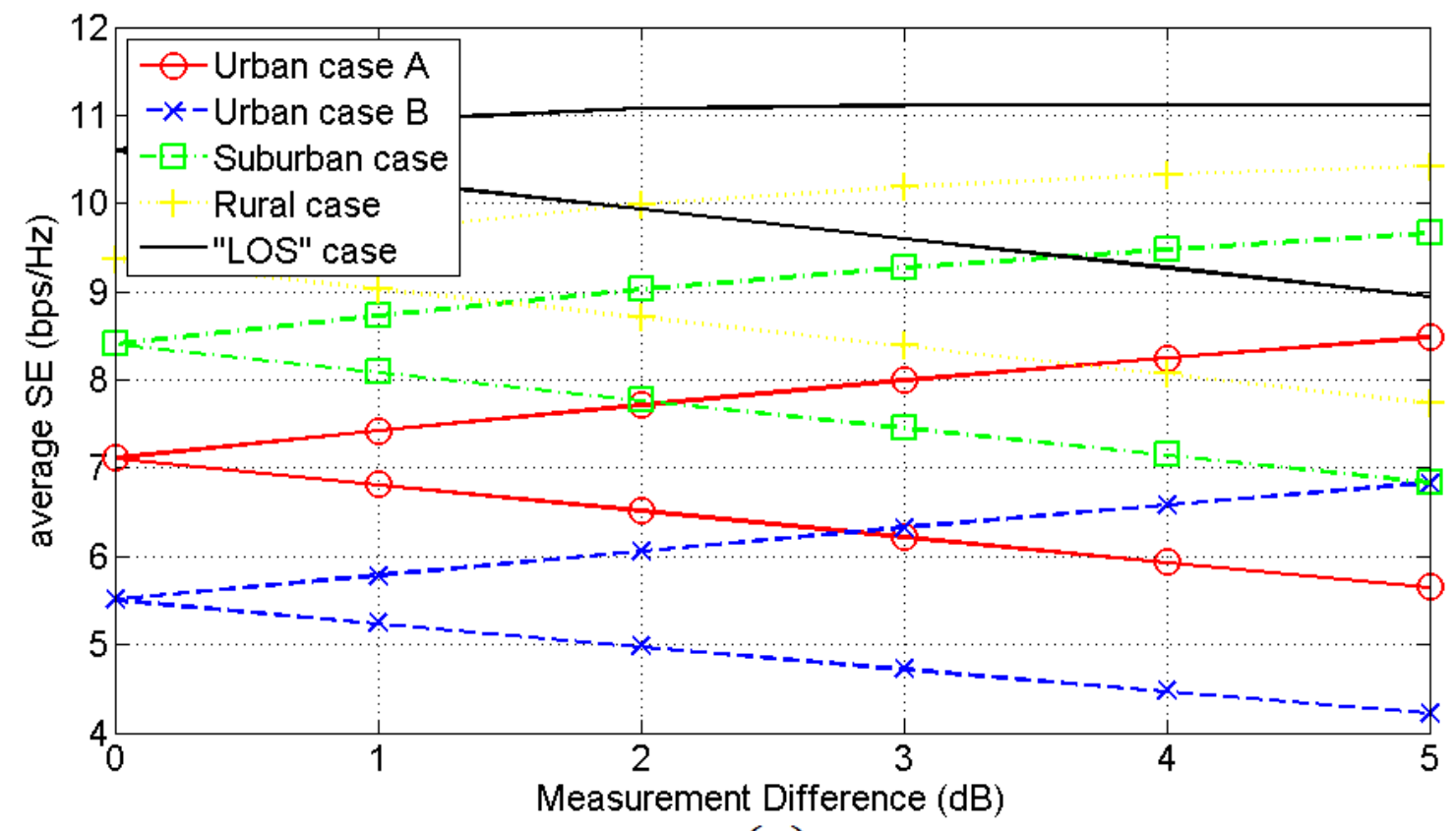

(a)

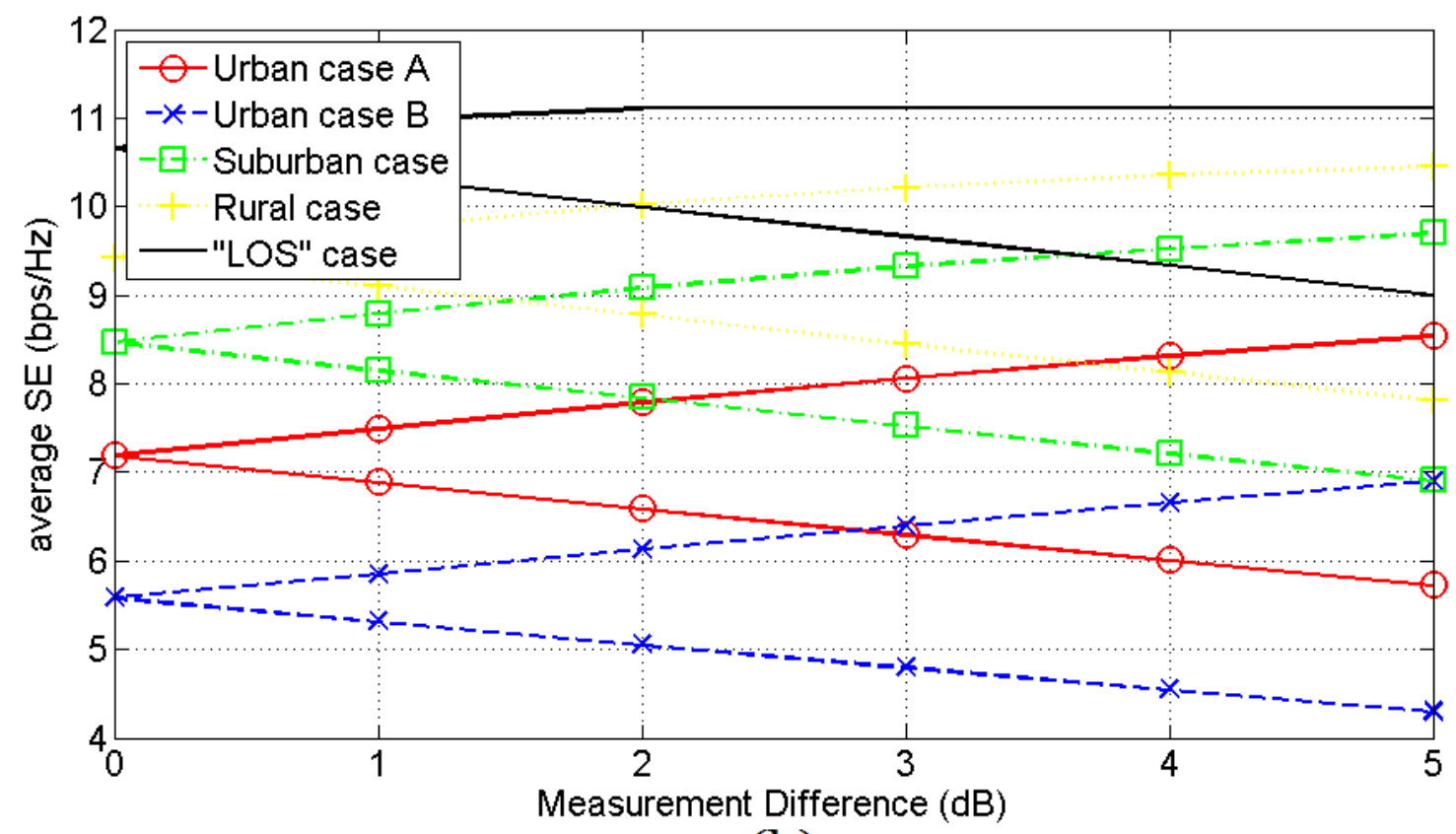

(b) 


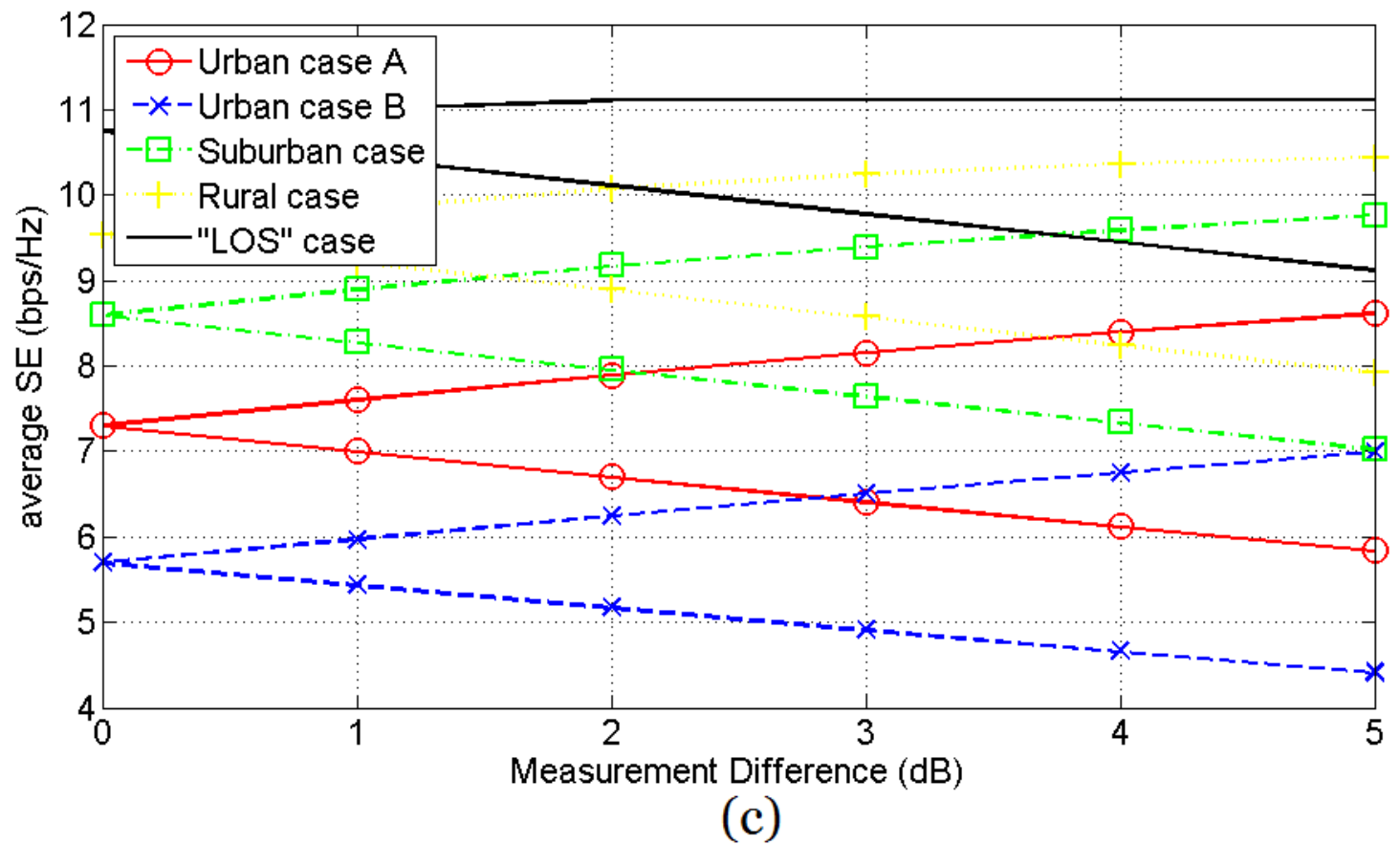

Fig. 10. Same with Fig. 8 but for the case of the indicative OV LV BPL topologies. 


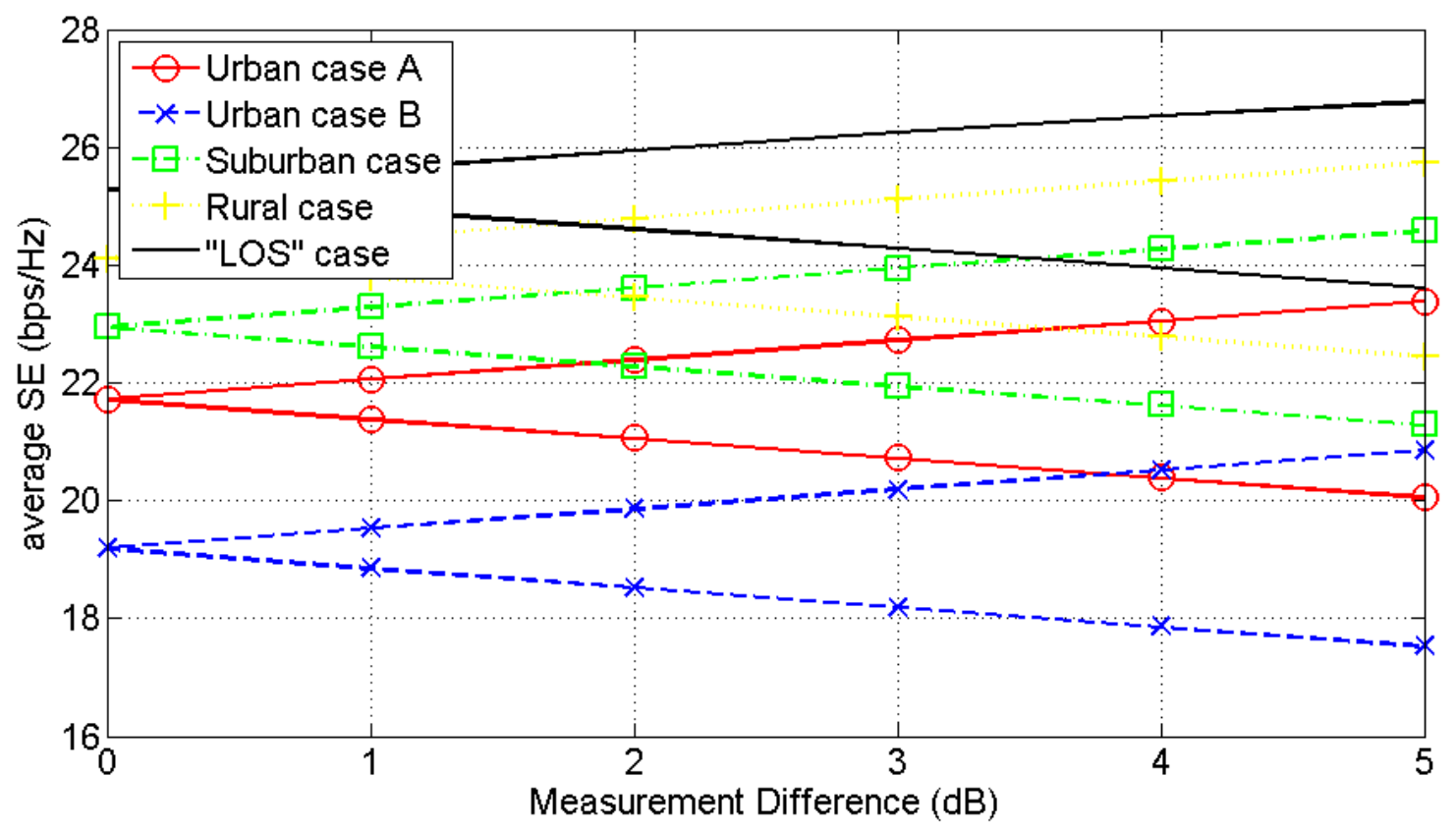

(a)

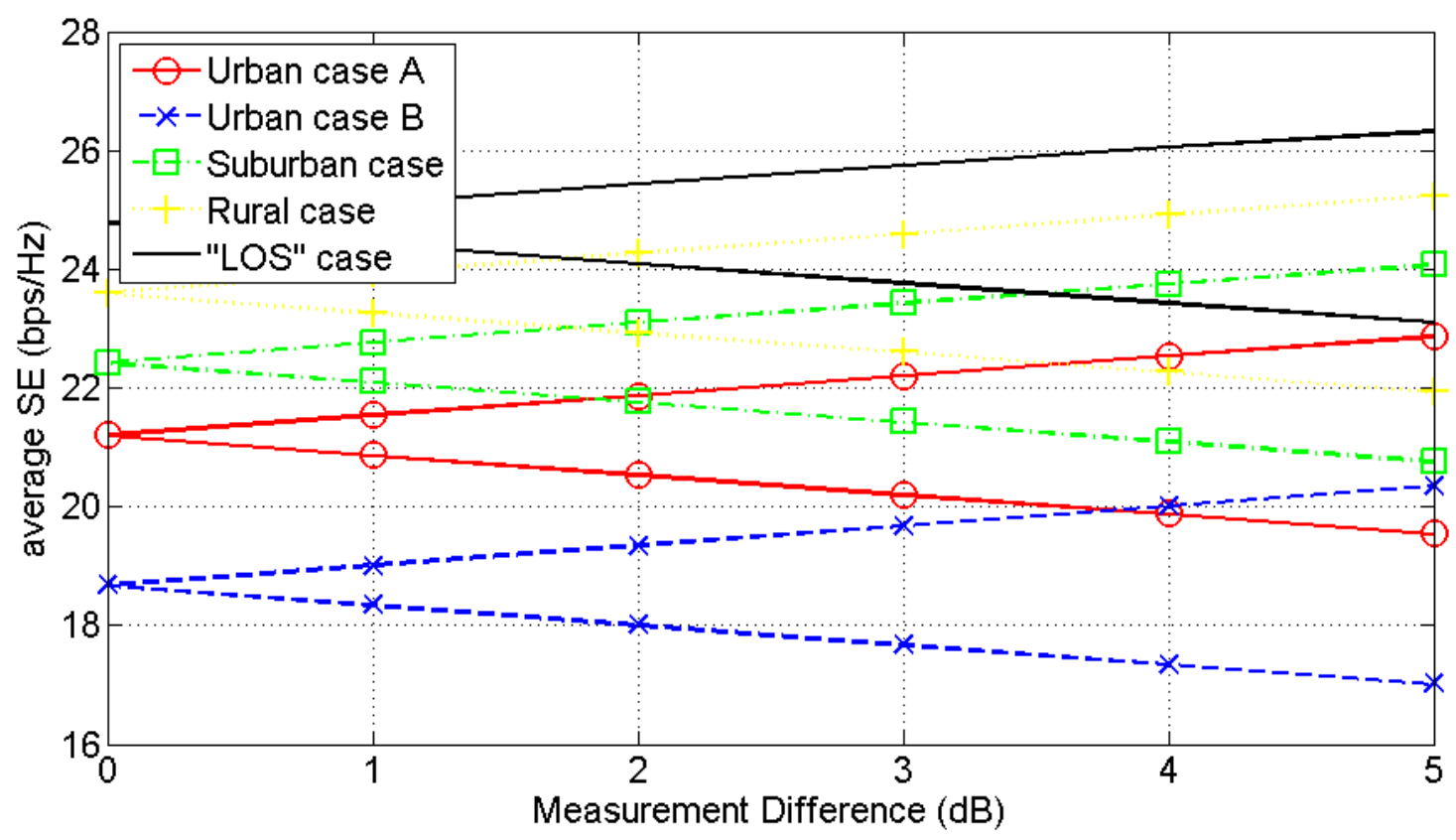

(b) 


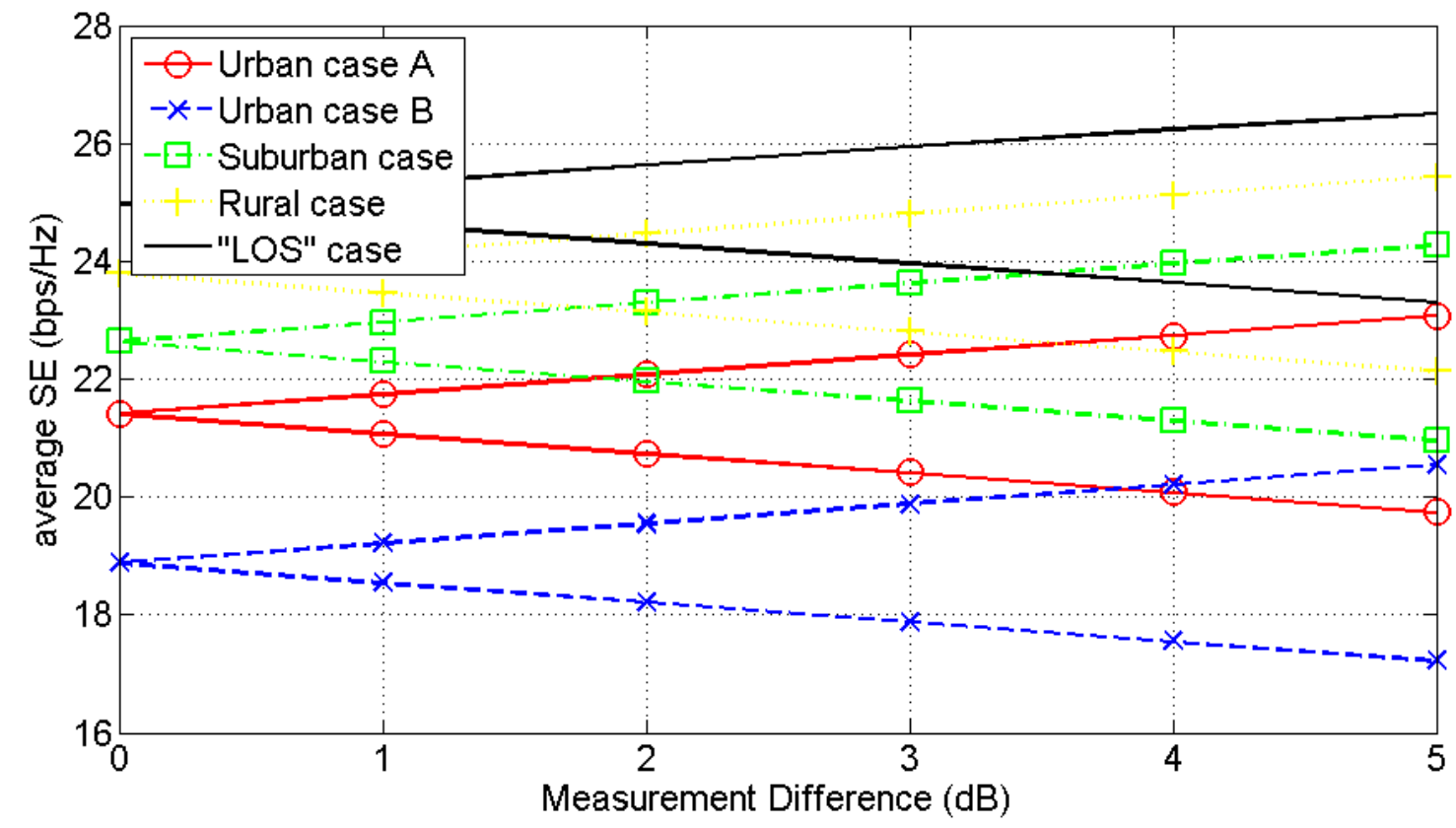

(c)

Fig. 11. Same with Fig. 9 but for the case of the indicative UN LV BPL topologies. 
Table 4. Average SE Range for Different a Values

(the frequency spacing is equal to $0.1 \mathrm{MHz}$ )

\begin{tabular}{|c|c|c|c|c|c|c|c|c|c|c|c|c|c|}
\hline \multirow[b]{3}{*}{$\begin{array}{c}\text { Distribution } \\
\text { power grid } \\
\text { type }\end{array}$} & \multirow[b]{3}{*}{$\begin{array}{l}\text { Topology } \\
\text { Name }\end{array}$} & \multicolumn{12}{|c|}{$\begin{array}{c}\text { Average SE Range } \\
(\mathrm{bps} / \mathrm{Hz})\end{array}$} \\
\hline & & \multicolumn{4}{|c|}{$\left(\mathrm{WtG}^{1} / \mathrm{StP}^{1}\right)$} & \multicolumn{4}{|c|}{$\left(\mathrm{WtW}^{1-2} / \mathrm{PtP}^{1-2}\right)$} & \multicolumn{4}{|c|}{$\mathrm{MtM}_{0.8-0.1-0.1}^{1-2-3}$} \\
\hline & & $\begin{array}{l}a_{\mathrm{CUD}} \\
=0 \mathrm{~dB}\end{array}$ & $\begin{array}{l}a_{\mathrm{CUD}} \\
=1 \mathrm{~dB}\end{array}$ & $\begin{array}{l}a_{\mathrm{CUD}} \\
=2 \mathrm{~dB}\end{array}$ & $\begin{array}{l}a_{\text {CUD }} \\
=5 \mathrm{~dB}\end{array}$ & $\begin{array}{l}a_{\text {CUD }} \\
=0 \mathrm{~dB}\end{array}$ & $\begin{array}{l}a_{\text {CUD }} \\
=1 \mathrm{~dB}\end{array}$ & $\begin{array}{l}a_{\text {CUD }} \\
=2 \mathrm{~dB}\end{array}$ & $\begin{array}{l}a_{\text {CUD }} \\
=5 \mathrm{~dB}\end{array}$ & $\begin{array}{l}a_{\mathrm{CUD}} \\
=0 \mathrm{~dB}\end{array}$ & $\begin{array}{l}a_{\mathrm{CUD}} \\
=1 \mathrm{~dB}\end{array}$ & $\begin{array}{l}a_{\text {CUD }} \\
=2 \mathrm{~dB}\end{array}$ & $\begin{array}{l}a_{\mathrm{CUD}} \\
=5 \mathrm{~dB}\end{array}$ \\
\hline \multirow{5}{*}{ OVMV } & $\begin{array}{l}\text { Urban } \\
\text { case A }\end{array}$ & 0.00 & 0.60 & 1.20 & 2.85 & 0.00 & 0.60 & 1.20 & 2.81 & 0.00 & 0.60 & 1.19 & 2.77 \\
\hline & $\begin{array}{l}\text { Urban } \\
\text { case B }\end{array}$ & 0.00 & 0.54 & 1.07 & 2.61 & 0.00 & 0.54 & 1.07 & 2.60 & 0.00 & 0.54 & 1.07 & 2.57 \\
\hline & $\begin{array}{c}\text { Suburban } \\
\text { case }\end{array}$ & 0.00 & 0.63 & 1.26 & 2.87 & 0.00 & 0.63 & 1.24 & 2.79 & 0.00 & 0.62 & 1.20 & 2.72 \\
\hline & $\begin{array}{c}\text { Rural } \\
\text { case }\end{array}$ & 0.00 & 0.66 & 1.29 & 2.77 & 0.00 & 0.65 & 1.25 & 2.61 & 0.00 & 0.60 & 1.15 & 2.44 \\
\hline & $\begin{array}{l}\text { "LOS" } \\
\text { case }\end{array}$ & 0.00 & 0.66 & 1.18 & 2.27 & 0.00 & 0.65 & 1.08 & 2.08 & 0.00 & 0.54 & 0.94 & 1.93 \\
\hline \multirow{5}{*}{ OVLV } & $\begin{array}{l}\text { Urban } \\
\text { case A }\end{array}$ & 0.00 & 0.60 & 1.20 & 2.83 & 0.00 & 0.60 & 1.20 & 2.81 & 0.00 & 0.60 & 1.19 & 2.77 \\
\hline & $\begin{array}{l}\text { Urban } \\
\text { case B }\end{array}$ & 0.00 & 0.54 & 1.07 & 2.60 & 0.00 & 0.54 & 1.07 & 2.59 & 0.00 & 0.54 & 1.07 & 2.58 \\
\hline & $\begin{array}{c}\text { Suburban } \\
\text { case }\end{array}$ & 0.00 & 0.63 & 1.25 & 2.82 & 0.00 & 0.63 & 1.24 & 2.79 & 0.00 & 0.62 & 1.21 & 2.74 \\
\hline & $\begin{array}{c}\text { Rural } \\
\text { case }\end{array}$ & 0.00 & 0.65 & 1.27 & 2.68 & 0.00 & 0.65 & 1.25 & 2.63 & 0.00 & 0.61 & 1.18 & 2.50 \\
\hline & $\begin{array}{l}\text { "LOS" } \\
\text { case }\end{array}$ & 0.00 & 0.66 & 1.14 & 2.16 & 0.00 & 0.64 & 1.10 & 2.09 & 0.00 & 0.56 & 0.98 & 1.98 \\
\hline \multirow{5}{*}{ UNMV } & $\begin{array}{l}\text { Urban } \\
\text { case A }\end{array}$ & 0.00 & 0.48 & 0.96 & 2.39 & 0.00 & 0.48 & 0.96 & 2.39 & 0.00 & 0.48 & 0.96 & 2.39 \\
\hline & $\begin{array}{l}\text { Urban } \\
\text { case B } \\
\end{array}$ & 0.00 & 0.42 & 0.84 & 2.10 & 0.00 & 0.42 & 0.84 & 2.10 & 0.00 & 0.42 & 0.84 & 2.10 \\
\hline & $\begin{array}{c}\text { Suburban } \\
\text { case }\end{array}$ & 0.00 & 0.50 & 1.01 & 2.52 & 0.00 & 0.50 & 1.01 & 2.52 & 0.00 & 0.50 & 1.01 & 2.52 \\
\hline & $\begin{array}{c}\text { Rural } \\
\text { case }\end{array}$ & 0.00 & 0.53 & 1.06 & 2.65 & 0.00 & 0.53 & 1.06 & 2.65 & 0.00 & 0.53 & 1.06 & 2.65 \\
\hline & $\begin{array}{l}\text { "LOS" } \\
\text { case }\end{array}$ & 0.00 & 0.56 & 1.11 & 2.77 & 0.00 & 0.56 & 1.11 & 2.77 & 0.00 & 0.56 & 1.11 & 2.77 \\
\hline \multirow{5}{*}{ UNLV } & $\begin{array}{l}\text { Urban } \\
\text { case A }\end{array}$ & 0.00 & 0.66 & 1.33 & 3.32 & 0.00 & 0.66 & 1.33 & 3.32 & 0.00 & 0.66 & 1.33 & 3.32 \\
\hline & $\begin{array}{c}\text { Urban } \\
\text { case B }\end{array}$ & 0.00 & 0.66 & 1.33 & 3.32 & 0.00 & 0.66 & 1.33 & 3.32 & 0.00 & 0.66 & 1.33 & 3.32 \\
\hline & $\begin{array}{c}\text { Suburban } \\
\text { case }\end{array}$ & 0.00 & 0.66 & 1.33 & 3.29 & 0.00 & 0.66 & 1.33 & 3.31 & 0.00 & 0.66 & 1.33 & 3.30 \\
\hline & $\begin{array}{c}\text { Rural } \\
\text { case }\end{array}$ & 0.00 & 0.66 & 1.33 & 3.27 & 0.00 & 0.66 & 1.33 & 3.29 & 0.00 & 0.66 & 1.33 & 3.29 \\
\hline & $\begin{array}{l}\text { "LOS" } \\
\text { case }\end{array}$ & 0.00 & 0.66 & 1.32 & 3.15 & 0.00 & 0.66 & 1.33 & 3.22 & 0.00 & 0.66 & 1.33 & 3.19 \\
\hline
\end{tabular}

From Figs. 8-11, it is clear that the measurement differences significantly influence the computation accuracy of the average SE of the examined indicative distribution BPL topologies. As the measurement uncertainty increases so does the limits 
as well as the average SE range for given BPL topology and coupling scheme type. In accordance with the figures and the Table 4, each $\mathrm{dB}$ increase of the measurement difference uncertainty creates an average uncertainty of $0.60 \mathrm{bps} / \mathrm{Hz}$ in the computed average SE. Also, the average SE range cumulatively increases with the measurement uncertainty. Graphically, this almost stable cumulative relation between the average SE range and $a$ values of the measurement differences explains the linear representation of the upper and lower limits of the average SE range in Figs. 8-11 for given distribution BPL topology and coupling scheme type. Here, it should be noted that some deviations from the linear consideration, such as the "LOS" cases of Figs. 8(a)-(c) and 10(a)-(c), are due to the minimum channel attenuation restriction of $0 \mathrm{~dB}$. In addition, it should be pointed out that the SE impact of measurement differences remains almost the same regardless of the considered coupling scheme of the CS2 module.

\subsection{SE with CUD Measurement Differences}

As already been mentioned in [25], [26], [28], [31], measurement differences can comfortably be handled as error distributions such as CUDs. However, the handling of measurement differences through CUDs rather than the biased values of the previous subsection becomes a challenging issue due to the behavior of the traditional statistical metrics of maximum, minimum and average SE.

In order to examine the impact of real measurement differences CUDs on the SE as well as the measurement differences countermeasures of [55], five representative CUD measurement differences, which are denoted as CUD1-5, with respective $a_{\mathrm{CUD}}$ ranging from $1 \mathrm{~dB}$ to $5 \mathrm{~dB}$ are assumed. In Figs. 12(a)-(c), the metrics of set A, say, maximum, minimum and average SE of the indicative OV MV BPL topologies are plotted versus the value $a_{\text {CUD }}$ when $\mathrm{WtG}^{1}, \mathrm{WtW}^{1-2}$ and $\mathrm{MtM}_{0.8_{-}-0.1-0.1}^{1-2-1}$ coupling scheme is applied, respectively. Note that each $a_{\text {CUD }}$ corresponds to the respective CUD measurement difference whereas at zero the results refer to the SE case without measurement differences. In Figs. 13(a)-(c), maximum, minimum and average SE of the indicative UN MV BPL topologies are plotted versus the value $a_{\mathrm{CUD}}$ when $\mathrm{StP}^{1}, \mathrm{PtP}^{1-2}$ and $\mathrm{MtM}_{0.8_{-}-0.1_{-}-0.1}^{1-2-3}$ coupling scheme is applied, respectively. In Figs. 14(a)-(c), same plots with Figs. 12(a)-(c) are given but for the case of the indicative OV LV BPL topologies while in Figs. 15(a)-(c), same curves with Figs. 13(a)-(c) are presented but for the case of the indicative UN LV BPL topologies. 


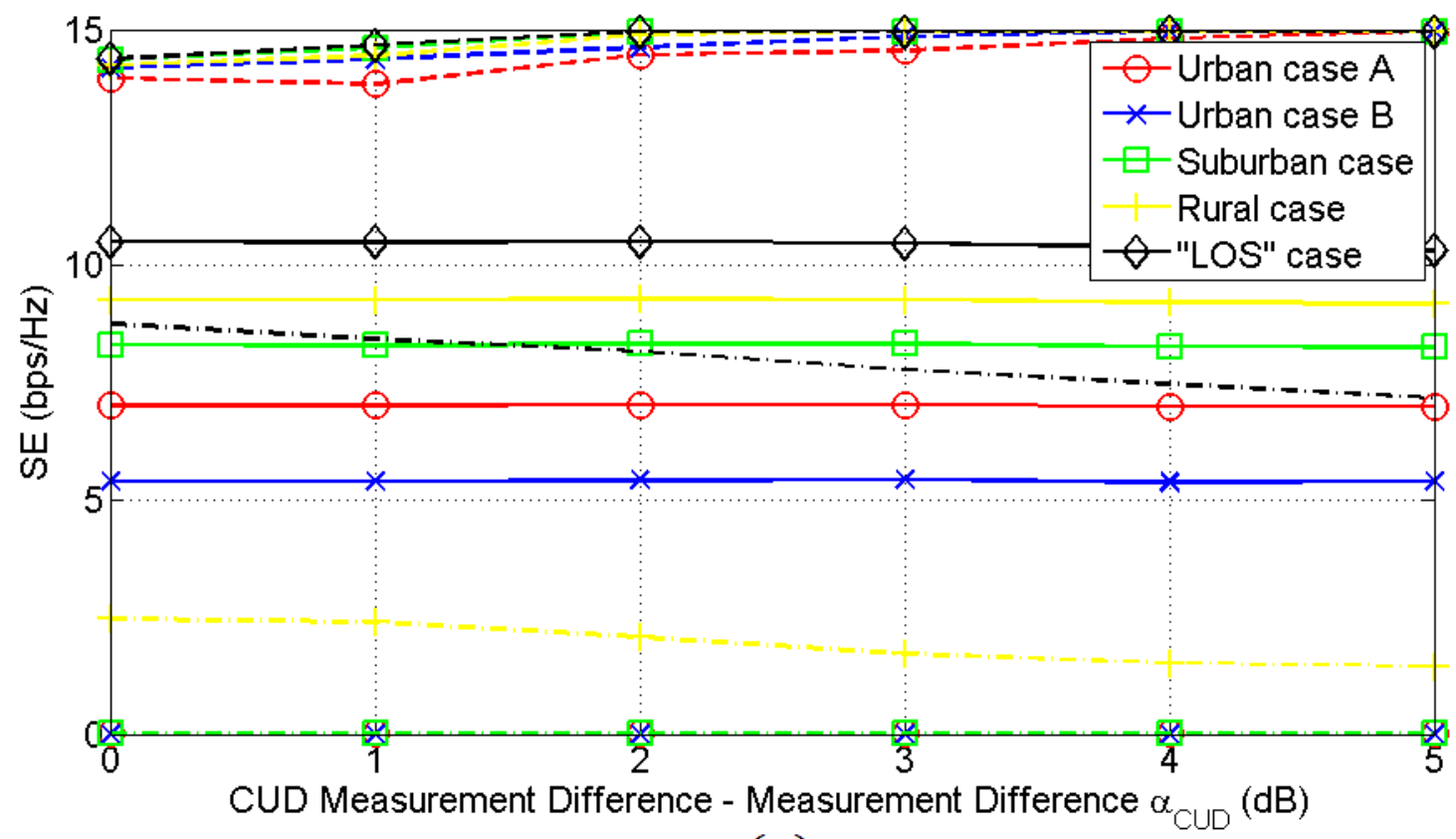

(a)

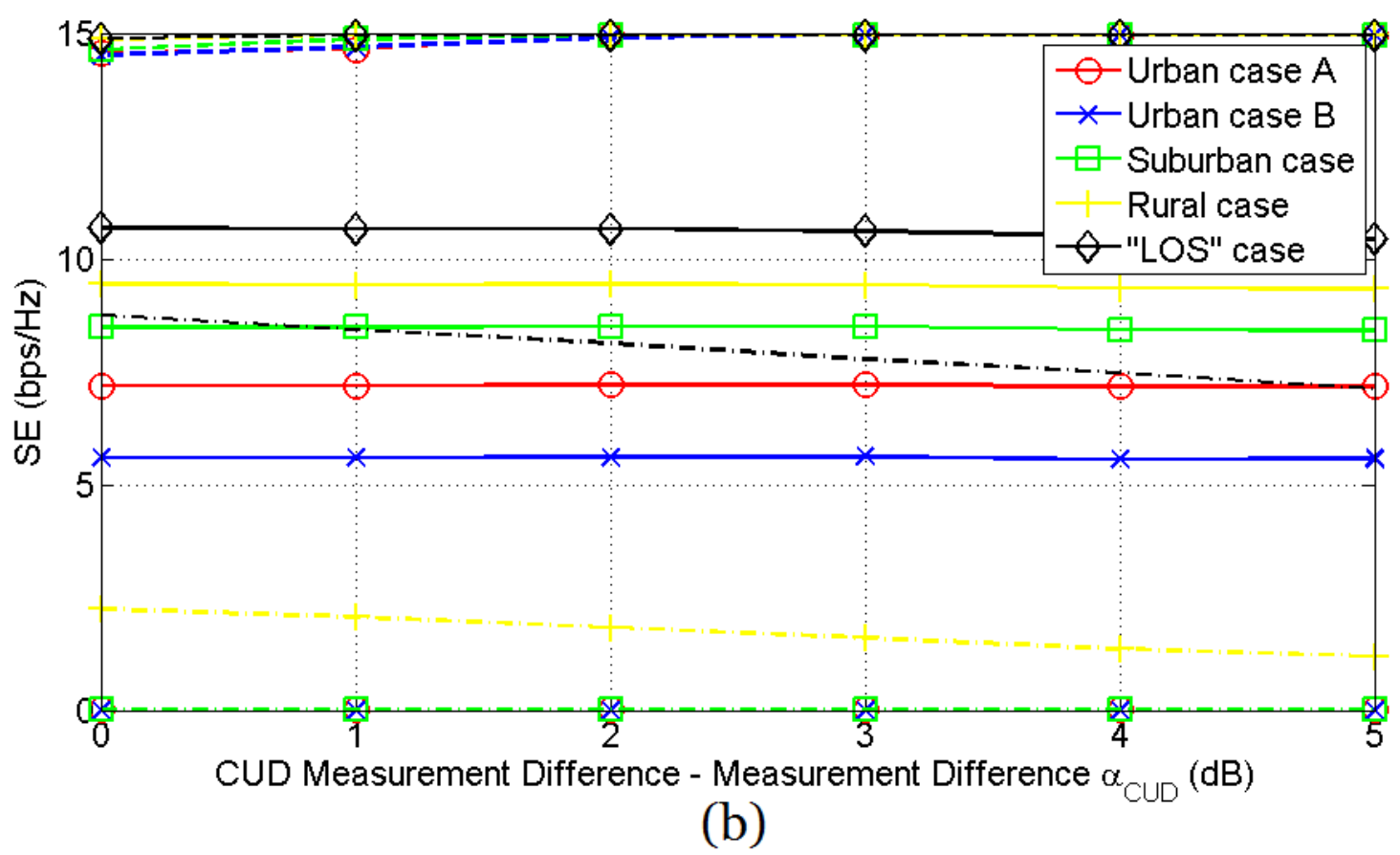




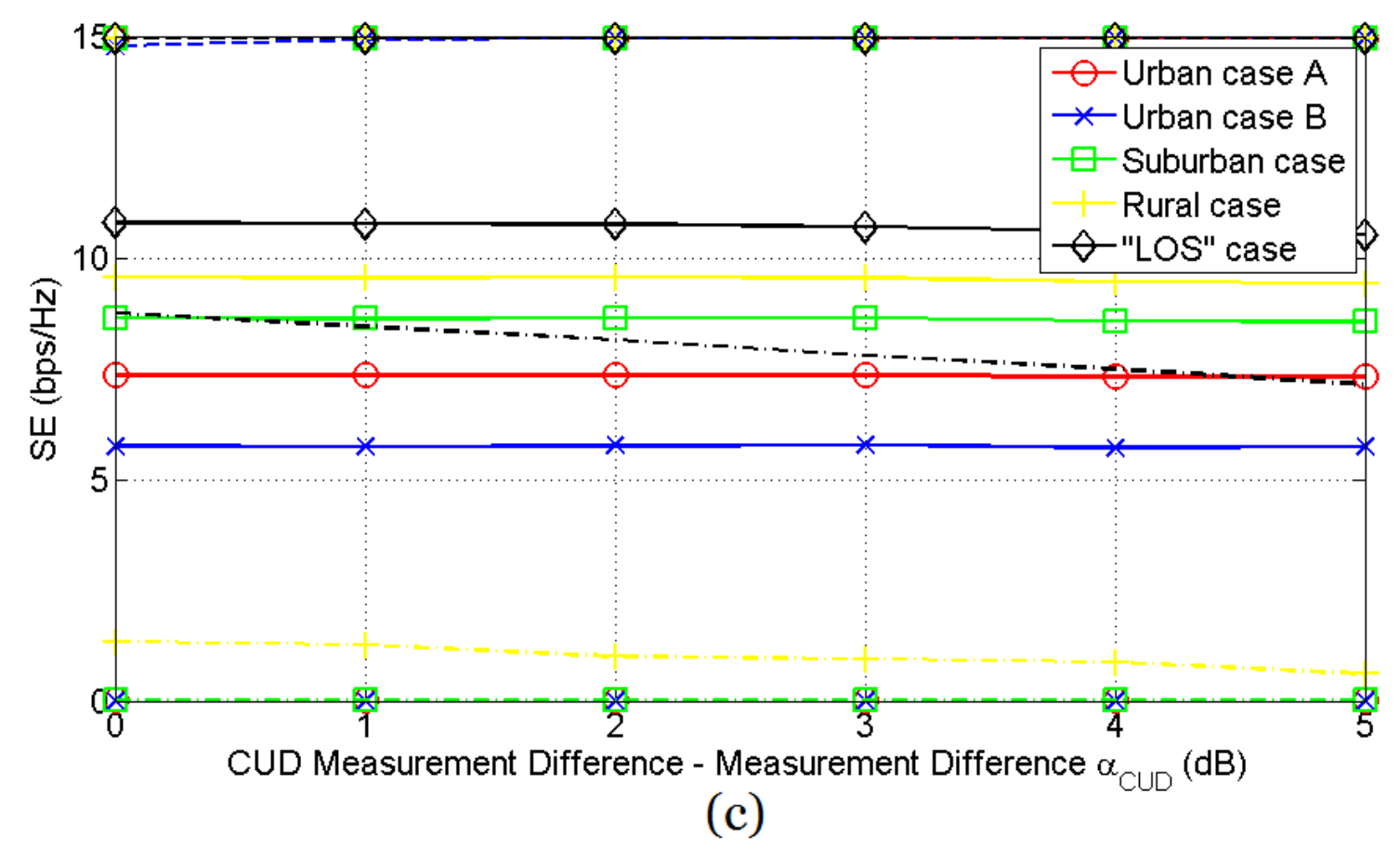

Fig. 12. Maximum, minimum and average SE of the indicative OV MV BPL topologies in the 3-88 MHz frequency band when FCC limits are assumed and different coupling schemes are applied for different CUD measurement differences. (a) $\mathrm{WtG}^{1}$ coupling scheme. (b) $\mathrm{WtW}^{1-2}$ coupling scheme. (c) $\mathrm{MtM}_{0.8-0.1-0.1}^{1-2-3}$ coupling scheme. 


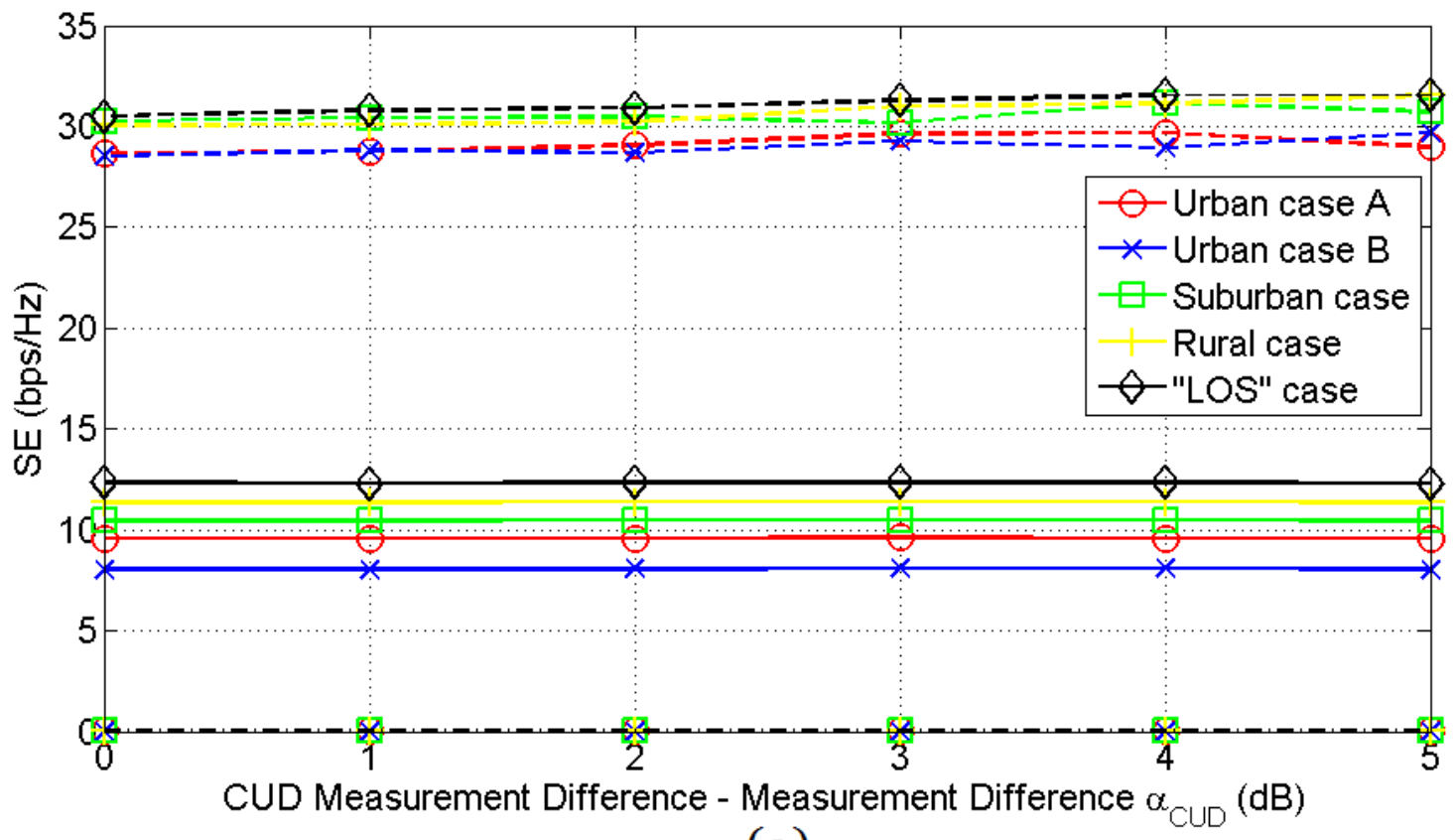

(a)

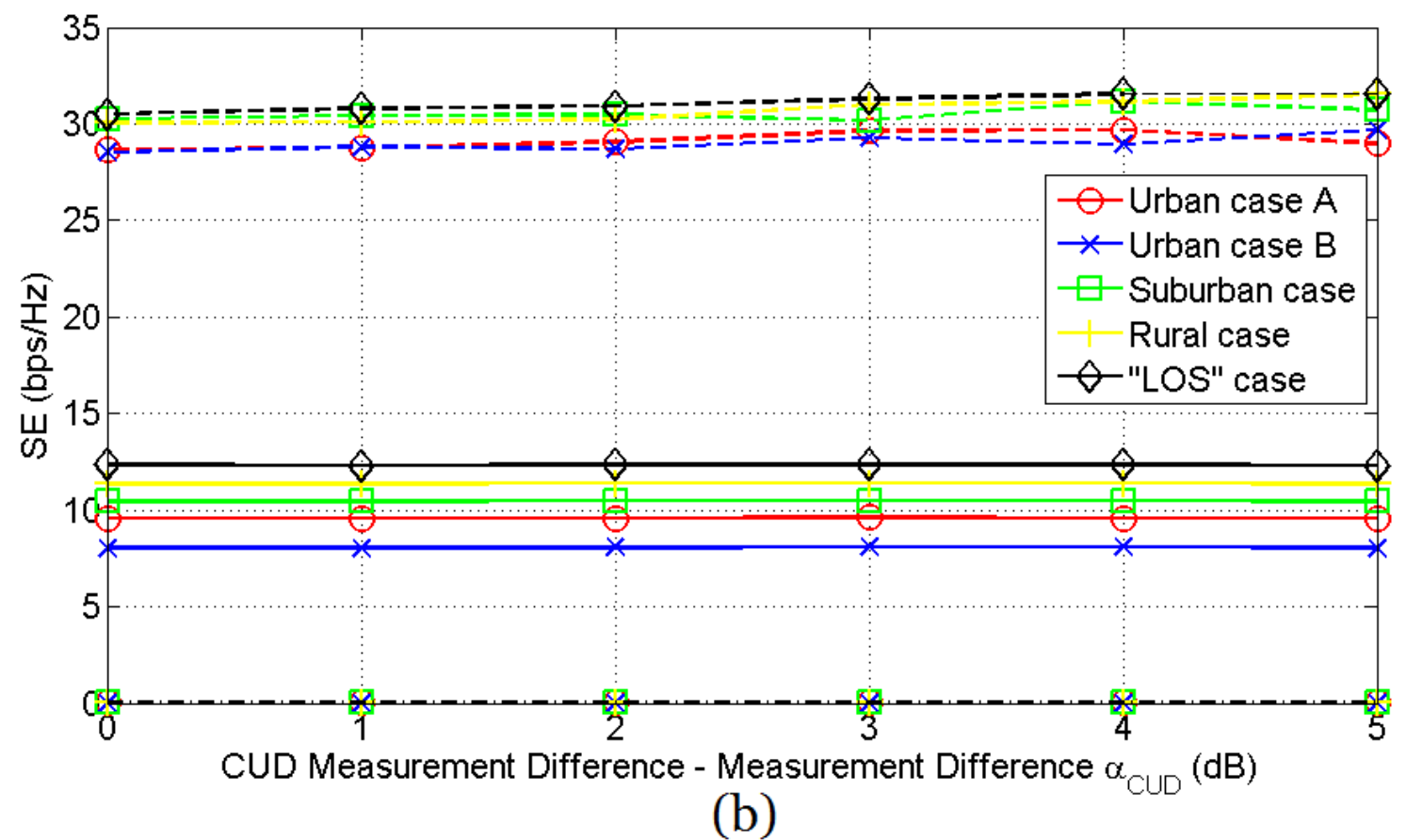




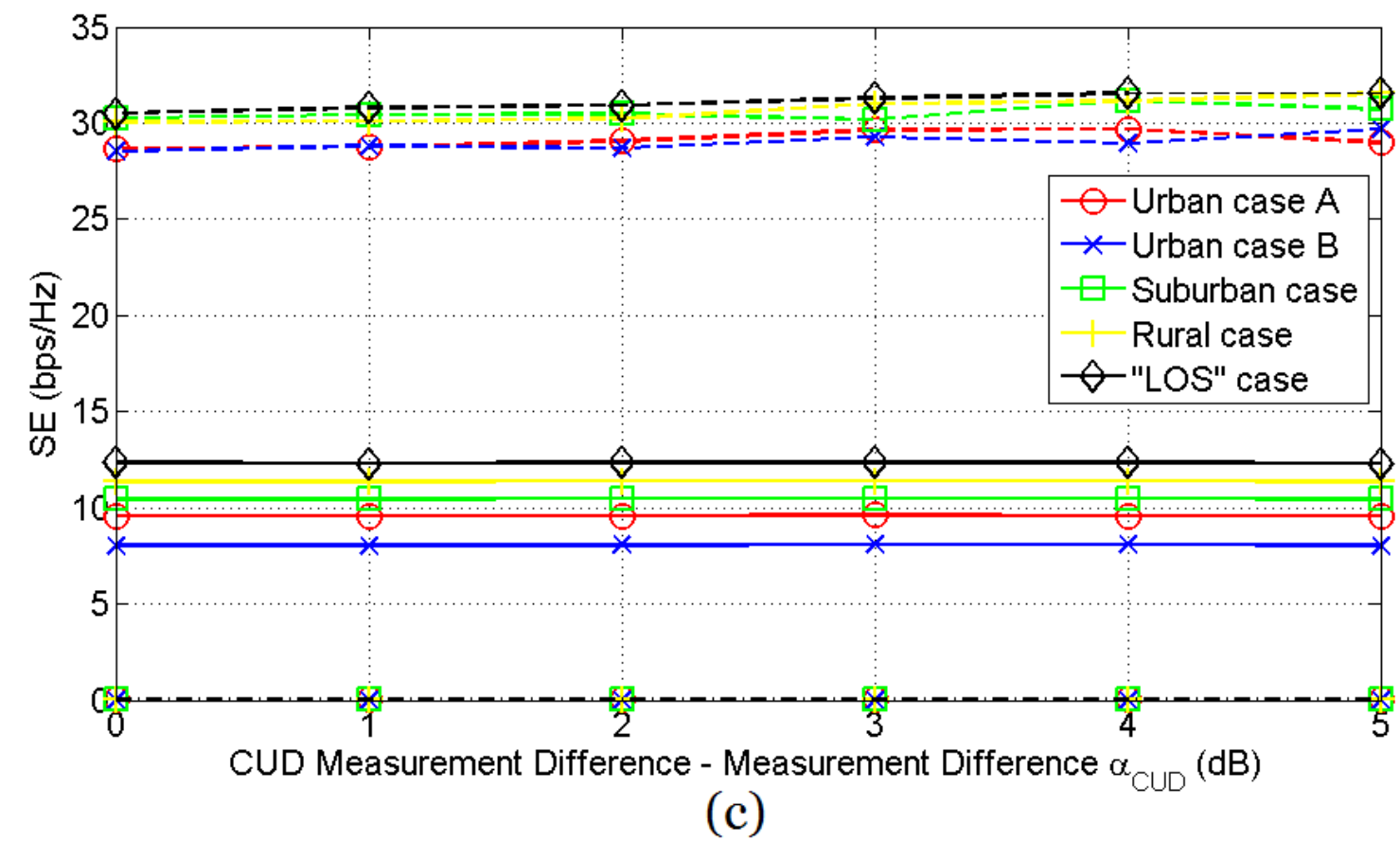

Fig. 13. Maximum, minimum and average SE of the indicative UN MV BPL topologies in the 3-88 MHz frequency band when FCC limits are assumed and different coupling schemes are applied for different CUD measurement differences. (a) $\mathrm{StP}^{1}$ coupling scheme. (b) $\mathrm{PtP}^{1-2}$ coupling scheme. (c) $\mathrm{MtM}_{0.8}^{1-2-3}-0.1_{-}^{-0.1}$ coupling scheme. 


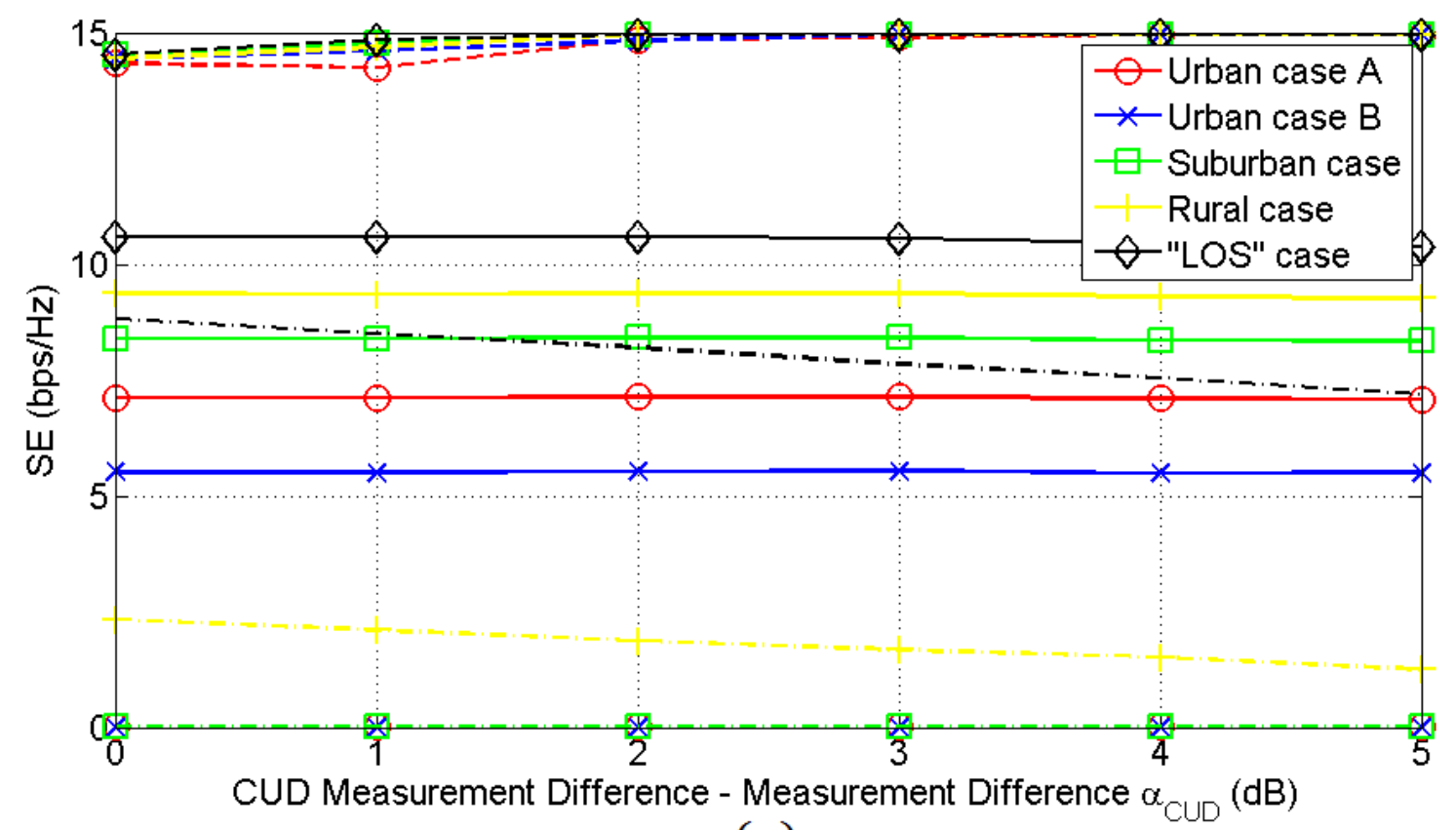

(a)

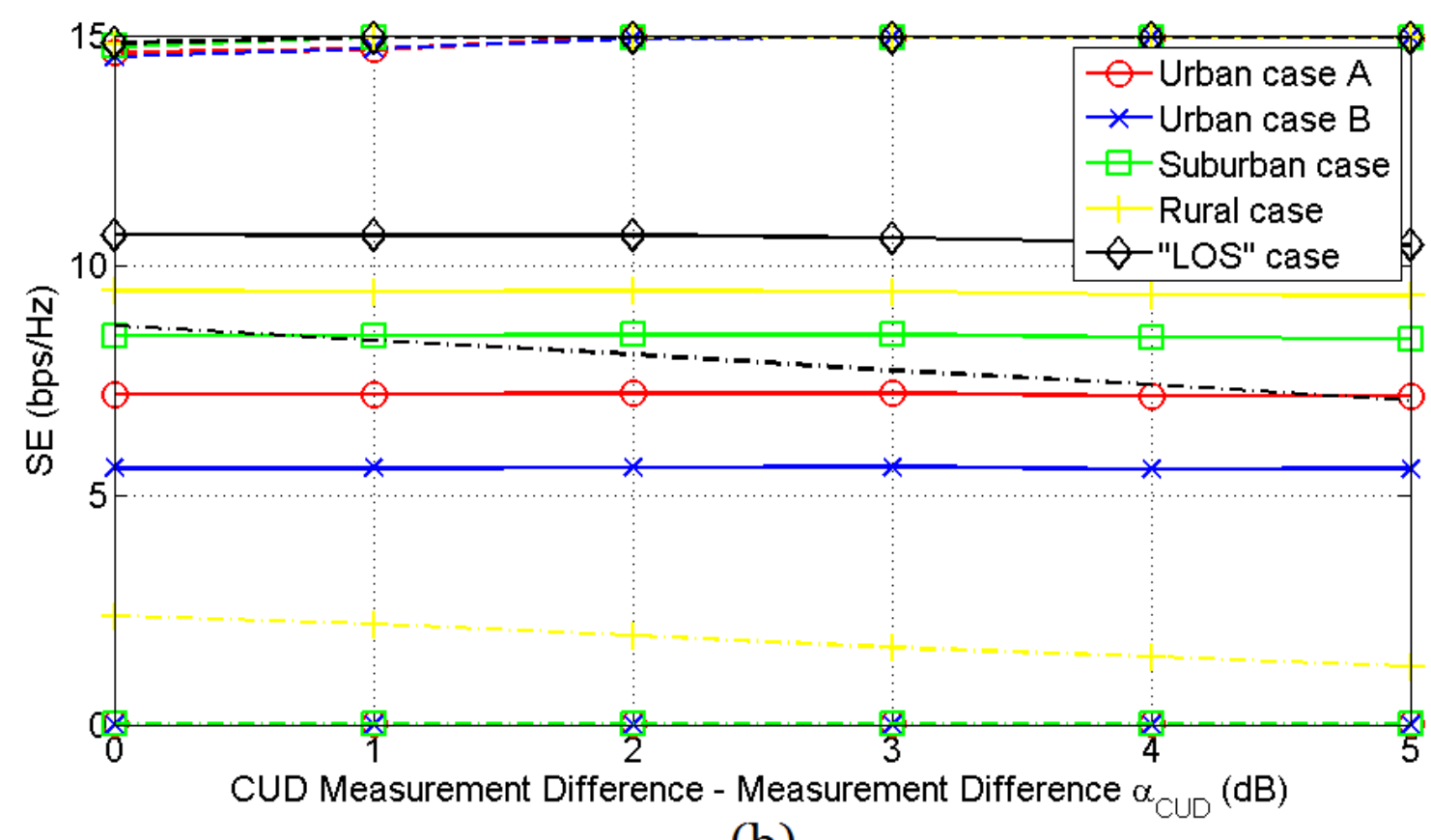

(b) 


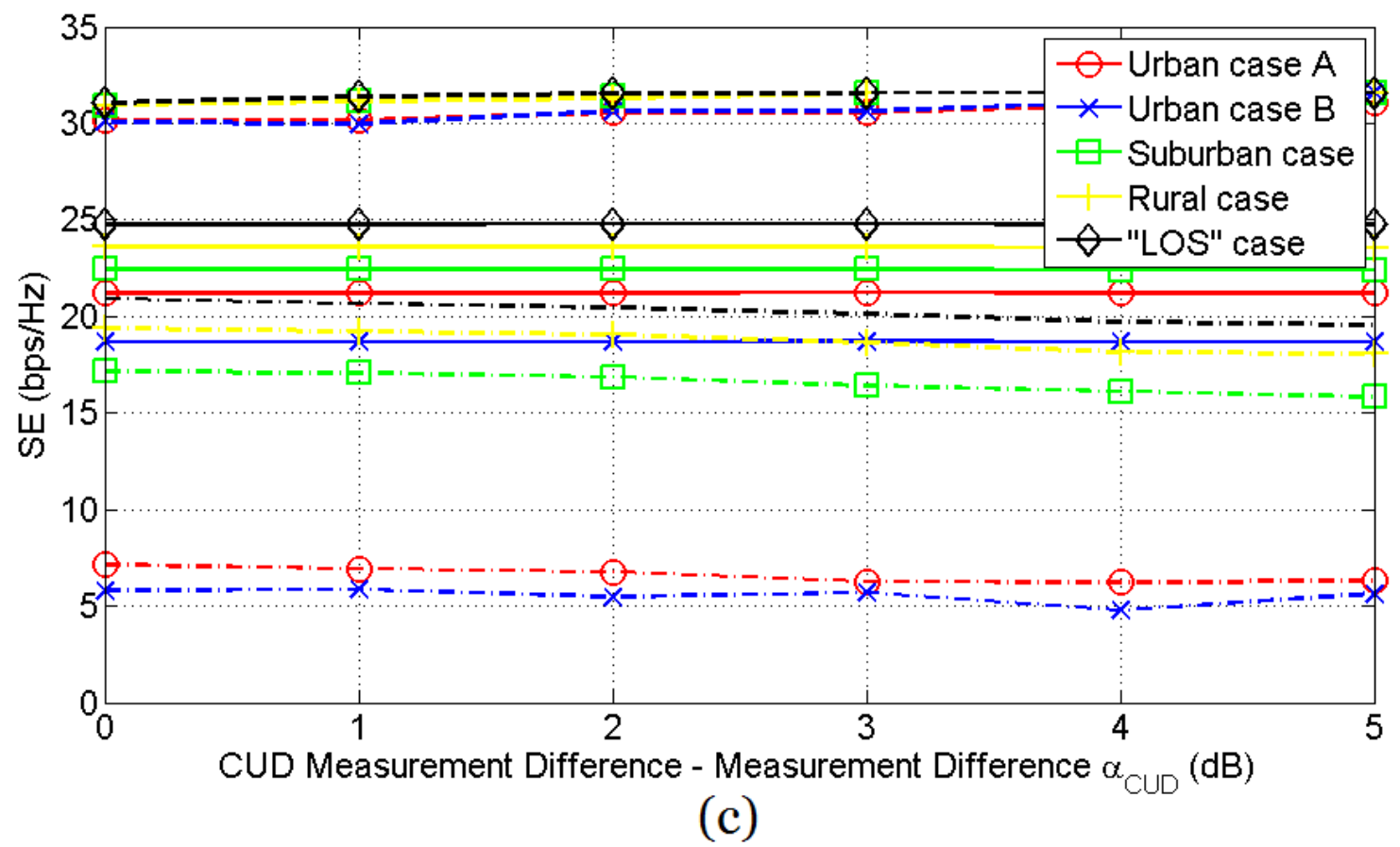

Fig. 14. Same with Fig. 12 but for the case of the indicative OV LV BPL topologies. 


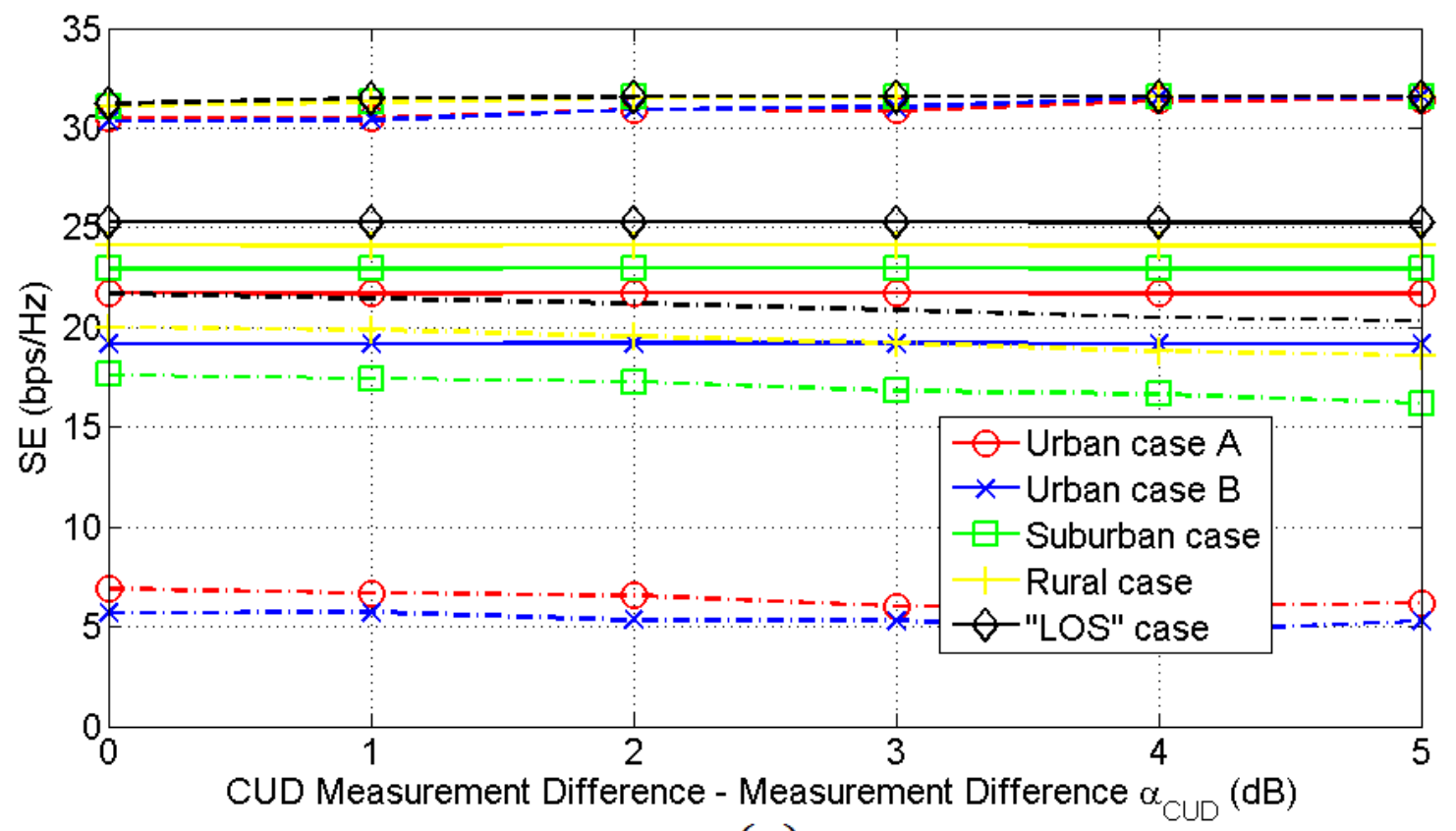

(a)

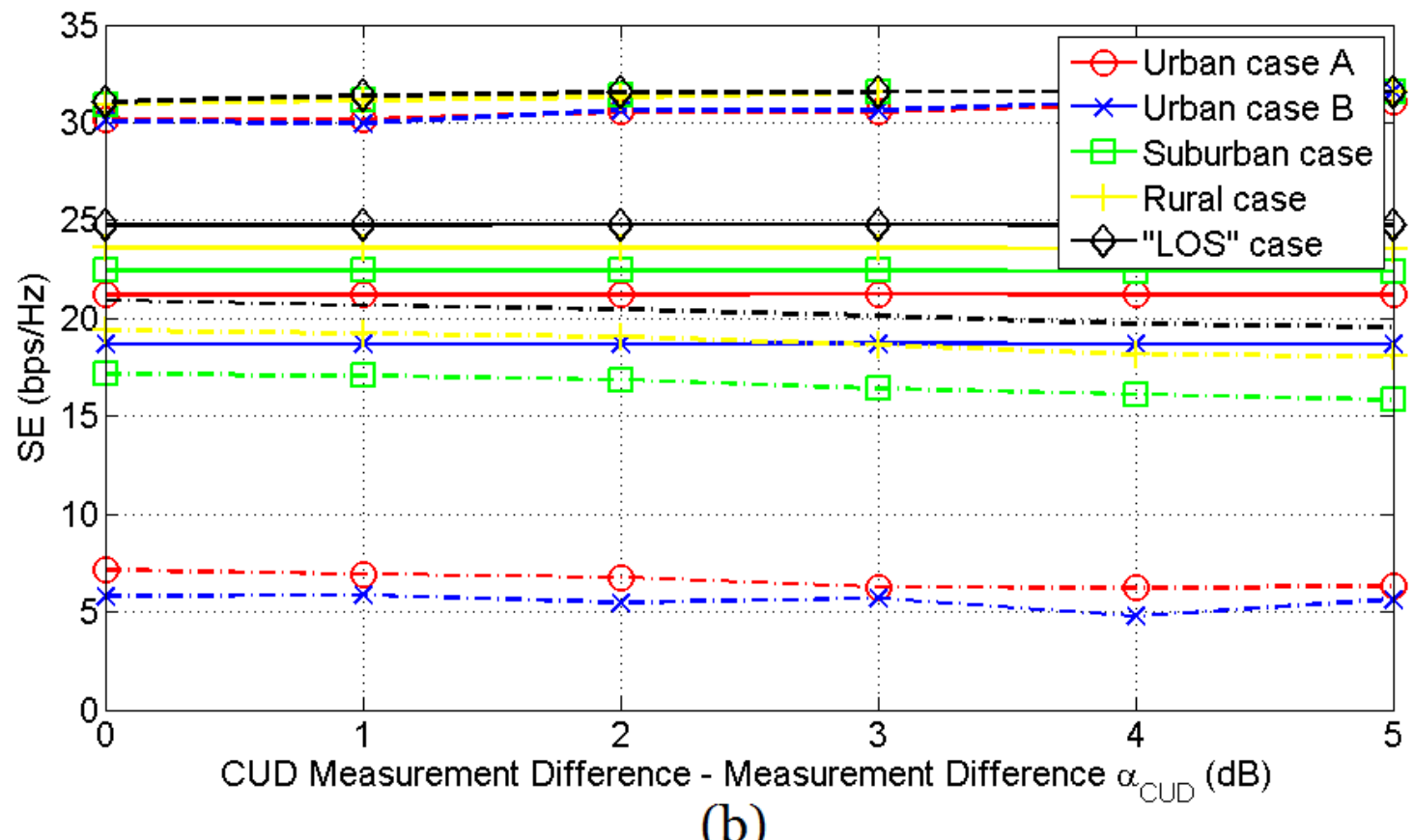

(b) 


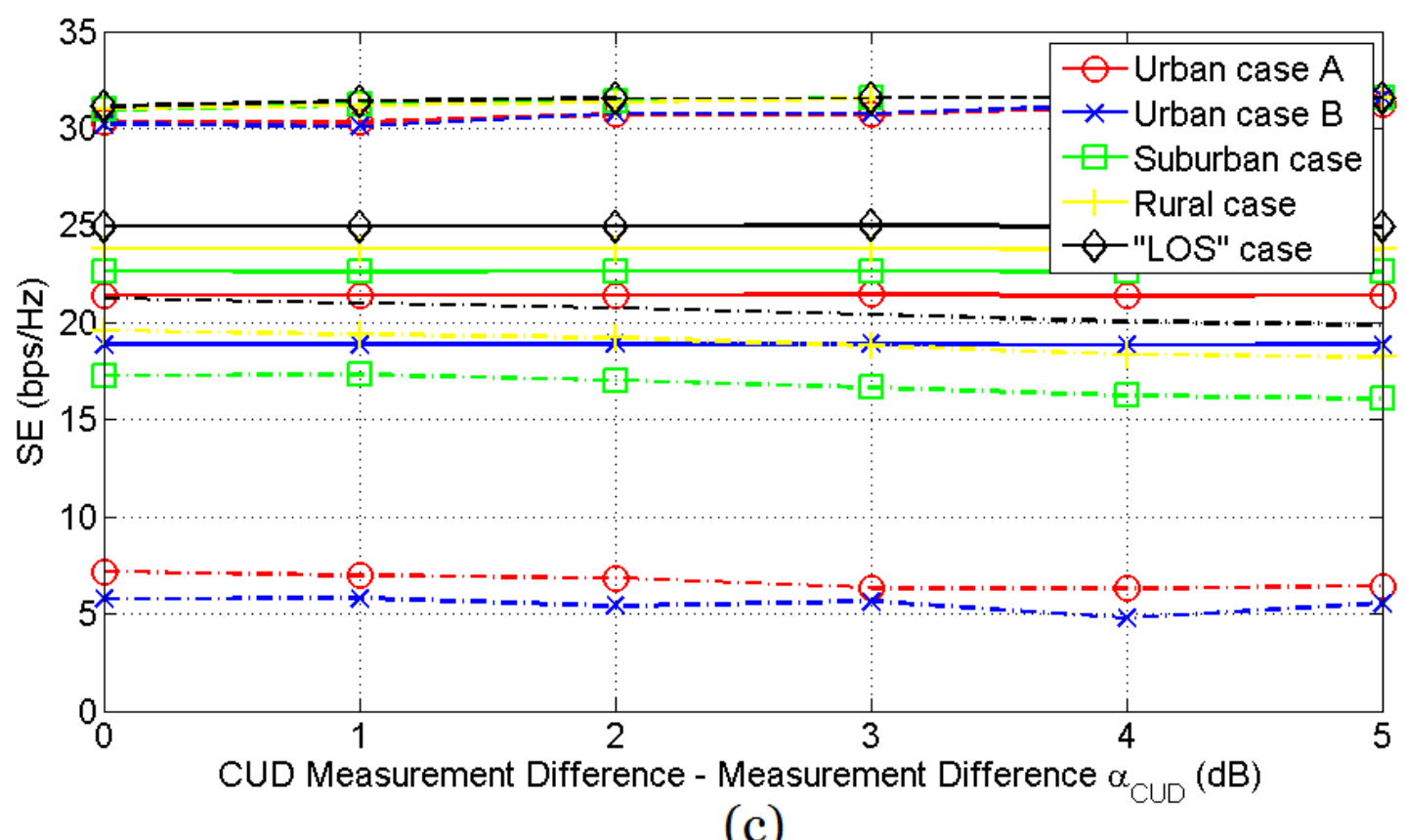

Fig. 15. Same with Fig. 13 but for the case of the indicative UN LV BPL topologies.

By observing Figs. 12-15, measurement differences slightly affect the maximum, minimum and average SE for given distribution BPL topology and coupling scheme type regardless of their maximum value $a_{\text {CUD }}$. This is a rational result since CUDs are adopted in order to describe the distribution of measurement differences. Although small differences of the average SE can be observed, these differences are not efficient to give an accurate estimation of the intensity of the occurred measurement differences in comparison with the respective results of biased measurement differences. Anyway, small average SE differences can be observed for the same maximum value $a_{\text {CUD }}$ if the different CUD is considered. However, after the application of countermeasures against the measurement differences, it is expected that the set A metrics after the measurement difference mitigation techniques should present values closer to the theoretical ones than set A metrics of the measured SE now do. This hypothesis is examined in [55].

The need for assessing the intensity of the measurement differences urges the application of statistical metrics that depend on the value $a_{\mathrm{CUD}}$ of the CUD measurement differences. In accordance with [25]-[29], two statistical metrics, i.e., mean absolute error (MAE) and root mean square deviation (RMSD), can easily assess the impact of measurement differences while their behavior depends on the value $a_{\text {CUD }}$ of the CUD measurement differences. Set B consists of these two metrics.

In Figs. 16(a)-(c), the MAE of the average SE of the indicative OV MV BPL topologies are plotted versus the value $a_{\mathrm{CUD}}$ when $\mathrm{WtG}^{1}, \mathrm{WtW}^{1-2}$ and $\mathrm{MtM}_{0.8}^{1-2-3}-0.1_{-}-0.1$ coupling scheme is applied, respectively. Note again that each $a_{\text {CUD }}$ corresponds to the respective CUD measurement difference whereas at zero the results refer to the SE case without measurement differences. In Figs. 17(a)-(c), the MAE of the average SE of the indicative UN MV BPL topologies are plotted versus the value $a_{\mathrm{CUD}}$ when $\mathrm{StP}^{1}, \mathrm{PtP}^{1-2}$ and $\mathrm{MtM}_{0.8-0.1_{-}-0.1}^{1-2-3}$ coupling scheme is applied, respectively. 


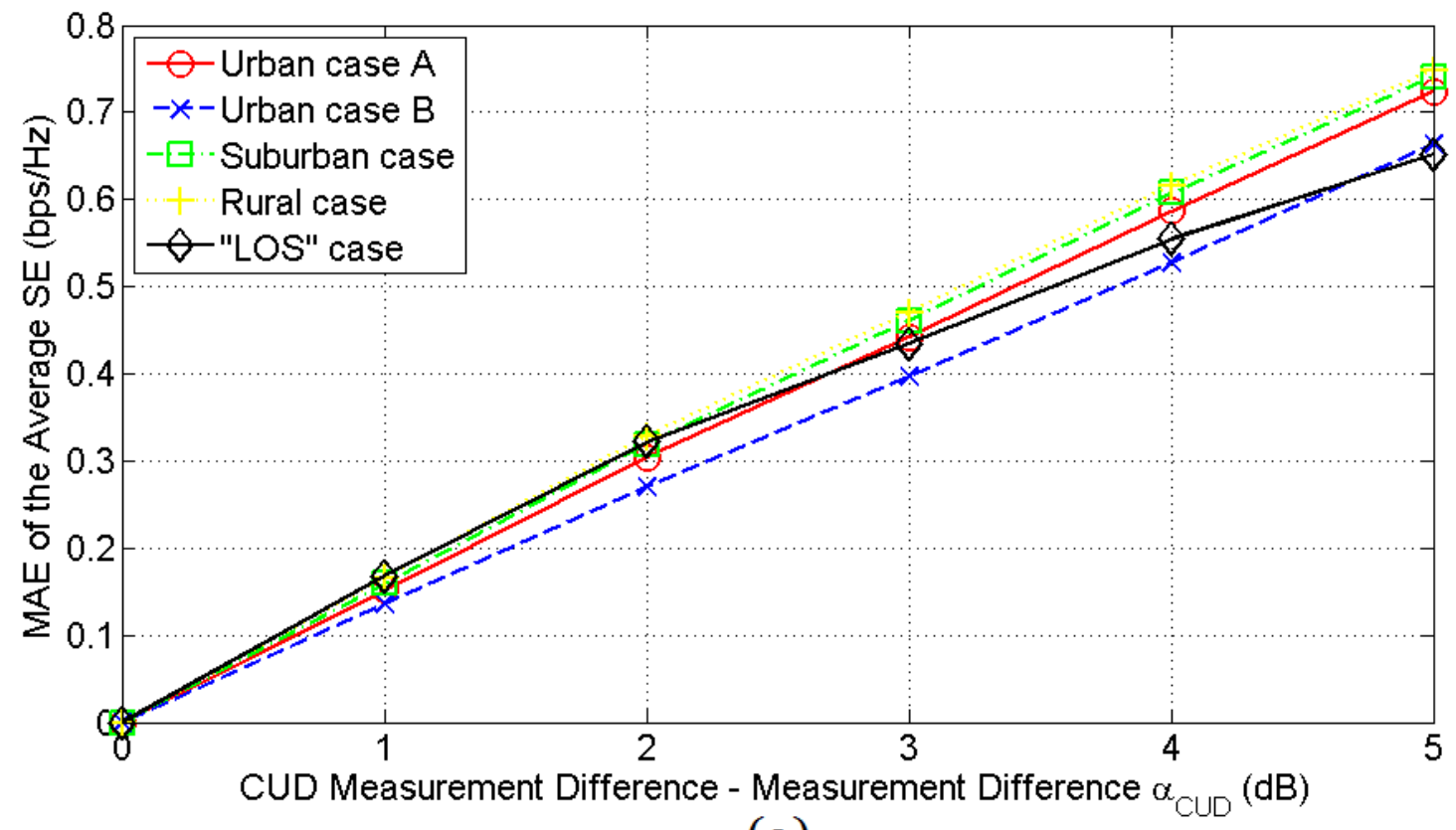

(a)

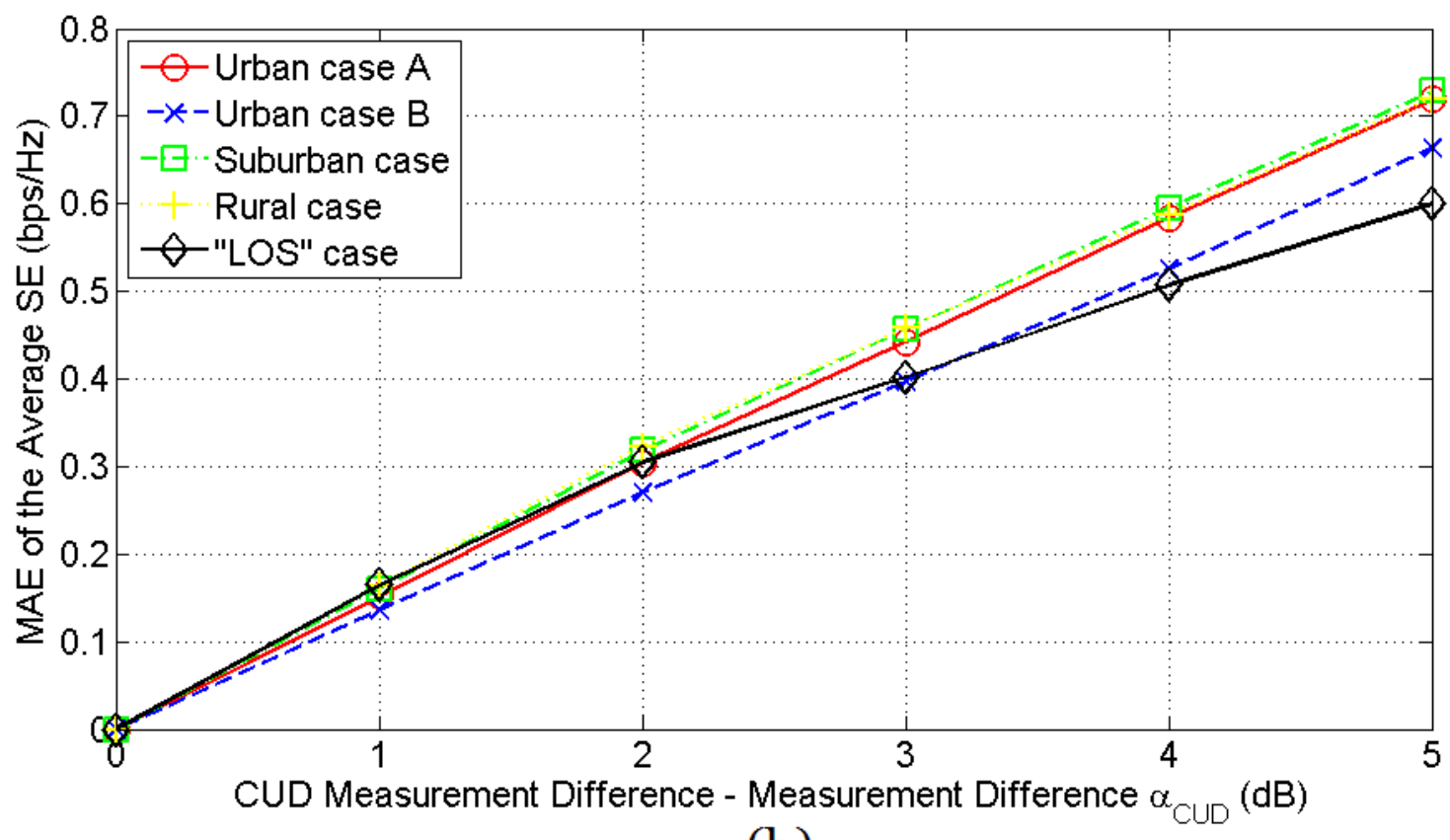

(b) 


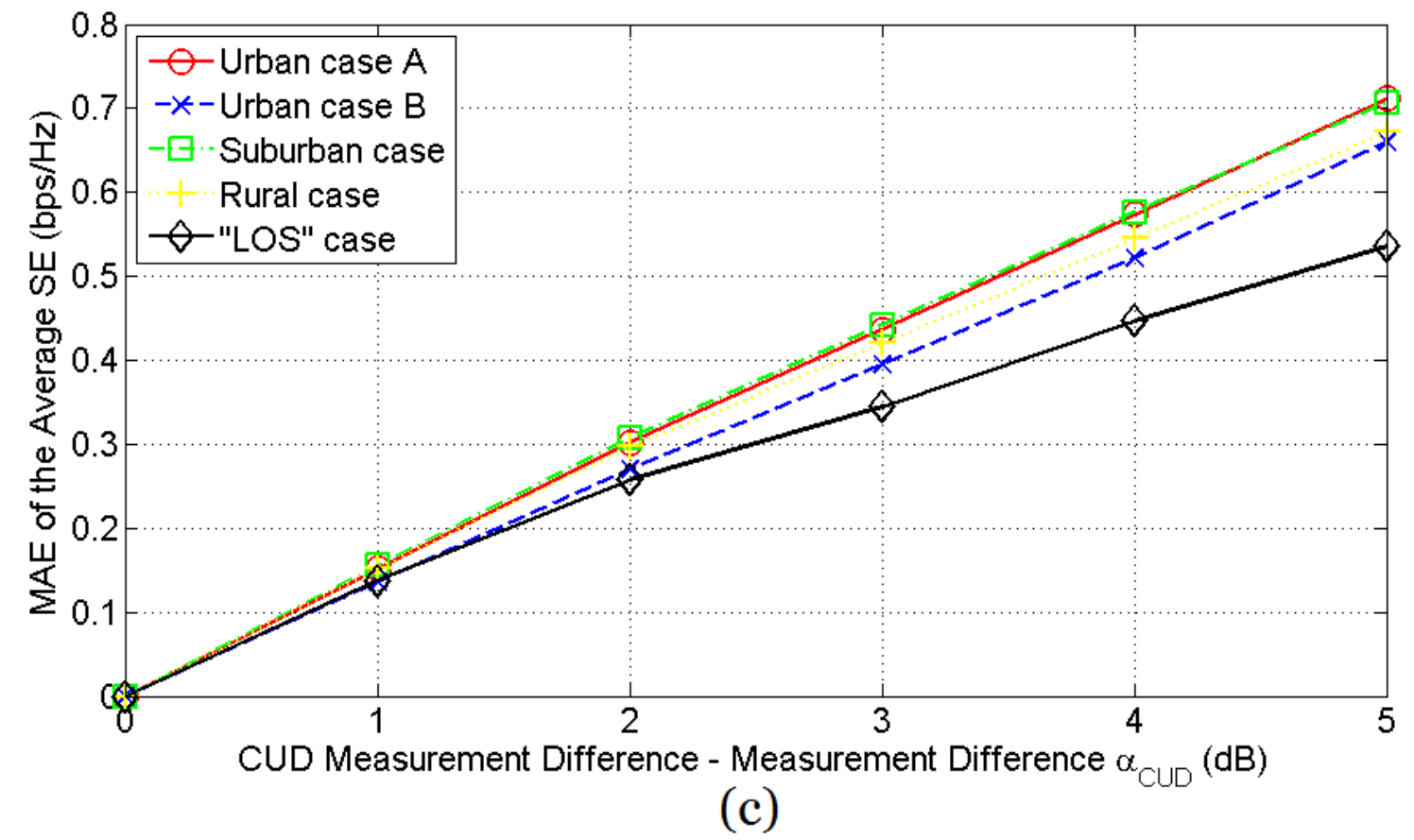

Fig. 16. MAE of SE of the indicative OV MV BPL topologies in the 3-88 MHz frequency band when FCC limits are assumed and different coupling schemes are applied for different CUD measurement differences. (a) $\mathrm{WtG}^{1}$ coupling scheme. (b) $\mathrm{WtW}^{1-2}$ coupling scheme. (c) $\mathrm{MtM}_{0.8-0.1-0.1}^{1-2-3}$ coupling scheme. 


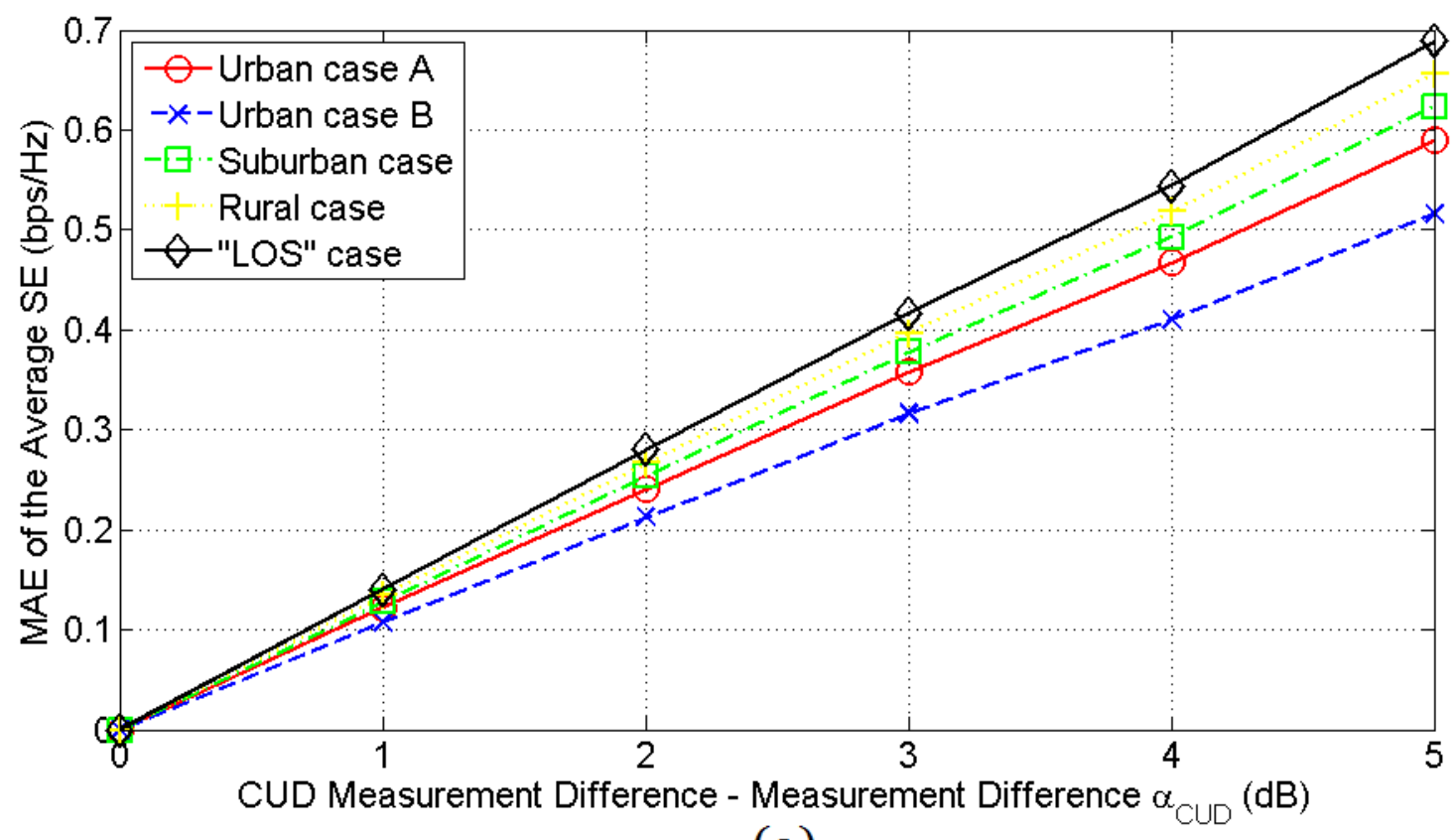

(a)

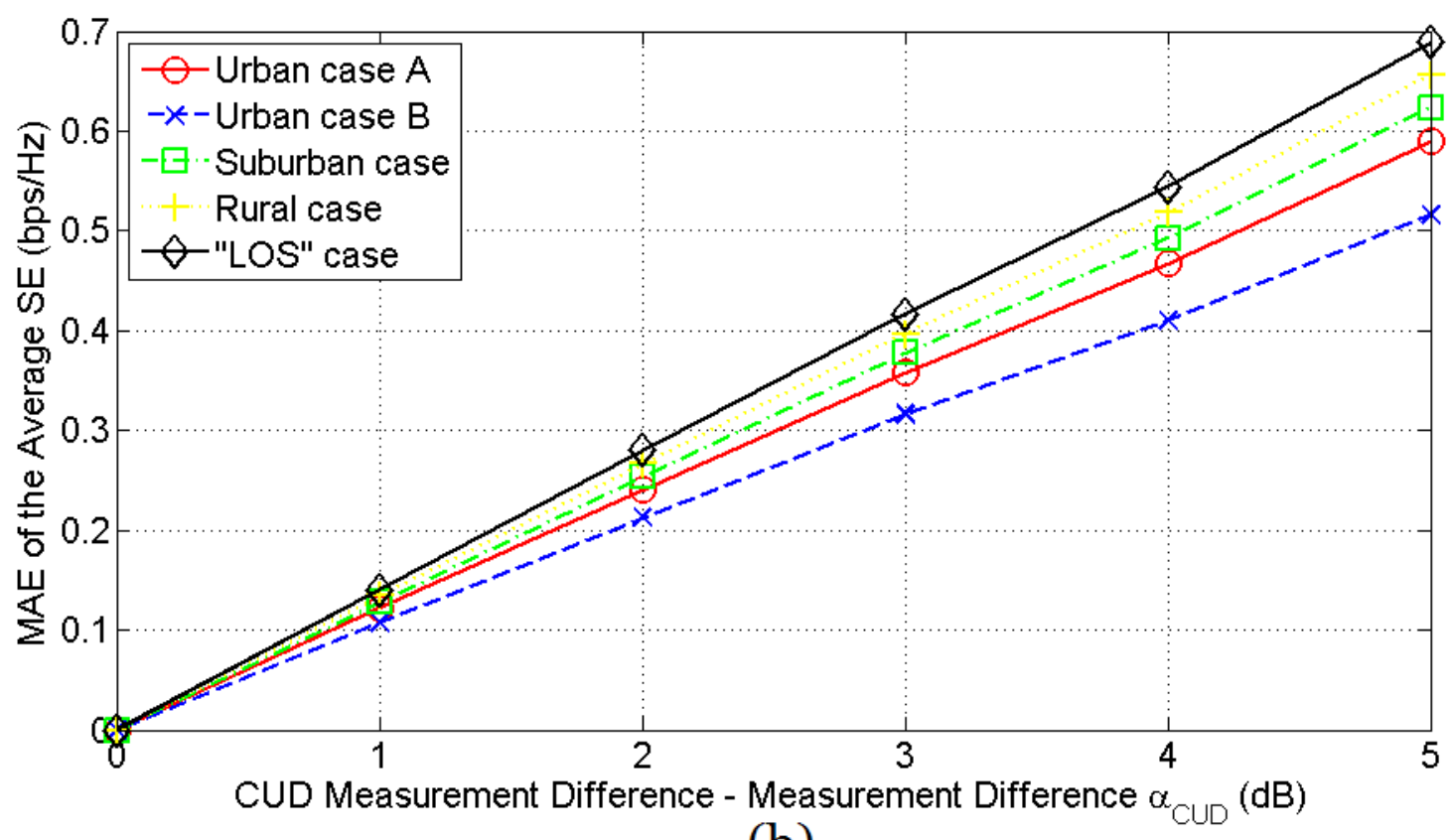

(b) 


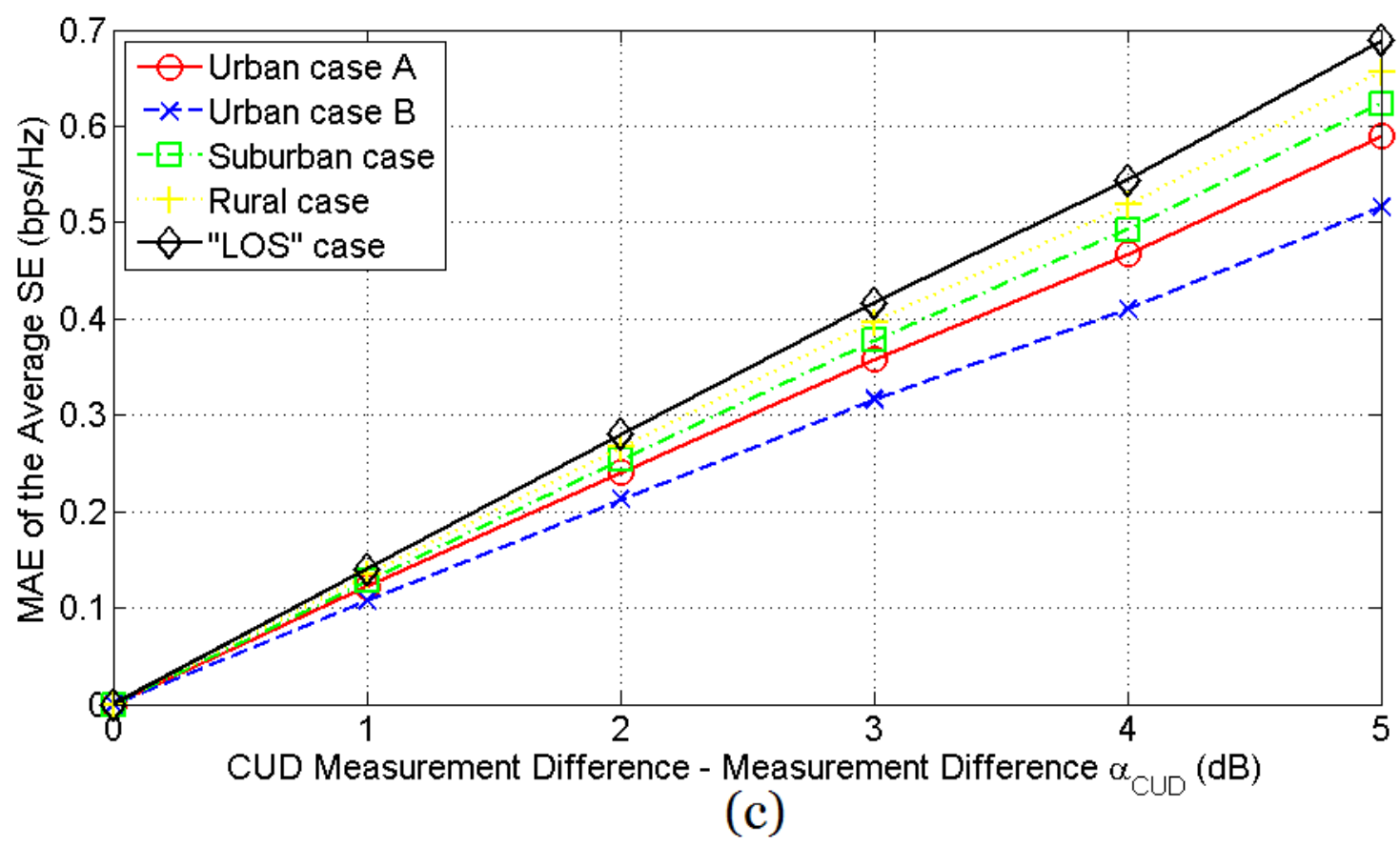

Fig. 17. MAE of SE of the indicative UN MV BPL topologies in the 3-88 MHz frequency band when FCC limits are assumed and different coupling schemes are applied for different CUD measurement differences. (a) $\mathrm{StP}^{1}$ coupling scheme. (b) $\mathrm{PtP}^{1-2}$ coupling scheme. (c) $\mathrm{MtM}_{0.8-0.1 \_-0.1}^{1-2-3}$ coupling scheme. 


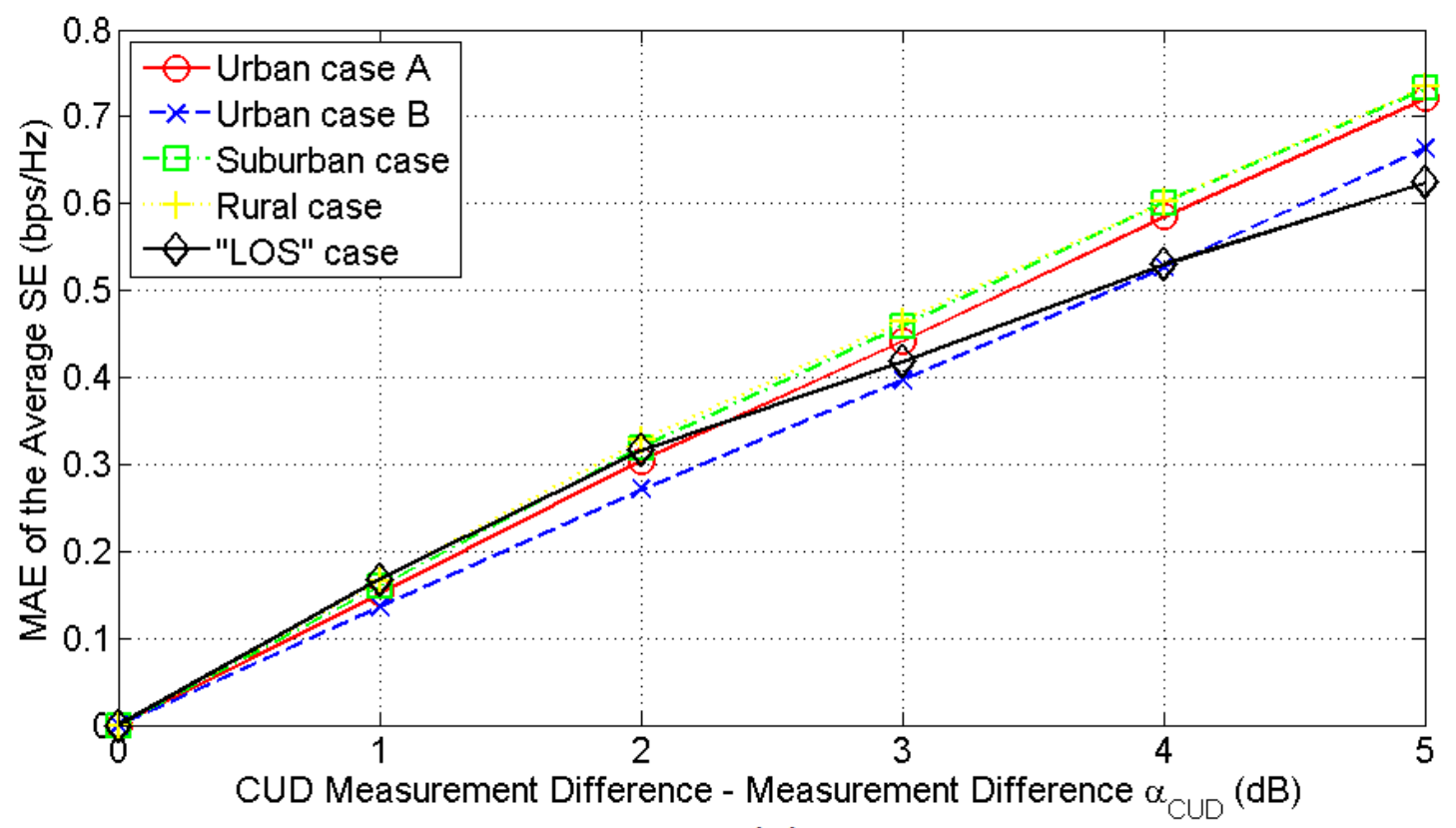

(a)

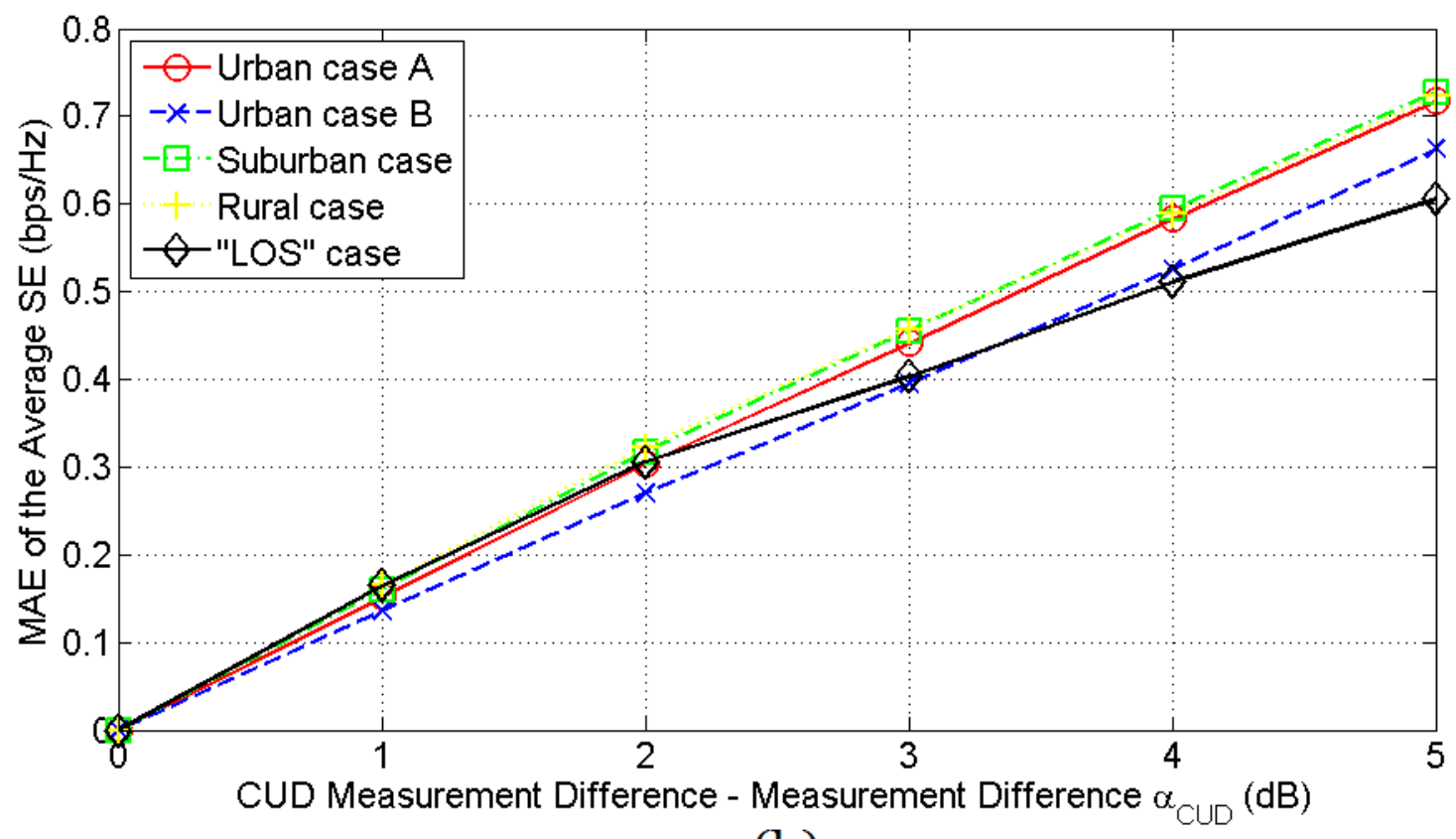

(b) 


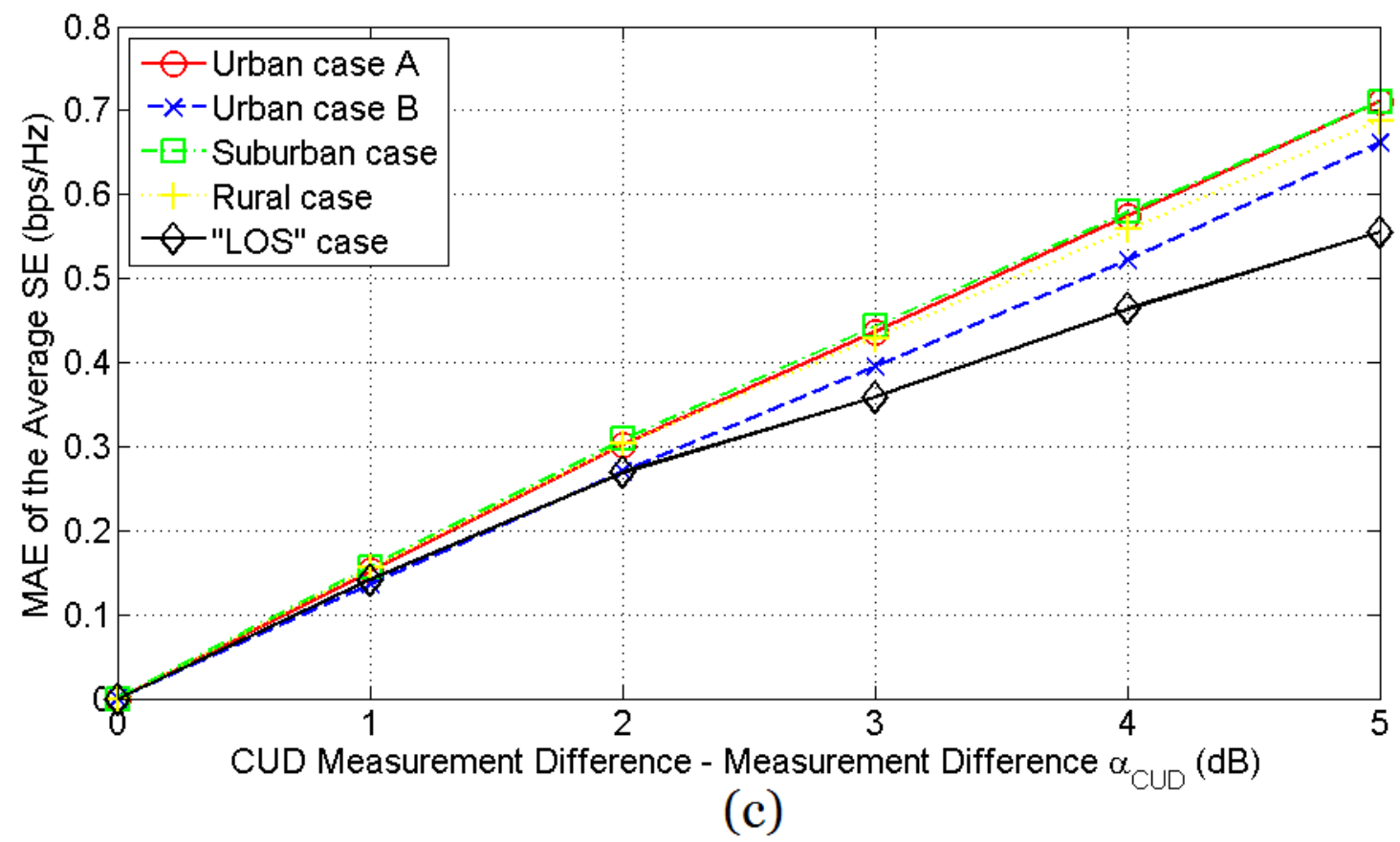

Fig. 18. Same with Fig. 16 but for the case of the indicative OV LV BPL topologies. 


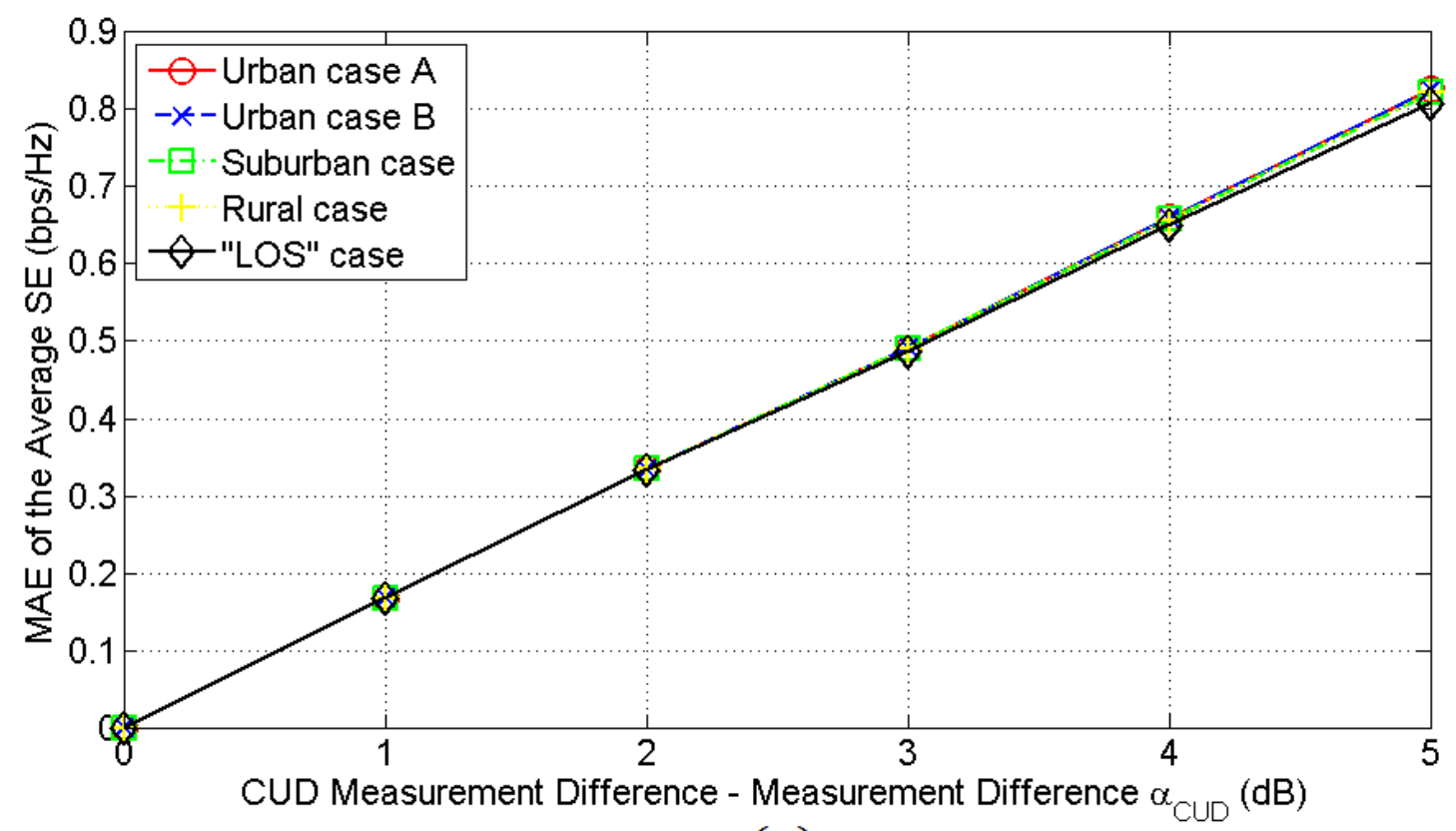

(a)

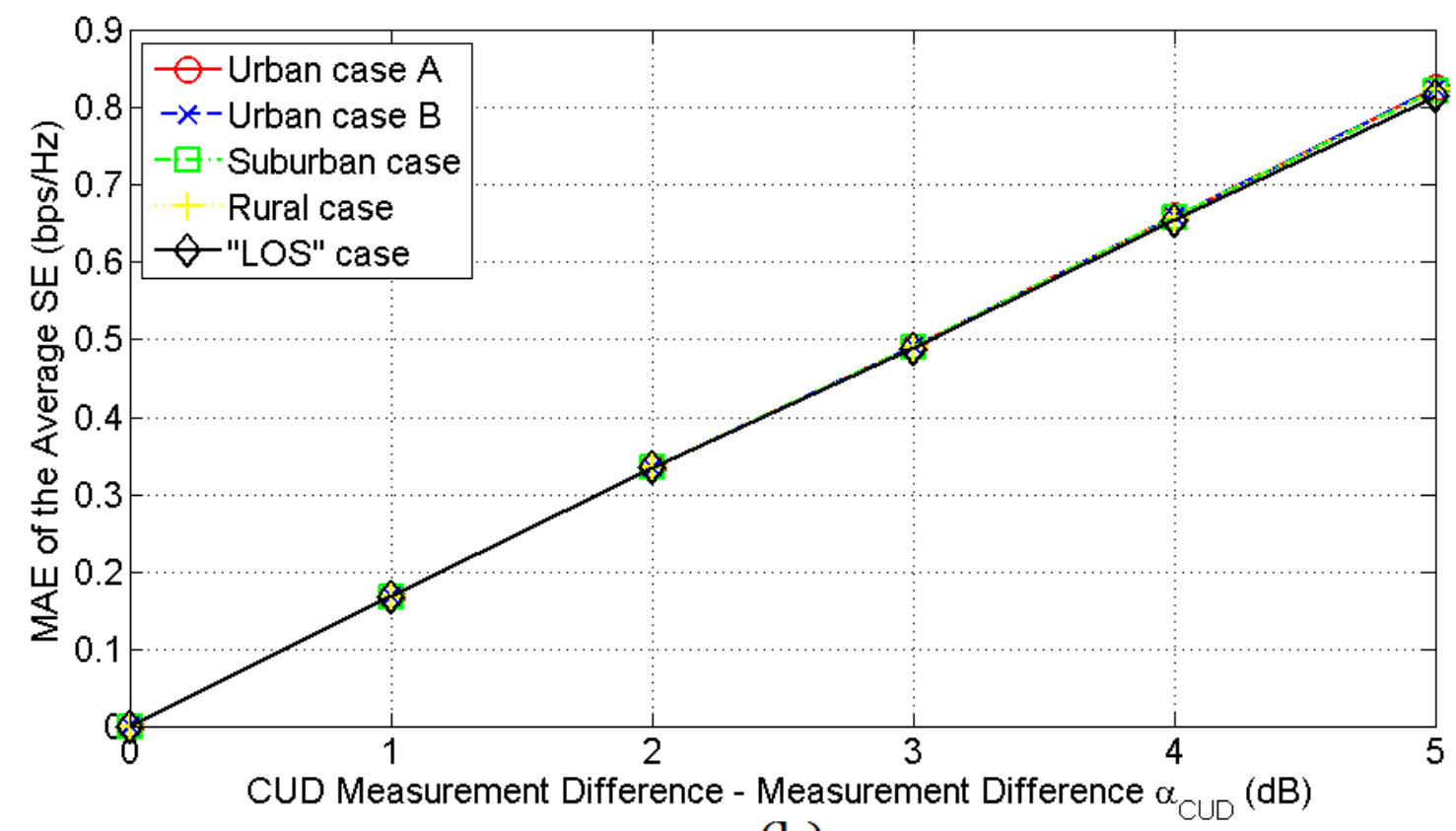

(b) 


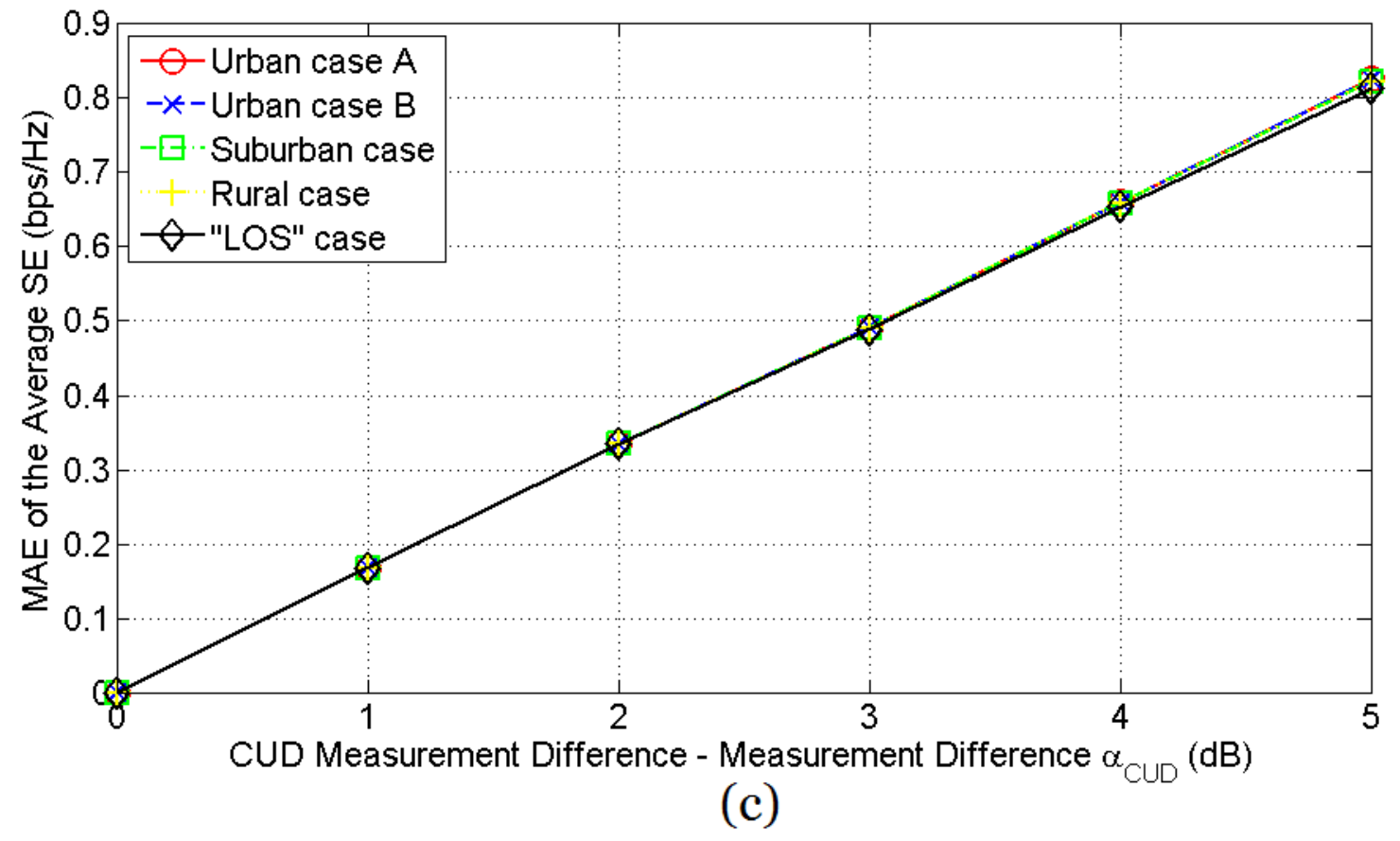

Fig. 19. Same with Fig. 17 but for the case of the indicative UN LV BPL topologies. 


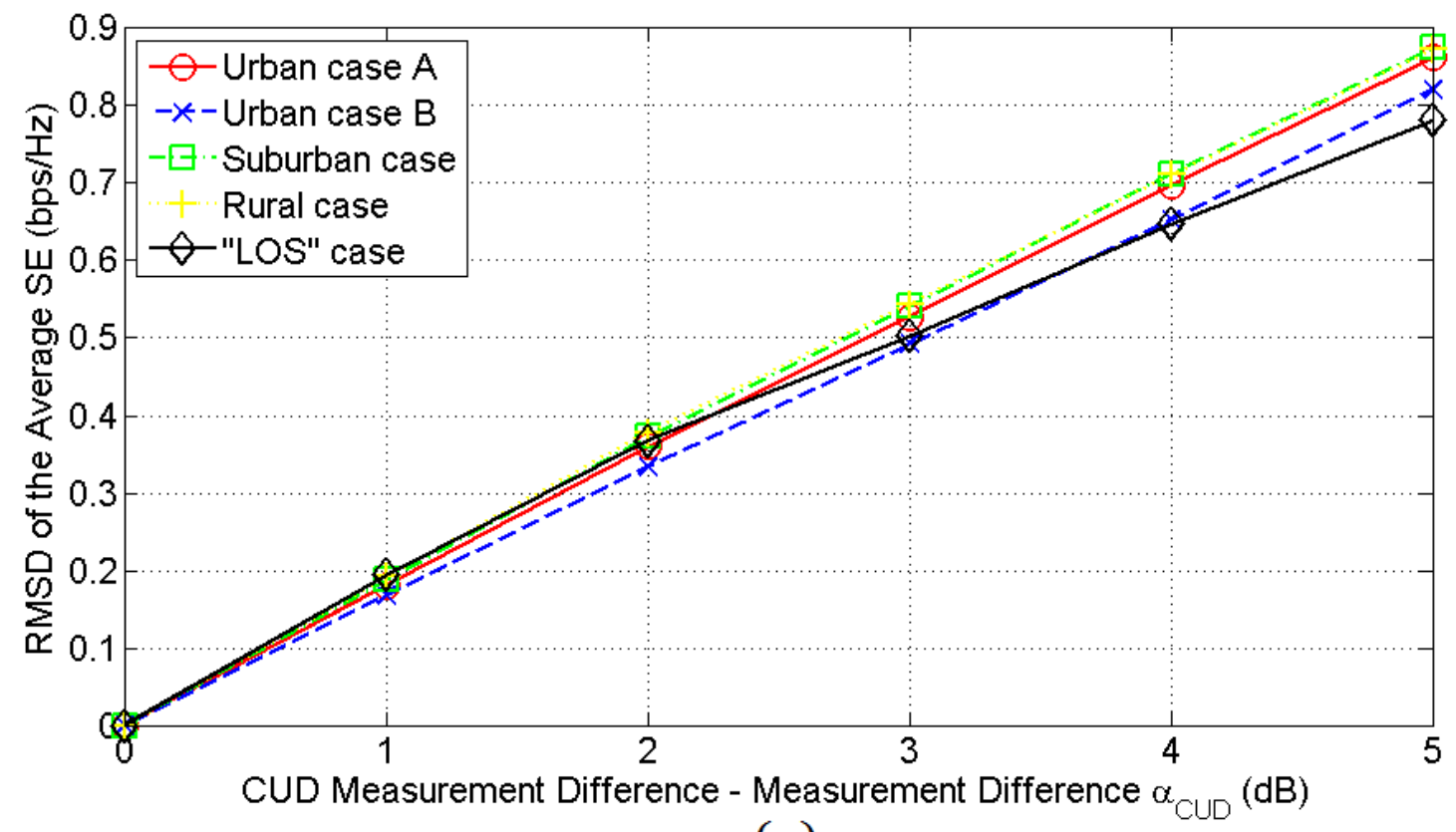

(a)

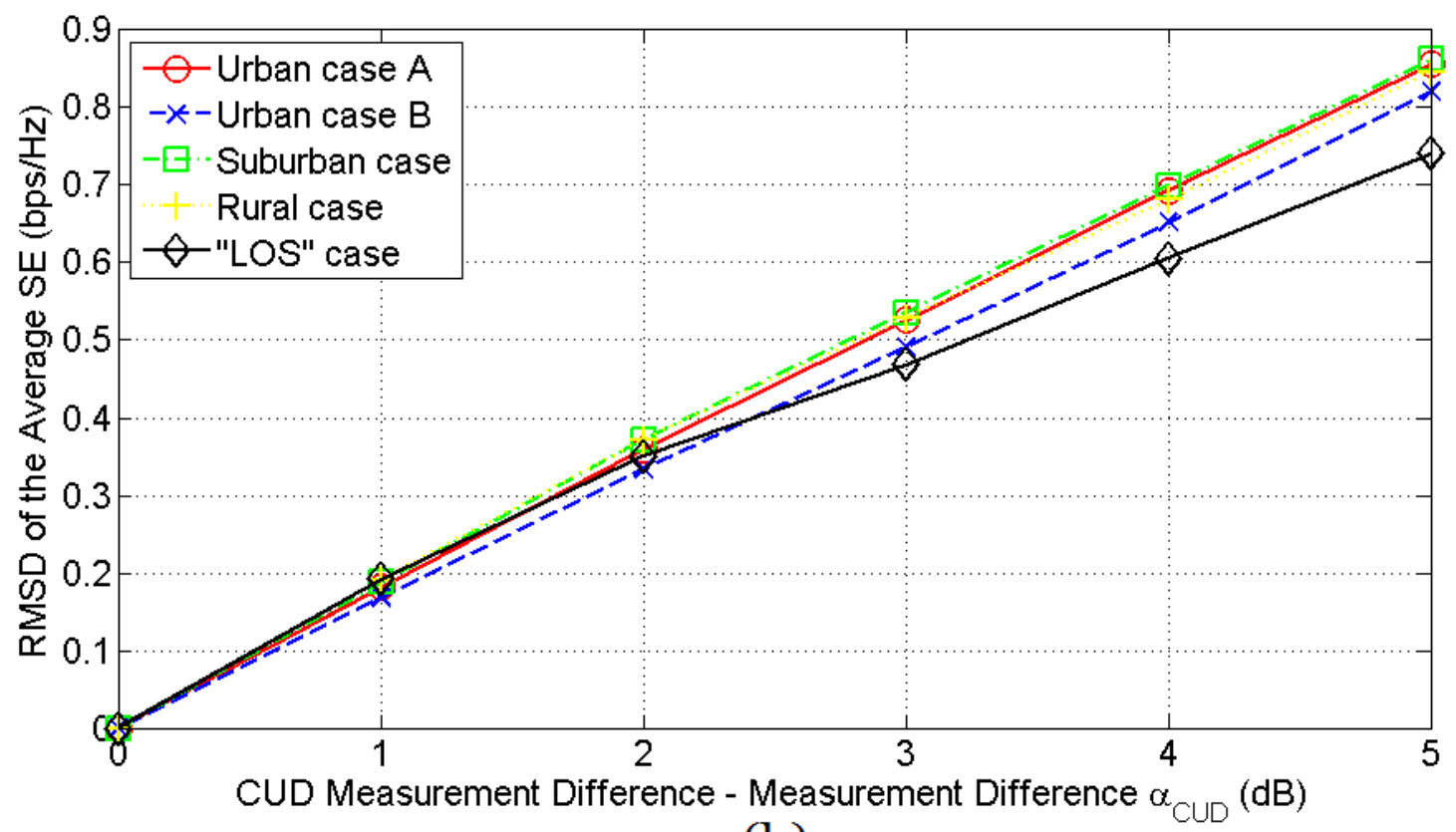

(b) 


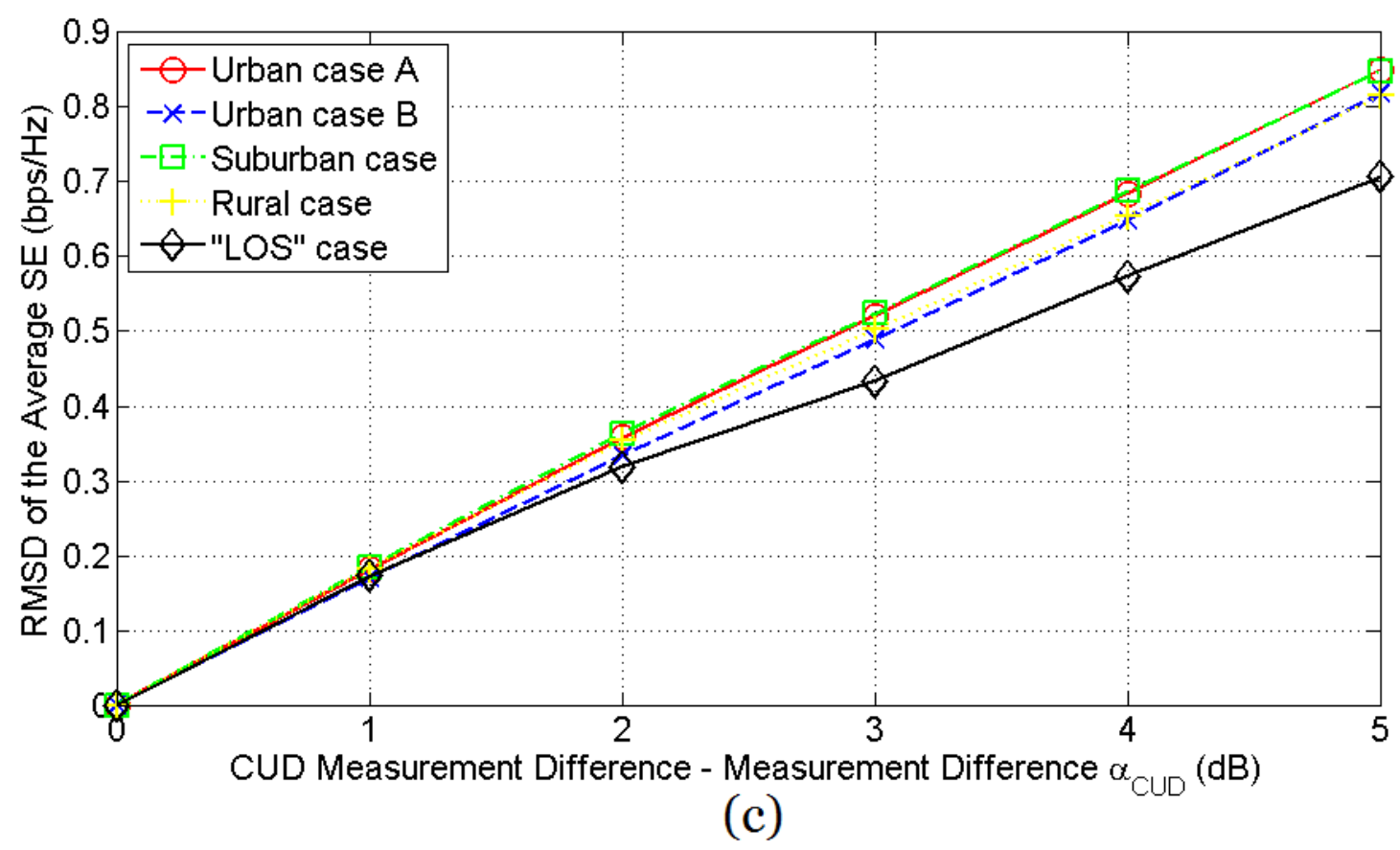

Fig. 20. RMSD of SE of the indicative OV MV BPL topologies in the 3-88 MHz frequency band when FCC limits are assumed and different coupling schemes are applied for different CUD measurement differences. (a) $\mathrm{WtG}^{1}$ coupling scheme. (b) $\mathrm{WtW}^{1-2}$ coupling scheme. (c) $\mathrm{MtM}_{0.8--0.1_{-}-0.1}^{1-2-3}$ coupling scheme. 

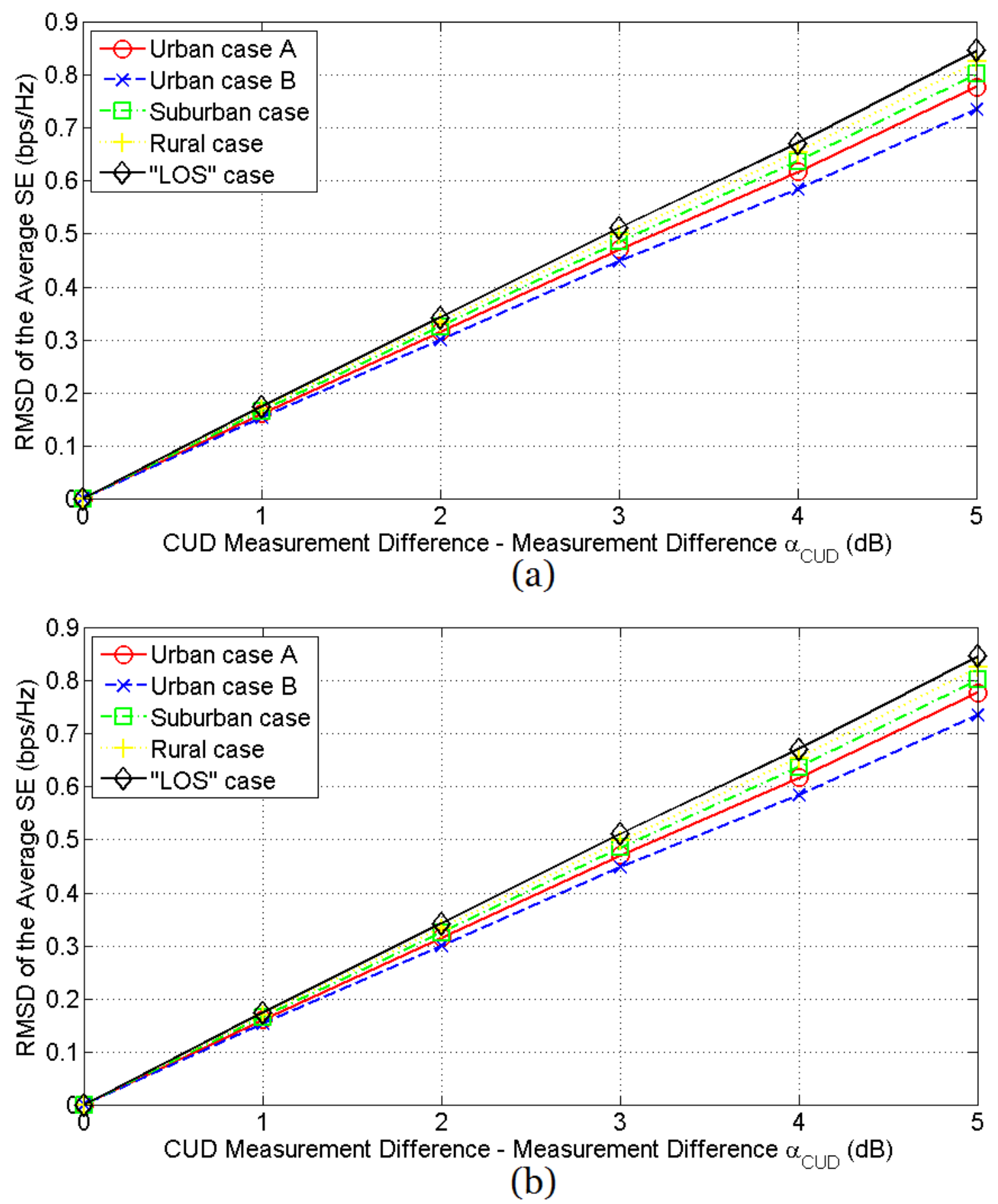


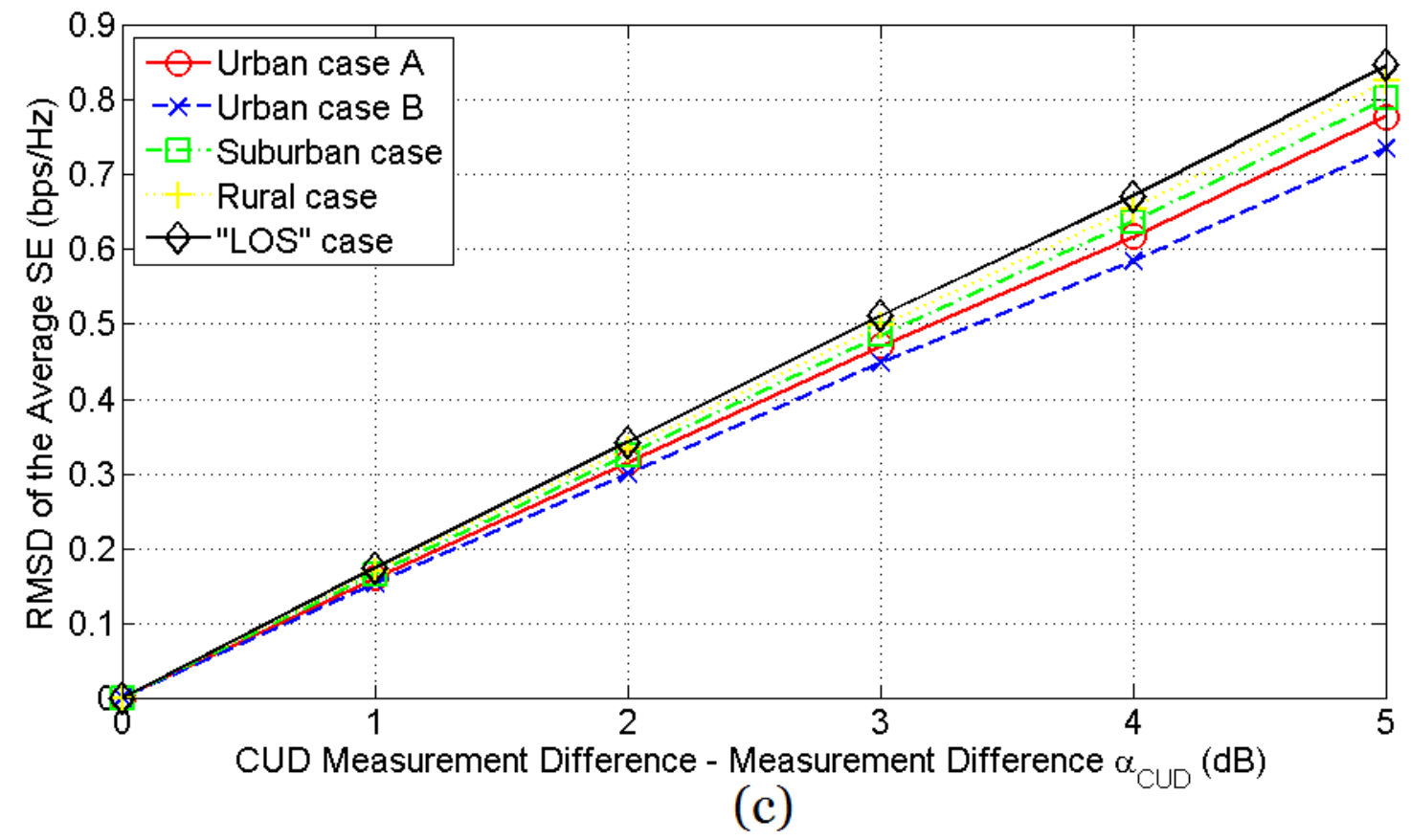

Fig. 21. RMSD of SE of the indicative UN MV BPL topologies in the 3-88 MHz frequency band when FCC limits are assumed and different coupling schemes are applied for different CUD measurement differences. (a) $\mathrm{StP}^{1}$ coupling scheme. (b) $\mathrm{PtP}^{1-2}$ coupling scheme. (c) $\mathrm{MtM}_{0.8-0.1-0.1}^{1-2-3}$ coupling scheme. 


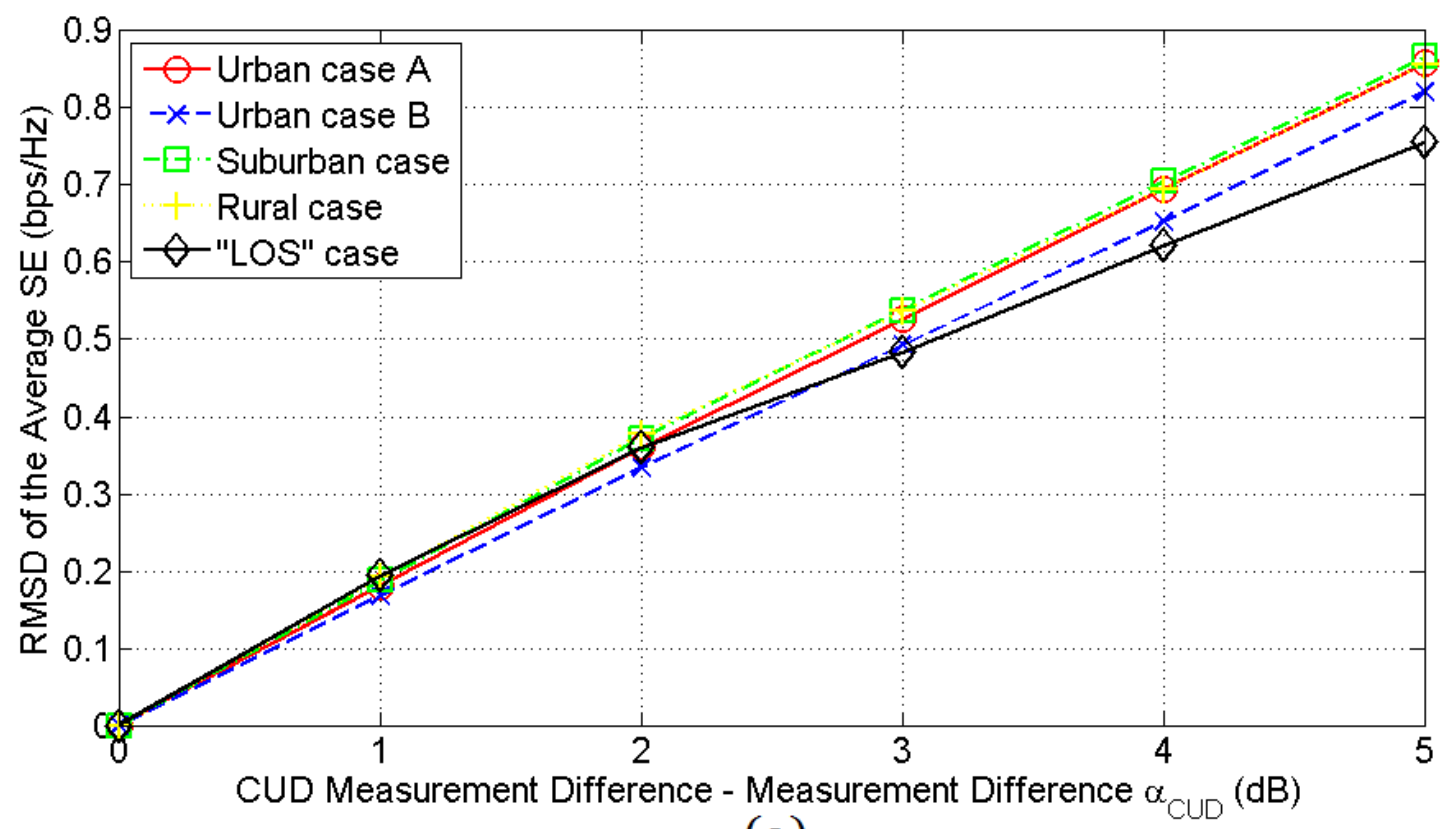

(a)

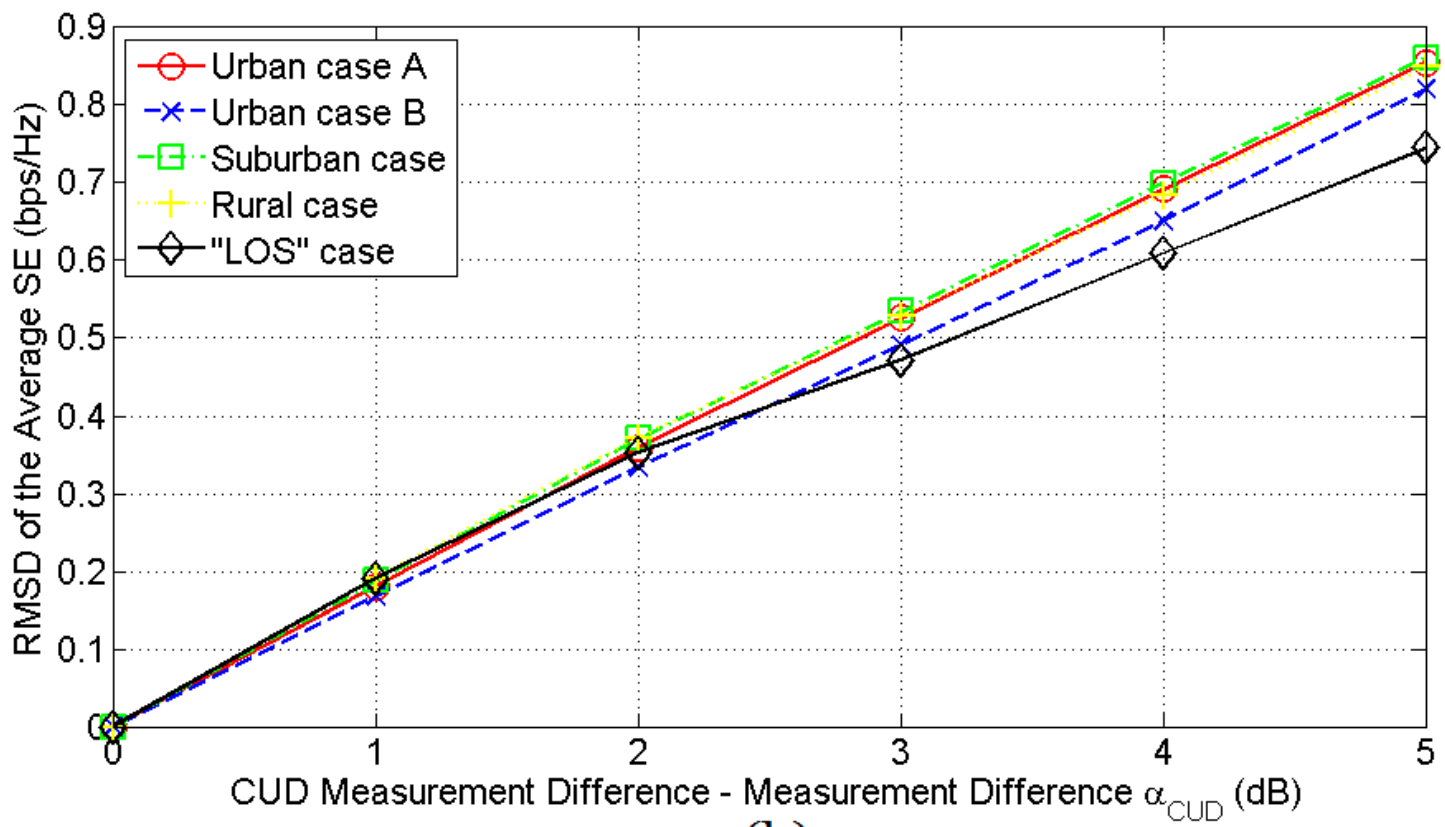

(b) 


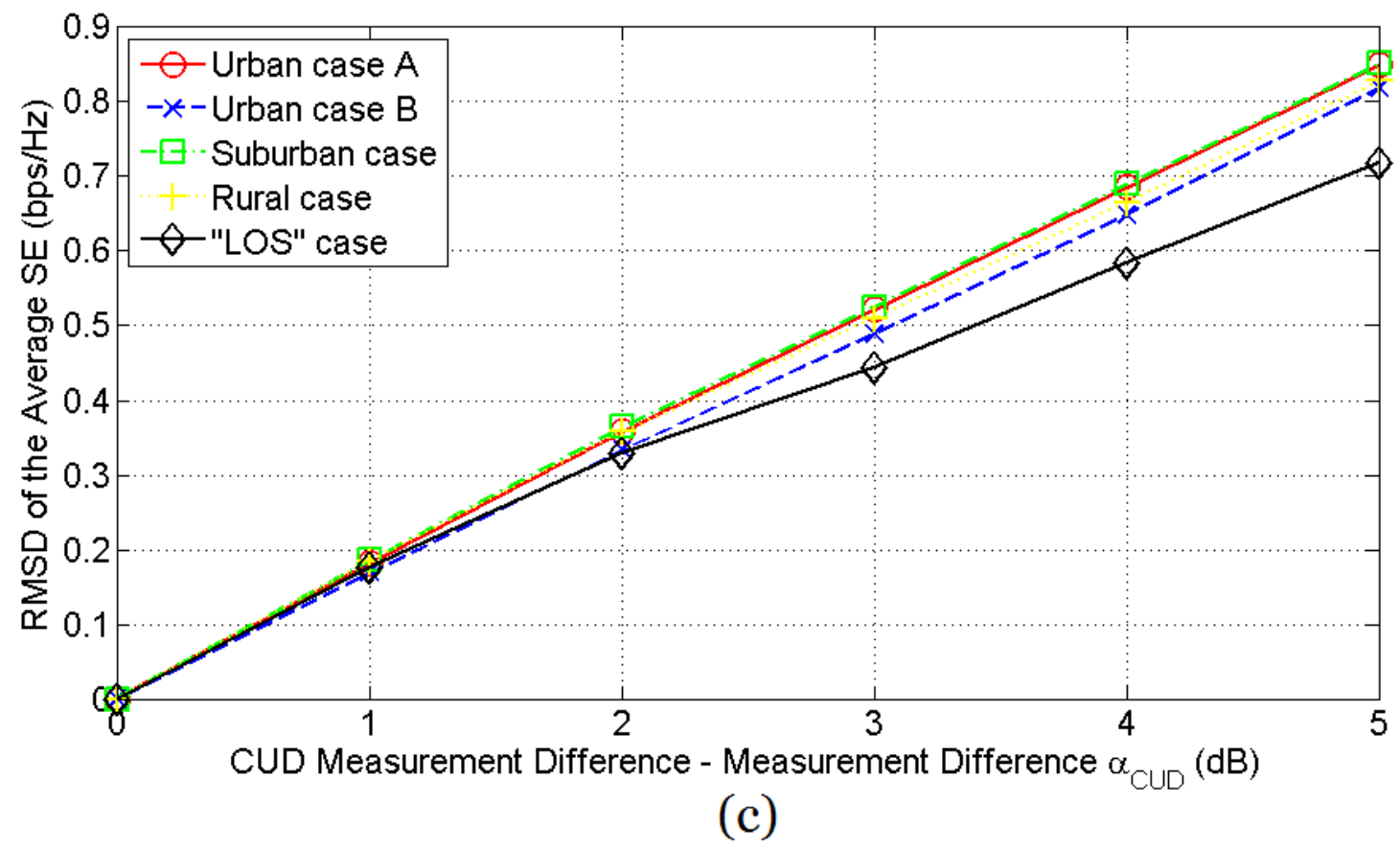

Fig. 22. Same with Fig. 20 but for the case of the indicative OV LV BPL topologies. 


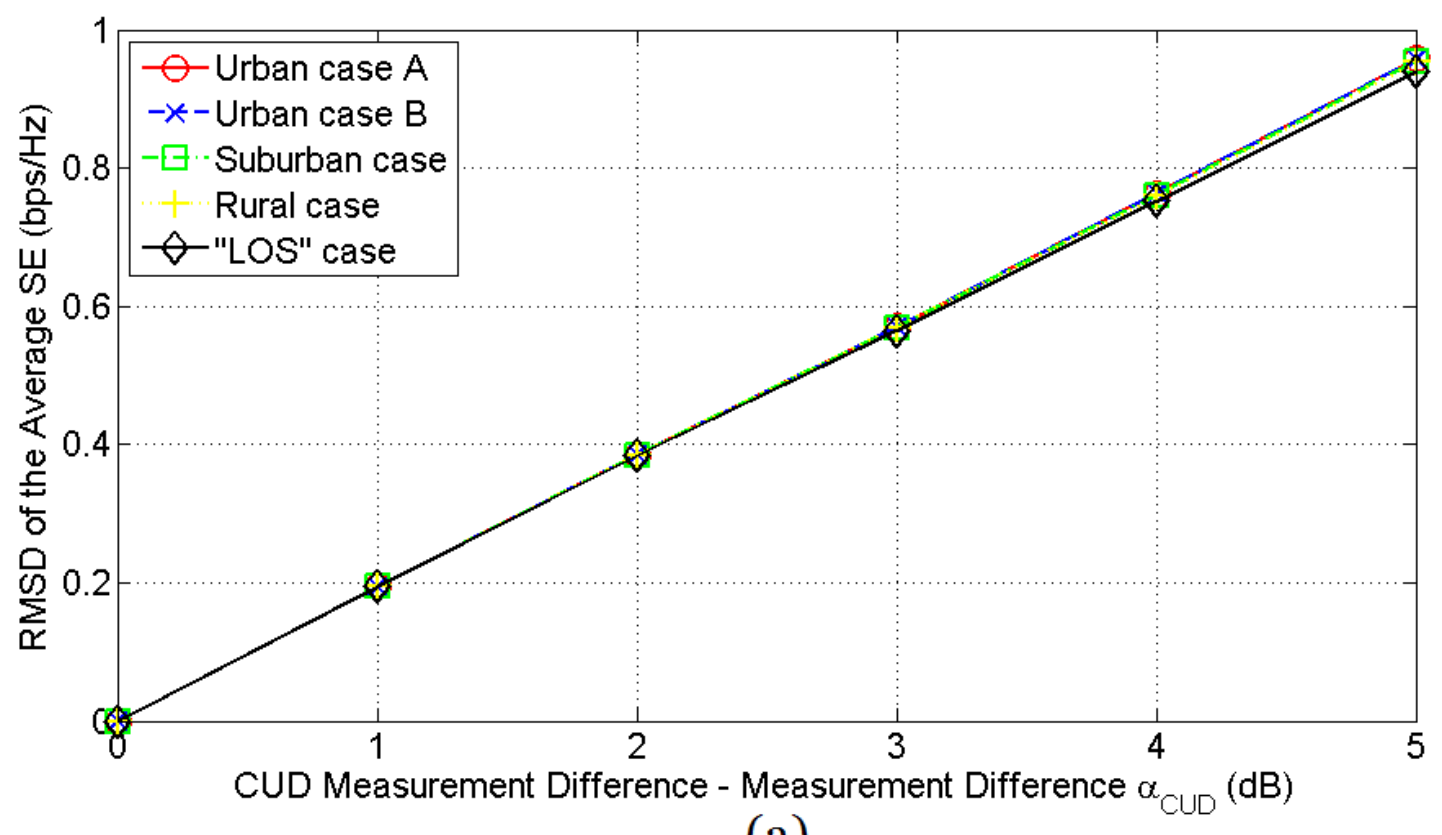

(a)

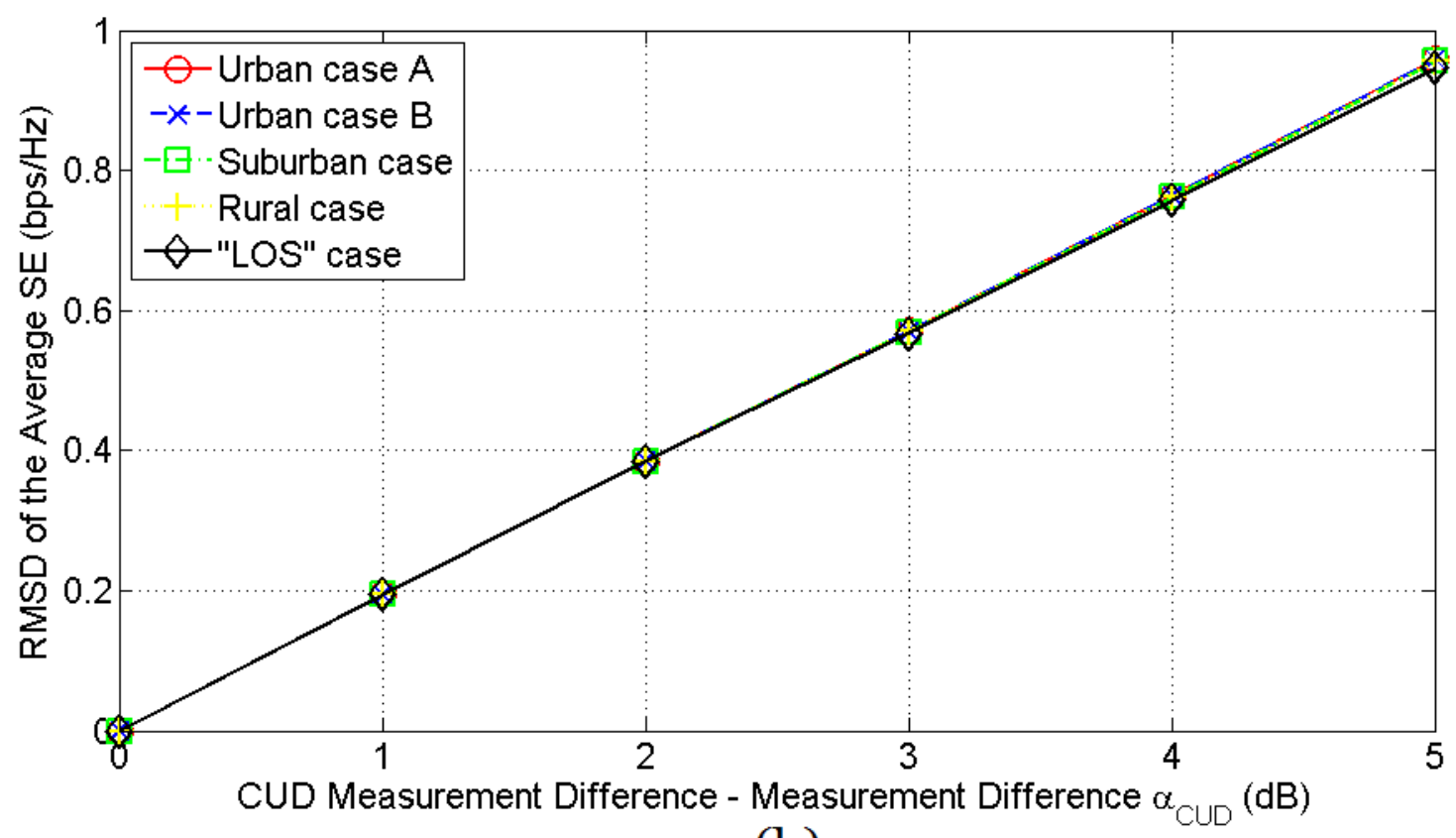

(b) 


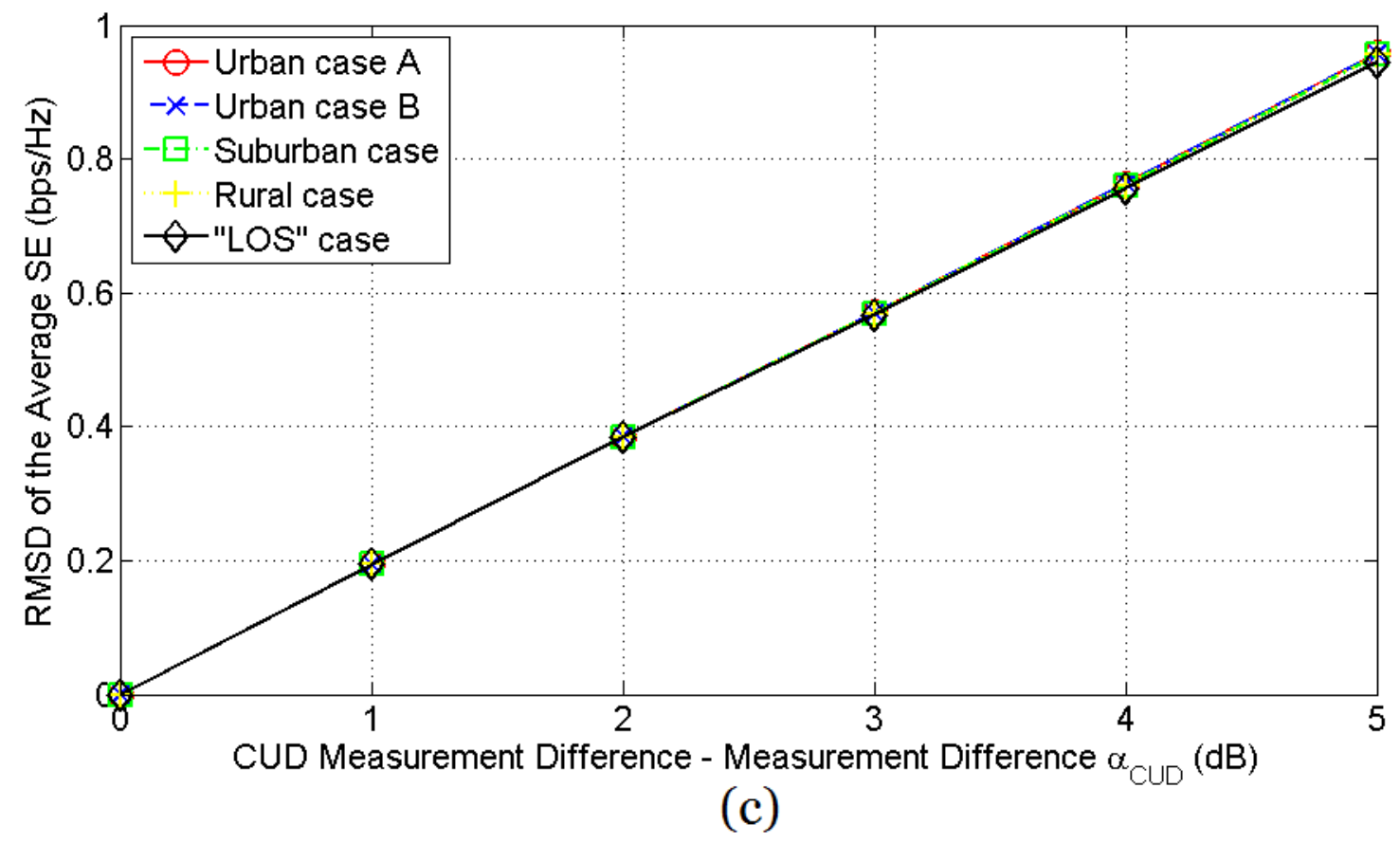

Fig. 23. Same with Fig. 21 but for the case of the indicative UN LV BPL topologies.

In Figs. 18(a)-(c), same plots with Figs. 12(a)-(c) are given but for the case of the indicative OV LV BPL topologies while in Figs. 19(a)-(c), same curves with Figs. 13(a)-(c) are presented but for the case of the indicative UN LV BPL topologies. In Figs. 20-23, same curves for the root mean square deviation (RMSD) of SE are given for the Figs. 16-19, respectively.

By observing Figs. 16-23, several interesting conclusions can be deduced. More specifically:

- In contrast with the traditional metrics of the maximum, minimum and average SE (i.e., metrics of Set A), the metrics of Set B (i.e., MAE and RMSD) can detect the existence of measurement differences while their values increase with the increase of the measurement difference $a_{\mathrm{CUD}}$.

- Measurement differences influence in a different way the MAE and RMSD of the average SE depending on the distribution power grid type and distribution BPL topology. However, small order differences among the indicative distribution BPL topologies can be pointed out. Anyway, approximately $0.2 \mathrm{bps} / \mathrm{Hz}$ of RMSD is added for each $1 \mathrm{~dB}$ increase of maximum value $a_{\mathrm{CUD}}$ regardless of the distribution power grid type and distribution BPL topology. Note that when measurement differences of $a_{\mathrm{CUD}}$ that is equal to $5 \mathrm{~dB}$ are assumed RMSD of $1 \mathrm{bps} / \mathrm{Hz}$ can be observed.

- When the SE is computed for given distribution BPL network and coupling scheme, it is unknown if measurement differences occur and if do which is their intensity. The countermeasures techniques of [55] aim at restoring the actual SE without a priori knowledge of the intensity of the measurement differences. In fact, the proposed SE countermeasure techniques can act as a necessary filter after the SE computation in order to identify and restore the actual SE that is free from measurement differences. 
- Although maximum, minimum and average SE cannot provide evidence about the intensity of measurement differences and their impact, they can act as integrity metric for the countermeasures techniques of [55] that aim at retrieving the real SE of distribution BPL topologies.

\section{Conclusions}

This paper has focused on the SE performance of distribution BPL networks when different coupling schemes of the CS2 module, different BPL topologies and different types and intensities of measurement differences are assumed. It has been revealed that the SE performance depends on the type of the distribution power grid type, IPSD limits, noise levels and the examined distribution BPL topology. Also, the maximum, minimum and average SE (i.e., metrics of Set A) significantly depend on the level of the biased measurement differences. In contrast with the biased measurement differences, CUD measurement differences have little effect to the maximum, minimum and average SE of the distribution BPL topologies. In order to identify the existence and the intensity of the measurement differences, MAE and RMSD (i.e., metrics of Set B) are employed during the SE computation in distribution BPL topologies. The behavior of MAE and RMSD strongly depends on the value $a_{\mathrm{CUD}}$ of the CUD measurement differences rather than the distribution power grid type, distribution BPL topology and the applied coupling scheme. The role of MAE and RMSD is important since they can assess the mitigation efficiency of the measurement difference countermeasure techniques of [55].

\section{CONFLICTS OF INTEREST}

The author declares that there is no conflict of interests regarding the publication of this paper.

\section{References}

[1] A. G. Lazaropoulos, "Towards Modal Integration of Overhead and Underground Low-Voltage and Medium-Voltage Power Line Communication Channels in the Smart Grid Landscape: Model Expansion, Broadband Signal Transmission Characteristics, and Statistical Performance Metrics (Invited Paper)," ISRN Signal Processing, vol. 2012, Article ID 121628, pp. 1-17, 2012. [Online]. Available: http://www.hindawi.com/isrn/sp/2012/121628/

[2] A. G. Lazaropoulos, "Towards broadband over power lines systems integration: Transmission characteristics of underground low-voltage distribution power lines," Progress in Electromagnetics Research B, 39, pp. 89-114, 2012. [Online]. Available: http://www.jpier.org/PIERB/pierb39/05.12012409.pdf

[3] A. G. Lazaropoulos and P. G. Cottis, "Transmission characteristics of overhead medium voltage power line communication channels," IEEE Trans. Power Del., vol. 24, no. 3, pp. 1164-1173, Jul. 2009.

[4] A. G. Lazaropoulos and P. G. Cottis, "Capacity of overhead medium voltage power line communication channels," IEEE Trans. Power Del., vol. 25, no. 2, pp. 723733, Apr. 2010. 
[5] A. G. Lazaropoulos and P. G. Cottis, "Broadband transmission via underground medium-voltage power lines-Part I: transmission characteristics," IEEE Trans. Power Del., vol. 25, no. 4, pp. 2414-2424, Oct. 2010.

[6] A. G. Lazaropoulos and P. G. Cottis, "Broadband transmission via underground medium-voltage power lines-Part II: capacity," IEEE Trans. Power Del., vol. 25, no. 4, pp. 2425-2434, Oct. 2010.

[7] A. G. Lazaropoulos, "Broadband transmission characteristics of overhead highvoltage power line communication channels,"Progress in Electromagnetics Research B, vol. 36, pp. 373-398, 2012. [Online]. Available: http://www.jpier.org/PIERB/pierb36/19.11091408.pdf

[8] A. G. Lazaropoulos, "Green Overhead and Underground Multiple-Input MultipleOutput Medium Voltage Broadband over Power Lines Networks: Energy-Efficient Power Control,"Springer Journal of Global Optimization, vol. 2012 / Print ISSN 0925-5001, pp. 1-28, Oct. 2012.

[9] H. Ferreira, L. Lampe, J. Newbury, and T. G. Swart, Power Line Communications, Theory and Applications for Narrowband and Broadband Communications over Power Lines. New York: Wiley, 2010.

[10] K. Sharma and L. M. Saini, "Power-line communications for smart grid: Progress, challenges, opportunities and status," Elsevier Renewable and Sustainable Energy Reviews, vol. 67, pp. 704-751, 2017.

[11] T. A. Papadopoulos, A. I. Chrysochos, A. ElSamadouny, N. Al-Dhahir, and G. K. Papagiannis, "MIMO-OFDM narrowband-PLC in distribution systems: Impact of power transformers on achievable data rates,". Elsevier Electric Power Systems Research, vol. 151, pp. 251-265, 2017.

[12] E. O. Kontis, T. A. Papadopoulos, A. I. Chrysochos, and G. K. Papagiannis, "Measurement-Based Dynamic Load Modeling Using the Vector Fitting Technique," IEEE Transactions on Power Systems, vol. 33, no. 1, pp. 338-351, 2018.

[13] A. G. Lazaropoulos, "Deployment Concepts for Overhead High Voltage Broadband over Power Lines Connections with Two-Hop Repeater System: Capacity Countermeasures against Aggravated Topologies and High Noise Environments," Progress in Electromagnetics Research B, vol. 44, pp. 283-307, 2012. [Online]. Available: http://www.jpier.org/PIERB/pierb44/13.12081104.pdf

[14] A. G. Lazaropoulos, "Broadband transmission and statistical performance properties of overhead high-voltage transmission networks,"HindawiJournal of Computer Networks and Commun., 2012, article ID 875632, 2012. [Online]. Available: http://www.hindawi.com/journals/jcnc/aip/875632/

[15] P. Amirshahi and M. Kavehrad, "High-frequency characteristics of overhead multiconductor power lines for broadband communications," IEEE J. Sel. Areas Commun., vol. 24, no. 7, pp. 1292-1303, Jul. 2006.

[16] T. Calliacoudas and F. Issa, "“Multiconductor transmission lines and cables solver," An efficient simulation tool for plc channel networks development," presented at the IEEE Int. Conf. Power Line Communications and Its Applications, Athens, Greece, Mar. 2002.

[17] T. Sartenaer and P. Delogne, "Deterministic modelling of the (Shielded) outdoor powerline channel based on the multiconductor transmission line equations," IEEE J. Sel. Areas Commun., vol. 24, no. 7, pp. 1277-1291, Jul. 2006. 
[18] C. R. Paul, Analysis of Multiconductor Transmission Lines. New York: Wiley, 1994.

[19] H. Meng, S. Chen, Y. L. Guan, C. L. Law, P. L. So, E. Gunawan, and T. T. Lie, "Modeling of transfer characteristics for the broadband power line communication channel," IEEE Trans. Power Del., vol. 19, no. 3, pp. 1057-1064, Jul. 2004.

[20] B. Li, D. Mansson, and G. Yang, "An efficient method for solving frequency responses of power-line networks," Progress In Electromagnetics Research B, Vol. 62, 303-317, 2015. doi:10.2528/PIERB15013008 http://www.jpier.org/pierb/pier.php?paper $=15013008$

[21] M. Chaaban, K. El KhamlichiDrissi, and D. Poljak, "Analytical model for electromagnetic radiation by bare-wire structures," Progress In Electromagnetics Research B, Vol. 45, 395-413, 2012. doi:10.2528/PIERB12091102 http://www.jpier.org/pierb/pier.php?paper=12091102

[22] Y. H. Kim, S. Choi, S. C. Kim, and J. H. Lee, "Capacity of OFDM two-hop relaying systems for medium-voltage power-line access networks," IEEE Trans. Power Del., vol. 27, no. 2, pp. 886-894, Apr. 2012.

[23] A. G. Lazaropoulos, "New Coupling Schemes for Distribution Broadband over Power Lines (BPL) Networks," Progress in Electromagnetics Research B, vol. 71, pp. 2016. 39-54, [Online]. Available: http://www.jpier.org/PIERB/pierb71/02.16081503.pdf

[24] A. G. Lazaropoulos, "Broadband Performance Metrics and Regression Approximations of the New Coupling Schemes for Distribution Broadband over Power Lines (BPL) Networks," Trends in Renewable Energy, vol. 4, no. 1, pp. 43 73, $2018 . \quad$ [Online]. Available: http://www.futureenergysp.com/index.php/tre/article/view/59/pdf

[25] A. G. Lazaropoulos, "Measurement Differences, Faults and Instabilities in Intelligent Energy Systems - Part 1: Identification of Overhead High-Voltage Broadband over Power Lines Network Topologies by Applying Topology Identification Methodology (TIM)," Trends in Renewable Energy, vol. 2, no. 3, pp. $85-112, \quad$ Oct. $2016 . \quad$ [Online]. Available: http://futureenergysp.com/index.php/tre/article/download/26/32

[26] A. G. Lazaropoulos, "Measurement Differences, Faults and Instabilities in Intelligent Energy Systems - Part 2: Fault and Instability Prediction in Overhead High-Voltage Broadband over Power Lines Networks by Applying Fault and Instability Identification Methodology (FIIM)," Trends in Renewable Energy, vol. 2, no. 3, pp. 113 - 142, Oct. 2016. [Online]. Available: http://futureenergysp.com/index.php/tre/article/view/27/33

[27] A. G. Lazaropoulos, "Best L1 Piecewise Monotonic Data Approximation in Overhead and Underground Medium-Voltage and Low-Voltage Broadband over Power Lines Networks: Theoretical and Practical Transfer Function Determination," Hindawi Journal of Computational Engineering, vol. 2016, Article ID 6762390, 24 pages, 2016. doi:10.1155/2016/6762390. [Online]. Available: https://www.hindawi.com/journals/jcengi/2016/6762390/cta/

[28] A. G. Lazaropoulos, "Power Systems Stability through Piecewise Monotonic Data Approximations - Part 2: Adaptive Number of Monotonic Sections and Performance of L1PMA, L2WPMA and L2CXCV in Overhead Medium-Voltage Broadband over Power Lines Networks," Trends in Renewable Energy, vol. 3, no. 
1, pp. $33-60, \quad$ Jan. 2017. [Online]. Available: http://futureenergysp.com/index.php/tre/article/view/30/35

[29] A. G. Lazaropoulos, "Power Systems Stability through Piecewise Monotonic Data Approximations - Part 1: Comparative Benchmarking of L1PMA, L2WPMA and L2CXCV in Overhead Medium-Voltage Broadband over Power Lines Networks," Trends in Renewable Energy, vol. 3, no. 1, pp. 2 - 32, Jan. 2017. [Online]. Available: http://futureenergysp.com/index.php/tre/article/view/29/34

[30] A. G. Lazaropoulos, "Main Line Fault Localization Methodology in Smart Grid Part 1: Extended TM2 Method for the Overhead Medium-Voltage Broadband over Power Lines Networks Case," Trends in Renewable Energy, vol. 3, no. 3, pp. 2-25, Dec. $2017 . \quad$ [Online]. Available: http://futureenergysp.com/index.php/tre/article/view/36

[31] A. G. Lazaropoulos, "Main Line Fault Localization Methodology in Smart Grid Part 2: Extended TM2 Method, Measurement Differences and L1 Piecewise Monotonic Data Approximation for the Overhead Medium-Voltage Broadband over Power Lines Networks Case," Trends in Renewable Energy, vol. 3, no. 3, pp. 26-61, Dec. 2017. [Online]. Available: http://futureenergysp.com/index.php/tre/article/view/37

[32] A. G. Lazaropoulos, "Main Line Fault Localization Methodology in Smart Grid Part 3: Main Line Fault Localization Methodology (MLFLM)," Trends in Renewable Energy, vol. 3, no. 3, pp. 62-81, Dec. 2017. [Online]. Available: http://futureenergysp.com/index.php/tre/article/view/38

[33] P. Amirshahi and M. Kavehrad, "Medium voltage overhead powerline broadband communications; Transmission capacity and electromagnetic interference," in Proc. IEEE Int. Symp. Power Line Commun. Appl., Vancouver, BC, Canada, Apr. 2005, pp. 2-6.

[34] OPERA1, D44: Report presenting the architecture of plc system, the electricity network topologies, the operating modes and the equipment over which PLC access system will be installed, IST Integr. Project No 507667, Dec. 2005.

[35] OPERA1, D5: Pathloss as a function of frequency, distance and network topology for various LV and MV European powerline networks. IST Integrated Project No 507667, Apr. 2005.

[36] P. C. J. M. van der Wielen, "On-line detection and location of partial discharges in medium-voltage power cables" Ph.D. dissertation, Tech. Univ. Eindhoven, Eindhoven, the Netherlands, Apr. 2005. [Online]. Available: http://alexandria.tue.nl/extra2/200511097.pdf

[37] P. C. J. M. van der Wielen, E. F. Steennis, and P. A. A. F. Wouters, "Fundamental aspects of excitation and propagation of on-line partial discharge signals in threephase medium voltage cable systems," IEEE Trans. Dielectr. Electr. Insul., vol. 10, no. 4, pp. 678-688, Aug. 2003.

[38] M. Tang, and M. Zhai, "Research of transmission parameters of four-conductor cables for power line communication," in Proc. Int. Conf. on Computer Science and Software Engineering, Wuhan, China, Dec. 2008, vol. 5, pp. 1306-1309.

[39] F. Issa, D. Chaffanjon, E. P. de la Bâthie, and A. Pacaud, "An efficient tool for modal analysis transmission lines for PLC networks development," presented at the IEEE Int. Conf. Power Line Communications and Its Applications, Athens, Greece, Mar. 2002. 
[40] M. D'Amore and M. S. Sarto, "A new formulation of lossy ground return parameters for transient analysis of multiconductor dissipative lines," IEEE Trans. Power Del., vol. 12, no. 1, pp. 303-314, Jan. 1997.

[41] M. D'Amore and M. S. Sarto, "Simulation models of a dissipative transmission line above a lossy ground for a wide-frequency range-Part I: Single conductor configuration," IEEE Trans. Electromagn. Compat., vol. 38, no. 2, pp. 127-138, May 1996.

[42] M. D'Amore and M. S. Sarto, "Simulation models of a dissipative transmission line above a lossy ground for a wide-frequency range-Part II: Multi-conductor configuration," IEEE Trans. Electromagn. Compat., vol. 38, no. 2, pp. 139-149, May 1996.

[43] N. Theethayi, "Electromagnetic interference in distributed outdoor electrical systems, with an emphasis on lightning interaction with electrified railway network," Ph.D. dissertation, Uppsala Univ., Uppsala, Sweden, Sep. 2005, [Online]. Available: http://uu.divaportal.org/smash/get/diva2:166746/FULLTEXT01

[44] A. G. Lazaropoulos, "Factors Influencing Broadband Transmission Characteristics of Underground Low-Voltage Distribution Networks,"'IET Commun., vol. 6, no. 17, pp. 2886-2893, Nov. 2012.

[45] J. Anatory, N. Theethayi, and R. Thottappillil, "Power-line communication channel model for interconnected networks-Part II: Multiconductor system," IEEE Trans. Power Del., vol. 24, no. 1, pp. 124-128, Jan. 2009.

[46] J. Anatory, N. Theethayi, R. Thottappillil, M. M. Kissaka, and N. H. Mvungi, "The effects of load impedance, line length, and branches in typical low-voltage channels of the BPLC systems of developing countries: transmission-line analyses," IEEE Trans. Power Del., vol. 24, no. 2, pp. 621-629, Apr. 2009.

[47] A. G. Lazaropoulos, "A Panacea to Inherent BPL Technology Deficiencies by Deploying Broadband over Power Lines (BPL) Connections with Multi-Hop Repeater Systems," Bentham Recent Advances in Electrical \& Electronic Engineering, vol. 10, no. 1, pp. 30-46, 2017.

[48] M. Gebhardt, F. Weinmann, and K. Dostert, "Physical and regulatory constraints for communication over the power supply grid," IEEE Commun. Mag., vol. 41, no. 5, pp. 84-90, May 2003.

[49] P. S. Henry, "Interference characteristics of broadband power line communication systems using aerial medium voltage wires," IEEE Commun. Mag., vol. 43, no. 4, pp. 92-98, Apr. 2005.

[50] Ofcom, “Amperion PLT Measurements in Crieff," Ofcom, Tech. Rep., Sept. 2005.

[51] NATO, "HF Interference, Procedures and Tools (Interférences HF, procédures et outils) Final Report of NATO RTO Information Systems Technology," RTO-TRISTR-050, Jun. 2007, [Online]. Available: http://ftp.rta.nato.int/public/PubFullText/RTO/TR/RTO-TR-IST-050/\$\$TR-IST050-ALL.pdf

[52] FCC, "In the Matter of Amendment of Part 15 regarding new requirements and measurement guidelines for Access Broadband over Power Line Systems," FCC 04-245 Report and Order, Jul. 2008.

[53] Ofcom, "DS2 PLT Measurements in Crieff," Ofcom, Tech. Rep. 793 (Part 2), May 2005. 
[54] Ofcom, "Ascom PLT Measurements in Winchester," Ofcom, Tech. Rep. 793 (Part 1), May 2005.

[55] A. G. Lazaropoulos, "Smart Energy and Spectral Efficiency (SE) of Distribution Broadband over Power Lines (BPL) Networks - Part 2: L1PMA, L2WPMA and L2CXCV for SE against Measurement Differences in Overhead Medium-Voltage BPL Networks," Trends in Renewable Energy, DOI: 10.17737/tre.2018.4.2.0077.

Article copyright: (C) 2018 Athanasios G. Lazaropoulos. This is an open access article distributed under the terms of the Creative Commons Attribution 4.0 International License, which permits unrestricted use and distribution provided the original author and source are credited. 